\title{
An Efficient One-pot Asymmetric Synthesis of Biaryl Compounds via Diels-Alder/retro-Diels-Alder Cascade Reactions
}

Yongxiang Liu, Kui Lu, Mingji Dai, ${ }^{\S}$ Kai Wang, Wanqing Wu, Jiahua Chen* Junmin Quan* and Zhen Yang*

\section{Spectra for the Synthesized Compounds}

\section{Table of Content}

Page S3: ${ }^{1} \mathrm{H}$ NMR and ${ }^{13} \mathrm{C}$ NMR of compound $\mathbf{1 b - 1}$

Page S4: ${ }^{1} \mathrm{H}$ NMR and ${ }^{13} \mathrm{C}$ NMR of compound 1c-1

Page S5: ${ }^{1} \mathrm{H}$ NMR and ${ }^{13} \mathrm{C}$ NMR of compound $\mathbf{1 d - 1}$

Page S6: ${ }^{1} \mathrm{H}$ NMR and ${ }^{13} \mathrm{C}$ NMR of compound 1e-1

Page S7: ${ }^{1} \mathrm{H}$ NMR and ${ }^{13} \mathrm{C}$ NMR of compound $\mathbf{1 f - 1}$

Page S8: ${ }^{1} \mathrm{H}$ NMR and ${ }^{13} \mathrm{C}$ NMR of compound $\mathbf{1 g - 1}$

Page S9: ${ }^{1} \mathrm{H}$ NMR and ${ }^{13} \mathrm{C}$ NMR of compound $\mathbf{1 h}-\mathbf{1}$

Page S10: ${ }^{1} \mathrm{H}$ NMR and ${ }^{13} \mathrm{C}$ NMR of compound 1i-1

Page S11: ${ }^{1} \mathrm{H}$ NMR and ${ }^{13} \mathrm{C}$ NMR of compound $\mathbf{1 a - 2}$

Page S12: ${ }^{1} \mathrm{H}$ NMR and ${ }^{13} \mathrm{C}$ NMR compounds of $\mathbf{1 b}-\mathbf{2}$

Page S13: ${ }^{1} \mathrm{H}$ NMR and ${ }^{13} \mathrm{C}$ NMR compound 1c-2

Page S14: ${ }^{1} \mathrm{H}$ NMR and ${ }^{13} \mathrm{C}$ NMR of compound $\mathbf{1 d - 2}$

Page S15: ${ }^{1} \mathrm{H}$ NMR and ${ }^{13} \mathrm{C}$ NMR of compound 1e-2

Page S16: ${ }^{1} \mathrm{H}$ NMR and ${ }^{13} \mathrm{C}$ NMR of compound $\mathbf{1 f - 2}$

Page S17: ${ }^{1} \mathrm{H}$ NMR and ${ }^{13} \mathrm{C}$ NMR of compound $\mathbf{1 g - 2}$

Page S18: ${ }^{1} \mathrm{H}$ NMR and ${ }^{13} \mathrm{C}$ NMR of compound $\mathbf{1 h}-\mathbf{2}$ 
Page S19: ${ }^{1} \mathrm{H}$ NMR and ${ }^{13} \mathrm{C}$ NMR of compound $\mathbf{1 i - 2}$

Page S20: ${ }^{1} \mathrm{H}$ NMR and ${ }^{13} \mathrm{C}$ NMR of compound 2a

Page S21: ${ }^{1} \mathrm{H}$ NMR and ${ }^{13} \mathrm{C}$ NMR of compound $\mathbf{2 b}$

Page S22: ${ }^{1} \mathrm{H}$ NMR and ${ }^{13} \mathrm{C}$ NMR of compound 2c

Page S23: ${ }^{1} \mathrm{H}$ NMR and ${ }^{13} \mathrm{C}$ NMR of compound 2d

Page S24: ${ }^{1} \mathrm{H}$ NMR and ${ }^{13} \mathrm{C}$ NMR of compound $2 \mathbf{e}$

Page S25: ${ }^{1} \mathrm{H}$ NMR and ${ }^{13} \mathrm{C}$ NMR of compound $\mathbf{2 f}$

Page S26: ${ }^{1} \mathrm{H}$ NMR and ${ }^{13} \mathrm{C}$ NMR of compound $\mathbf{2 g}$

Page S27: ${ }^{1} \mathrm{H}$ NMR and ${ }^{13} \mathrm{C}$ NMR of compound $\mathbf{2 h}$

Page S28: ${ }^{1} \mathrm{H}$ NMR and ${ }^{13} \mathrm{C}$ NMR of compound $2 \mathbf{i}$

Page S29: HPLC analysis using Chiralcel OJ-H column for 2a

Page S30: HPLC analysis using Chiralpak AD column (254 nm) for $\mathbf{2 b}$

Page S31: HPLC analysis using Chiralpak AD column (254 nm) for 2c

Page S32: HPLC analysis using Chiralpak AD column (254 nm) for 2d

Page S33: HPLC analysis using Chiralpak AD column $(254 \mathrm{~nm})$ for $\mathbf{2 e}$

Page S34: HPLC analysis using Chiralpak AD column (254 nm) for $\mathbf{2 f}$

Page S35: HPLC analysis using Chiralpak AD column (254 nm) for $\mathbf{2 g}$

Page S36: HPLC analysis using Chiralpak AD column (254 nm) for $\mathbf{2 h}$

Page S37: HPLC analysis using Chiralpak AD column (254 nm) for $\mathbf{2 i}$ 
athy rateonol

Arehfve firectory: /export/pose/vear1/vmarsys/date

pulse saquences szous

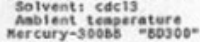

Relax. Selay 1.000 .

Acr 15.02 . 281 toe

ots revvetitiont

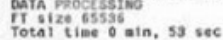
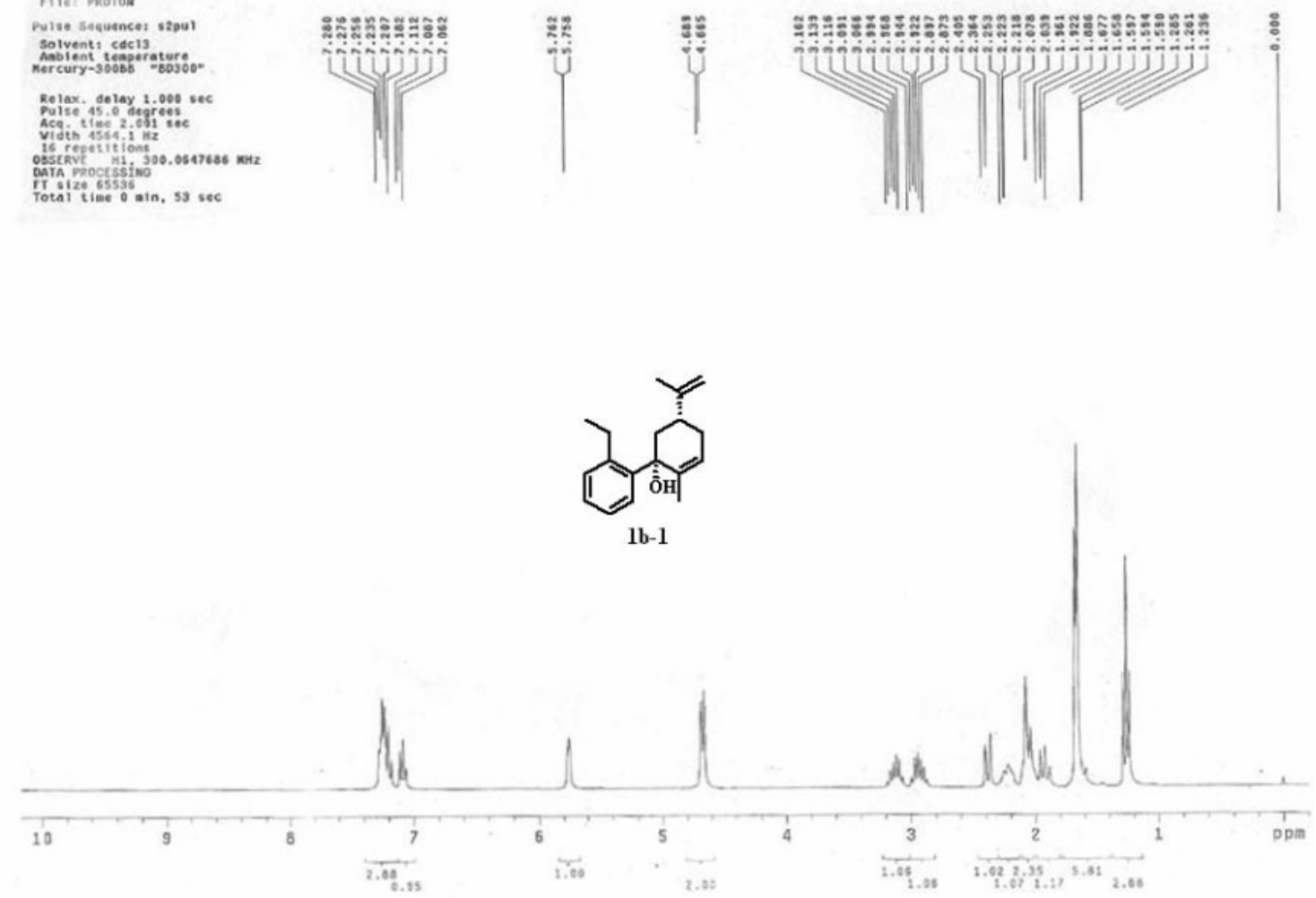

ethy la Icohol-c13

Pulse Sequence: s2pui
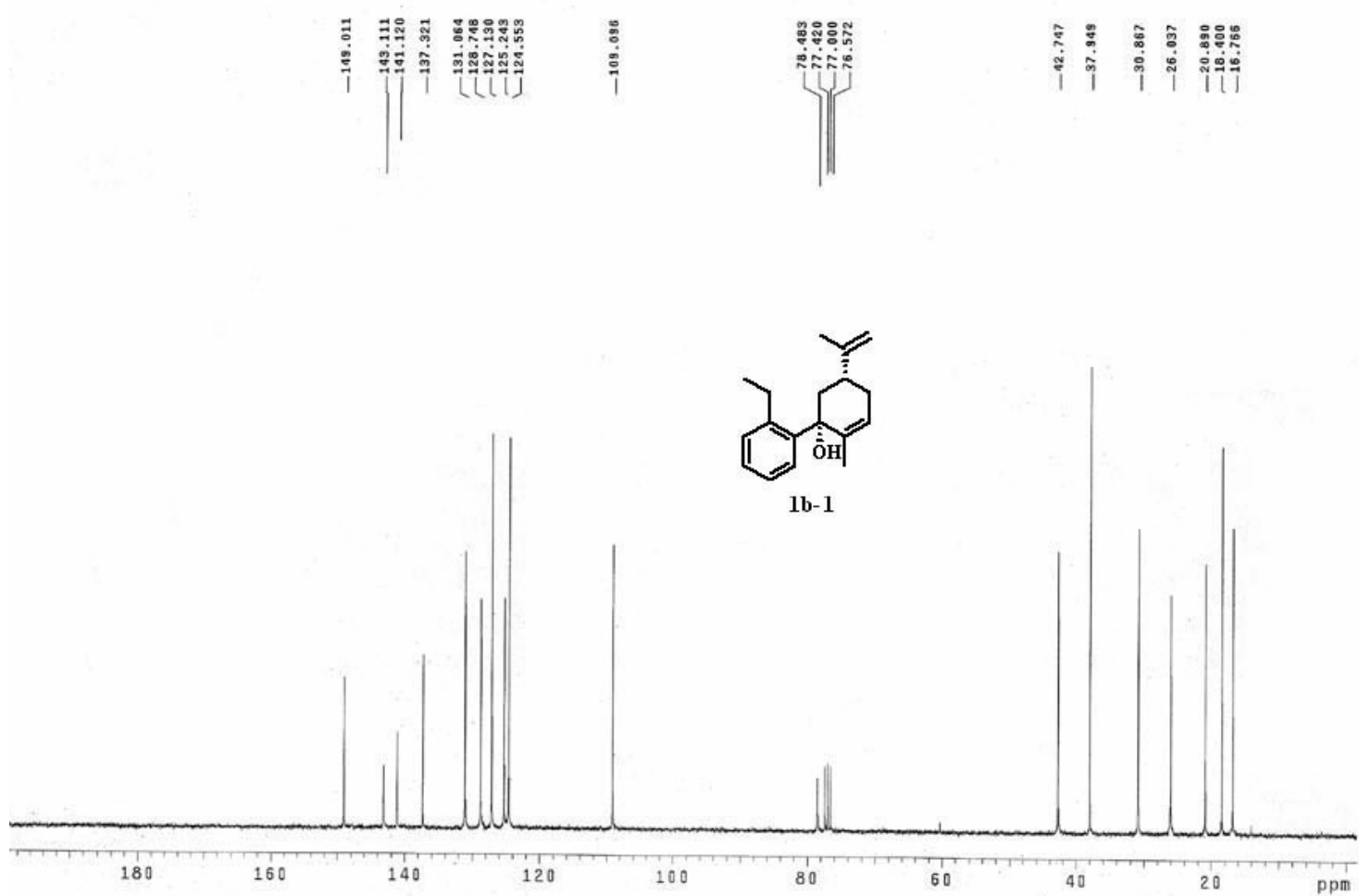
(sopropy la icomol

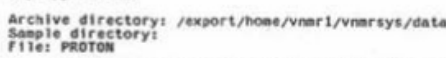

Puls s⿻ำ

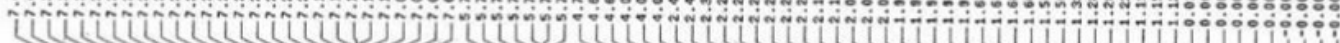
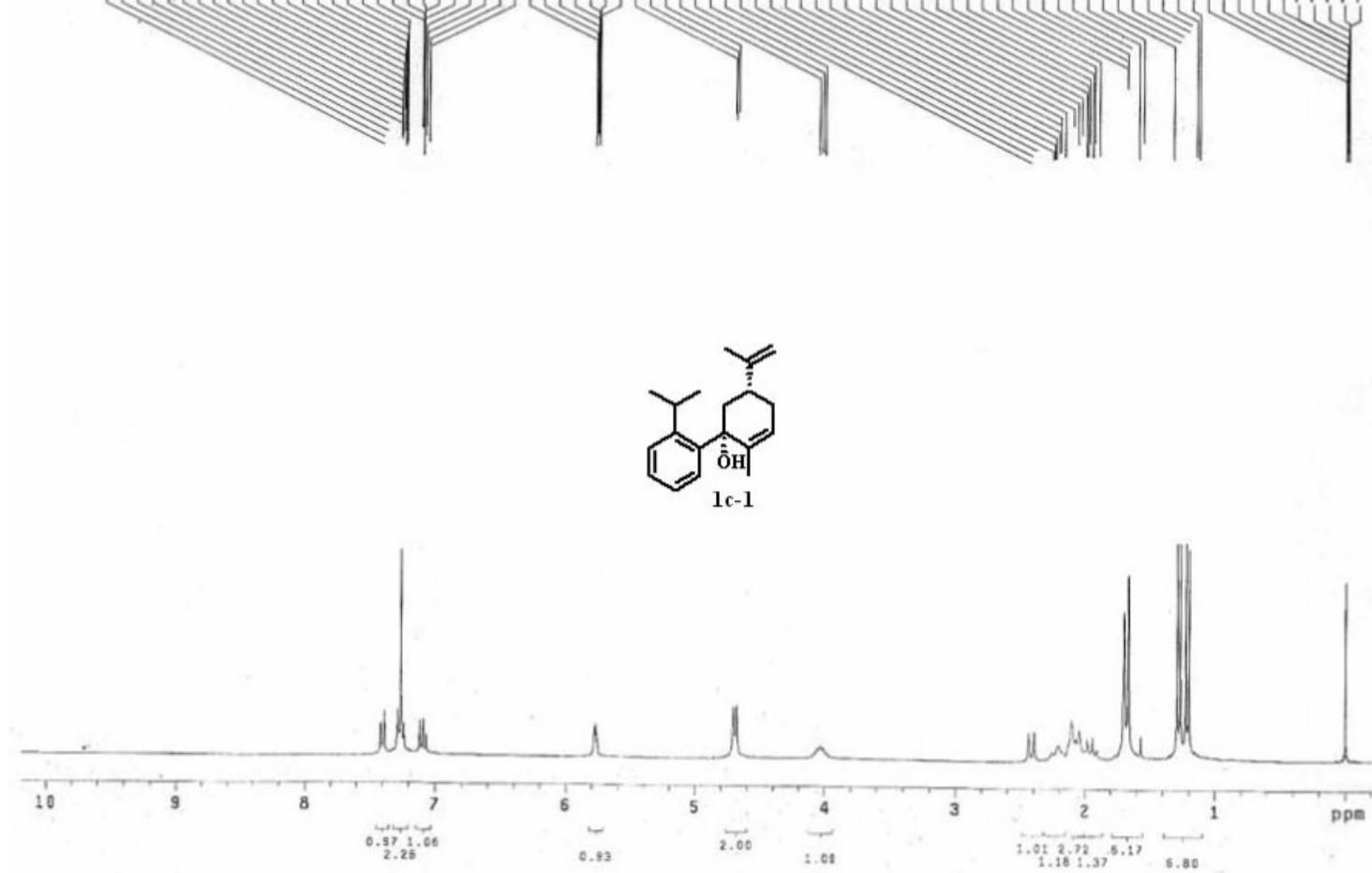

Isoproa Icohol
Pulse Sequence: 52 pul
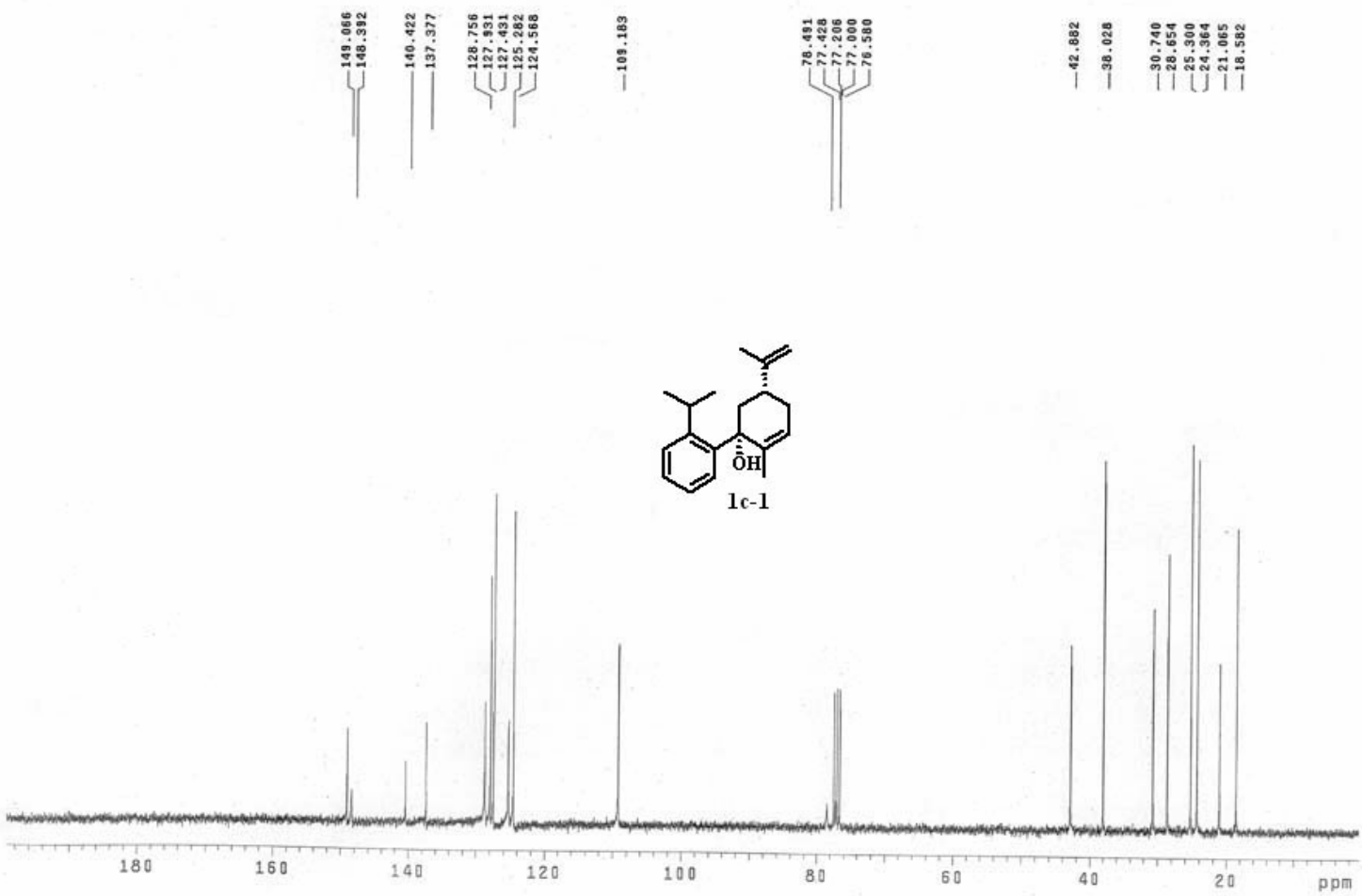

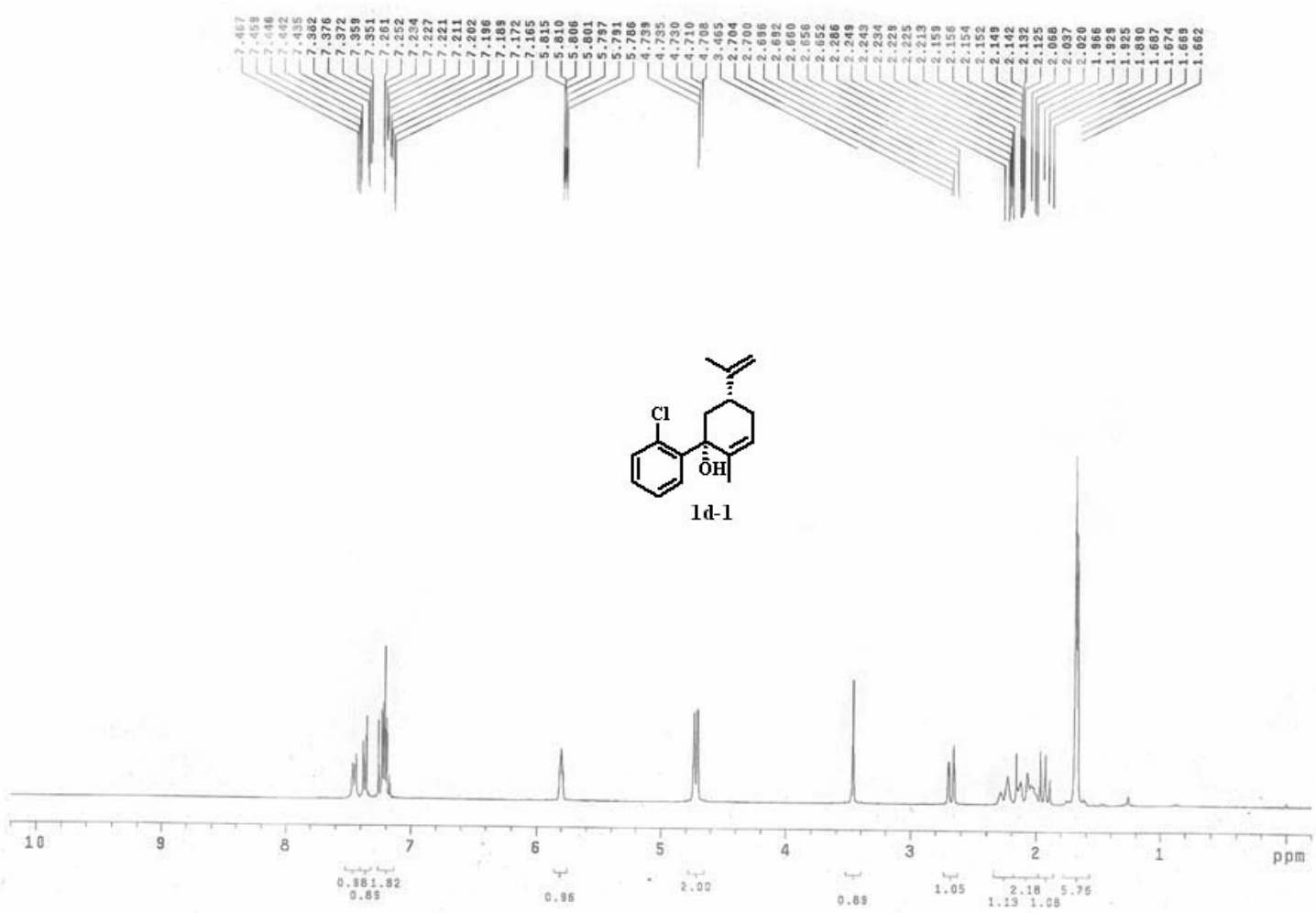

Fuise sequence: s2pui

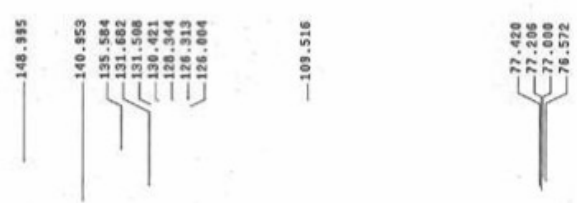

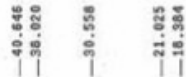

过苟

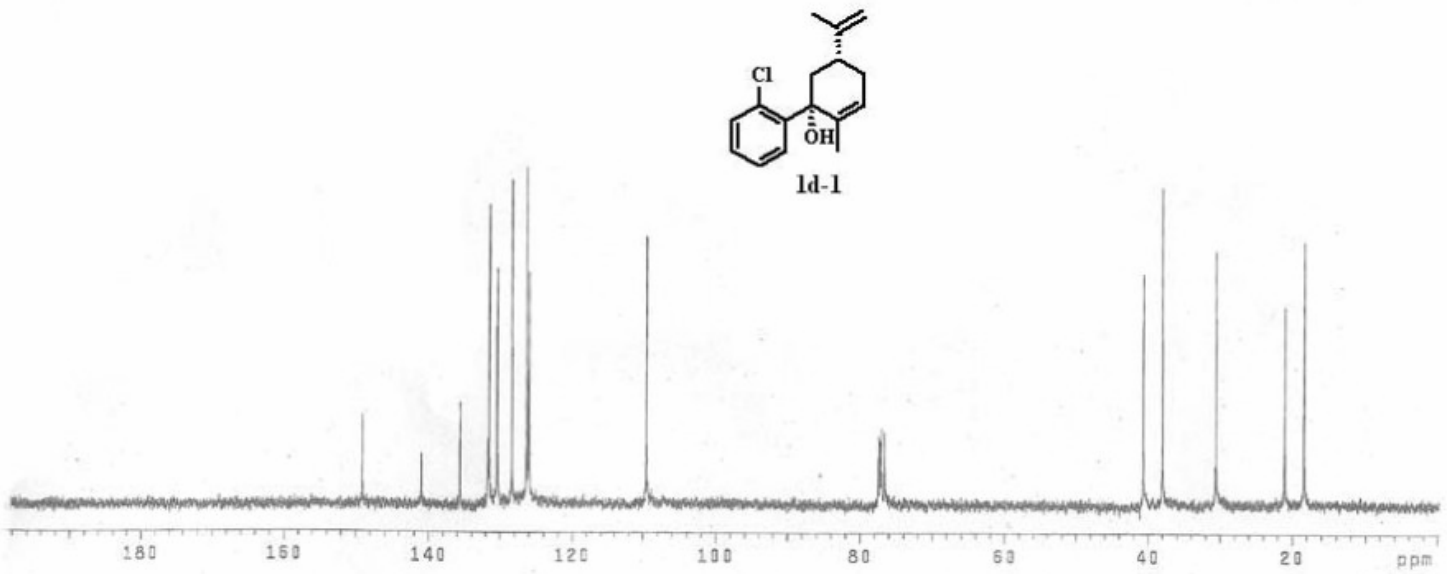


bromoalcohol

Archive directory: /export/home/vnar1/vnarsys/data
Sample directory:

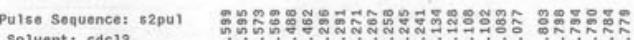

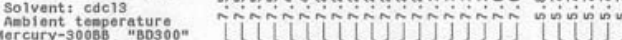

Relax

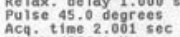

保ith 4564 , i Hz

OBSERVE HH1 300.0647619 MHZ

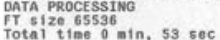
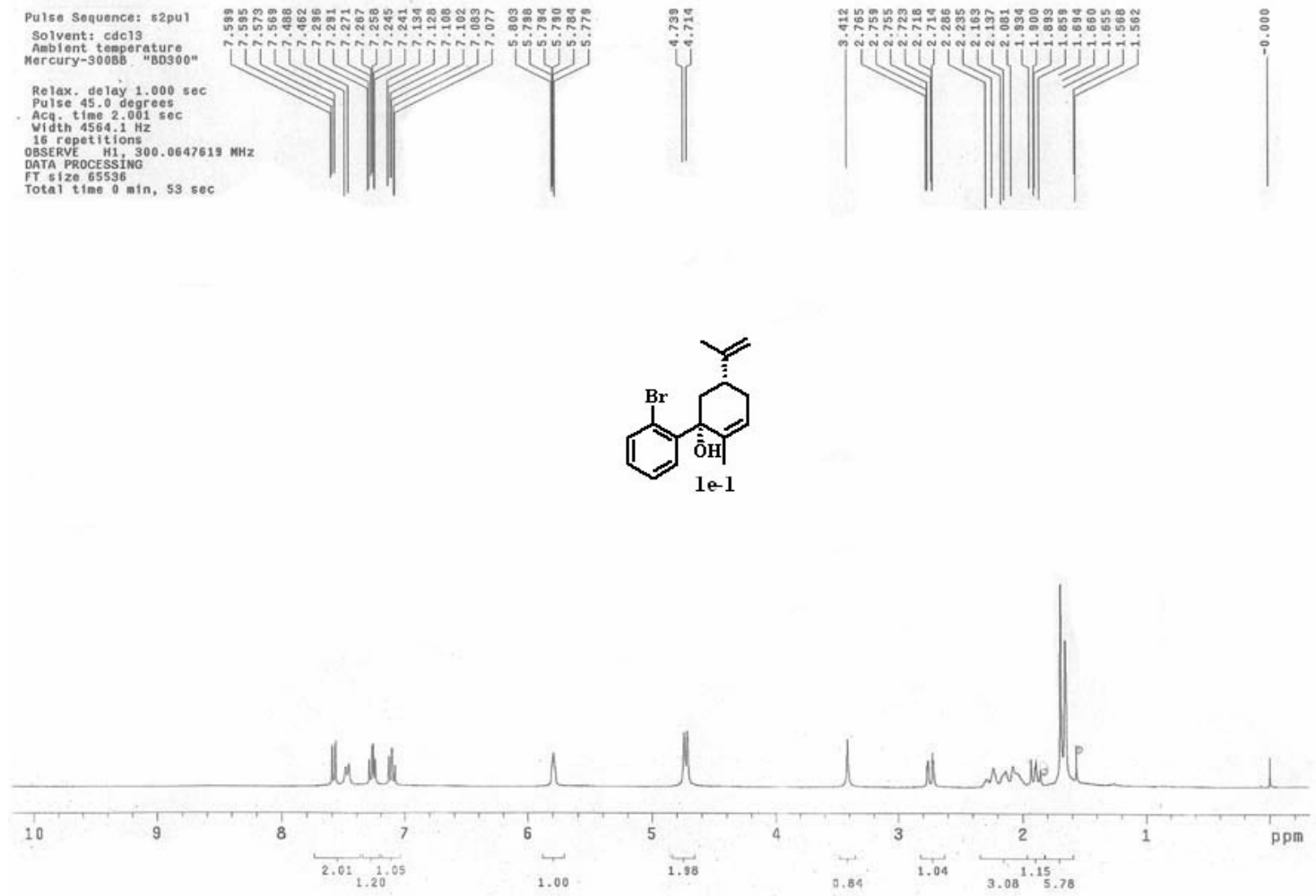

bromo-alcohol-c13

Pulse sequence: s2pul
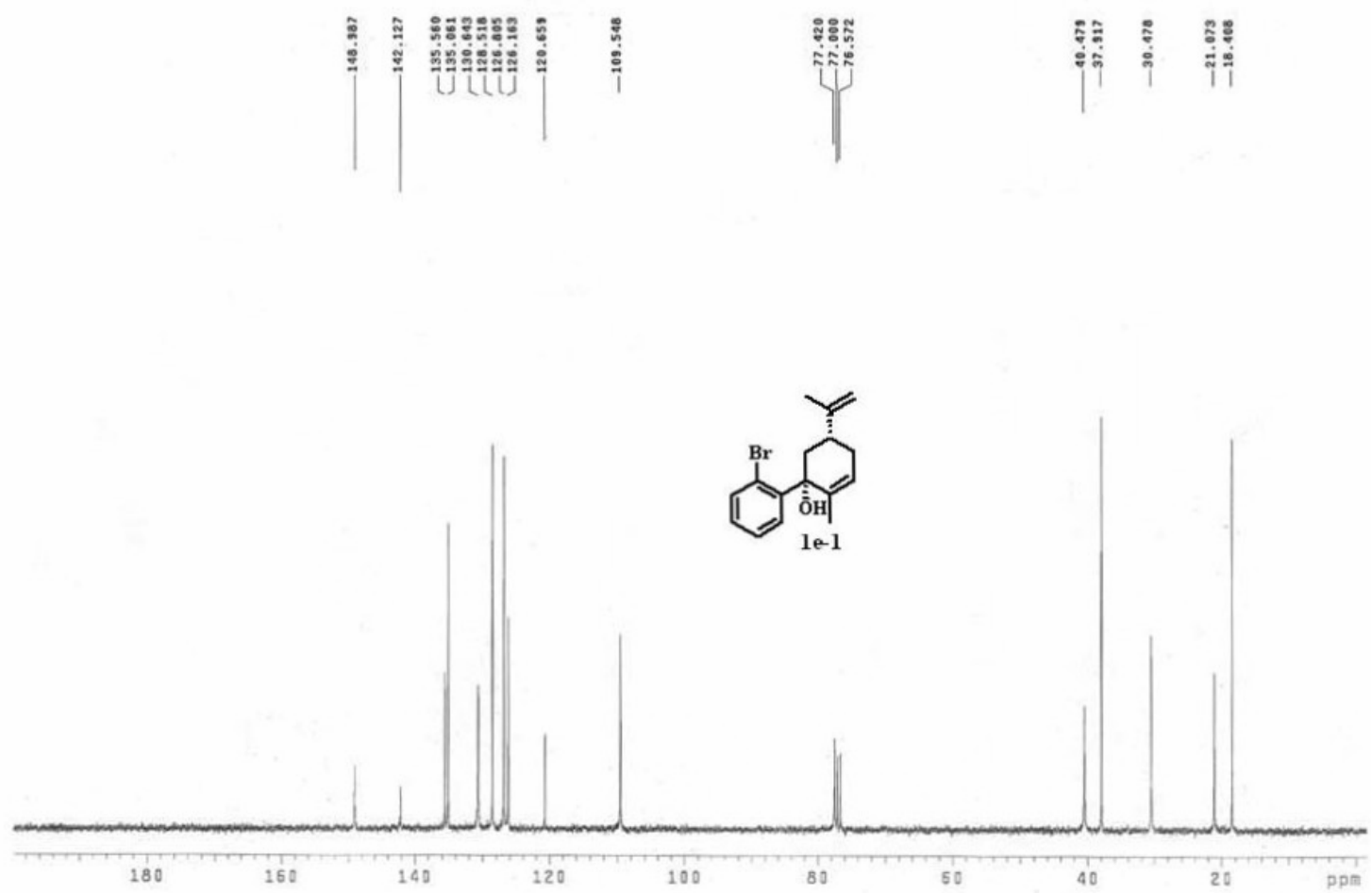
cf 3alcohol

Archive directory: /export/home/vnar1/vnersys/dat

File: PROTON

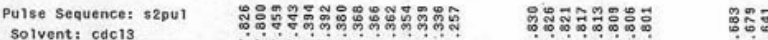

Ambient teaperature

Relax. delay $1.000 \mathrm{sec}$

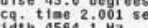

16 repetitions
OSERVE

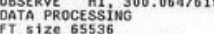
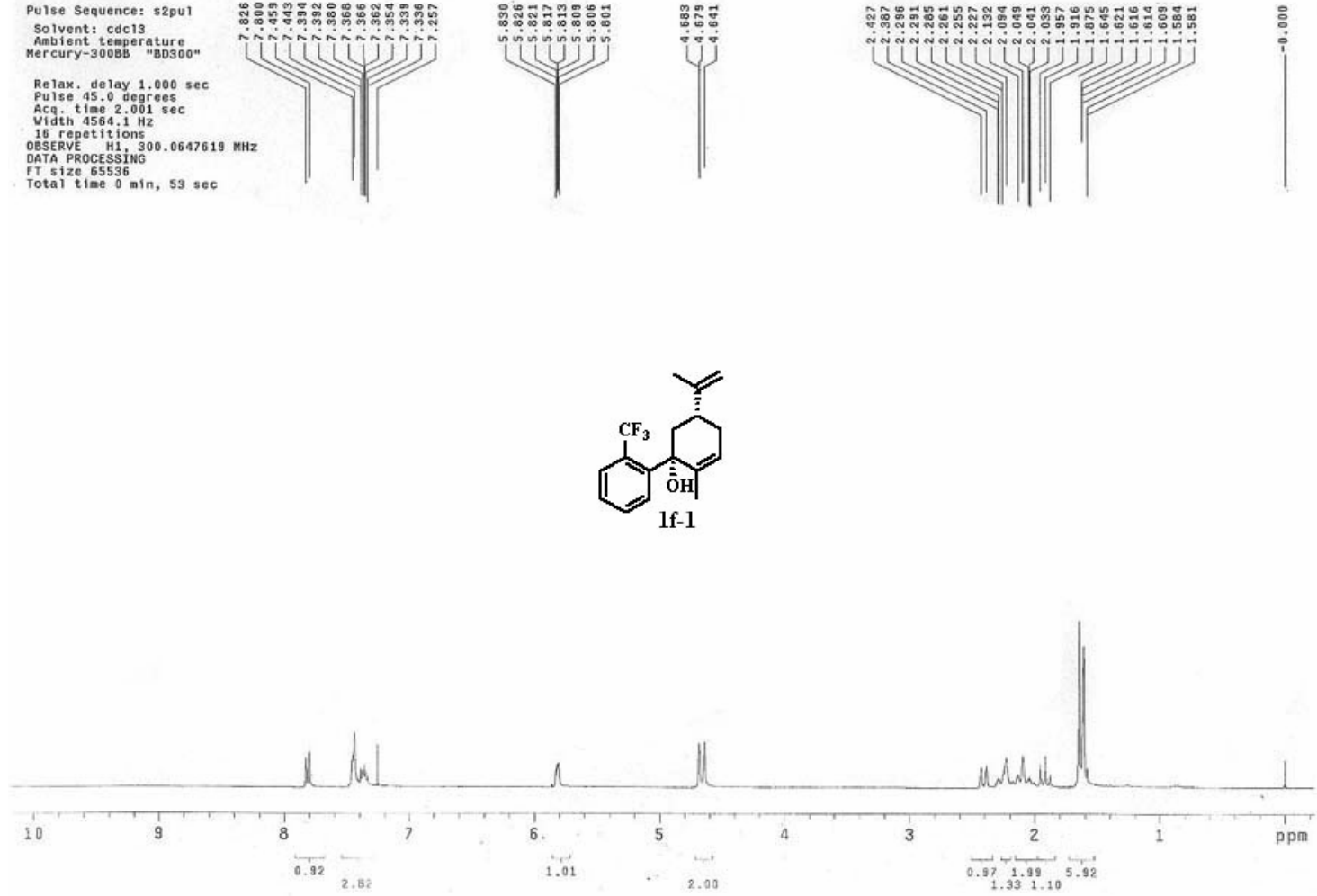

cf3alcoho-c19

Pulse Sequences s2pul
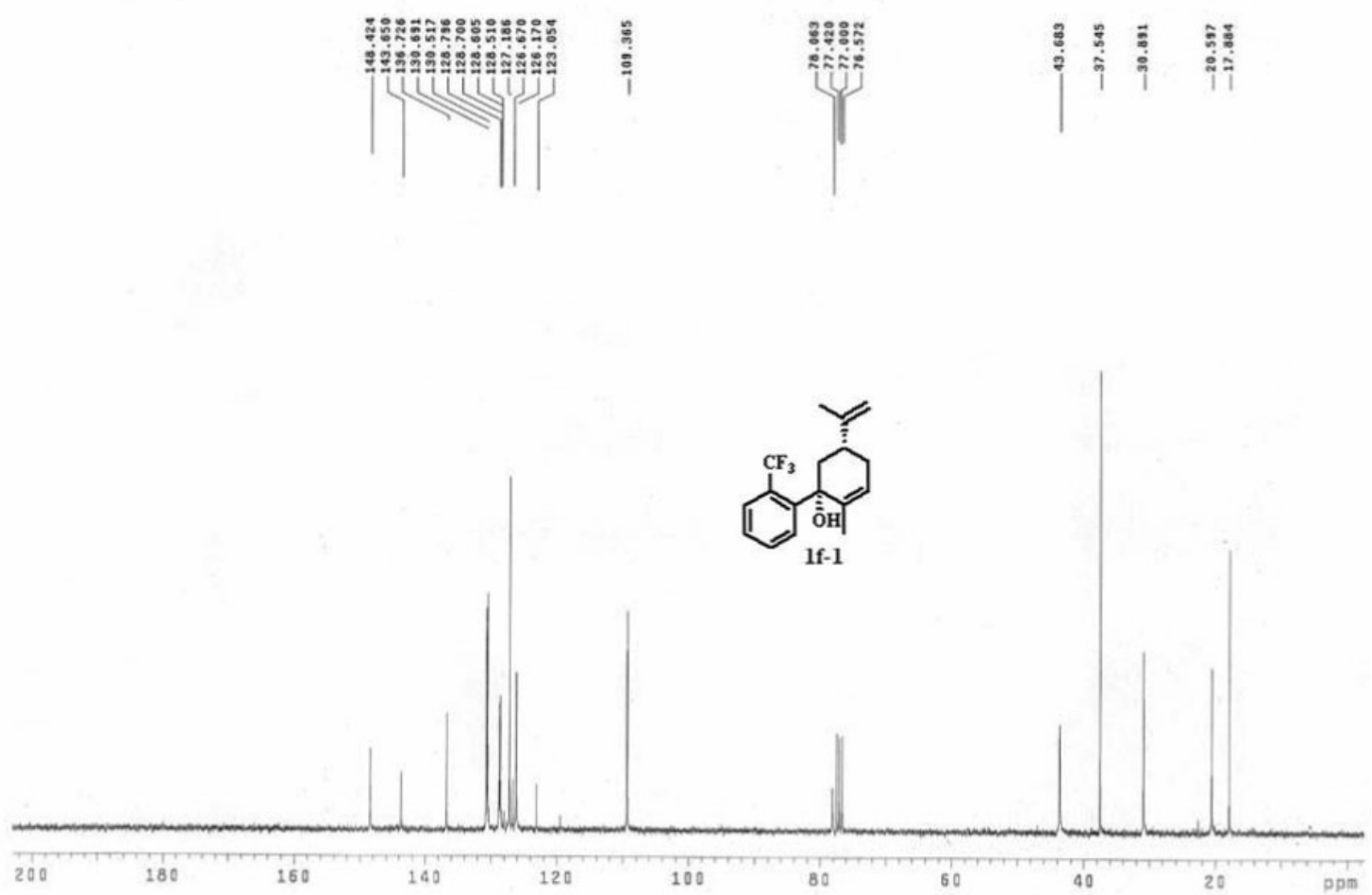
Archive flifectory /export/moeo/vnar 1/vmersys/cate
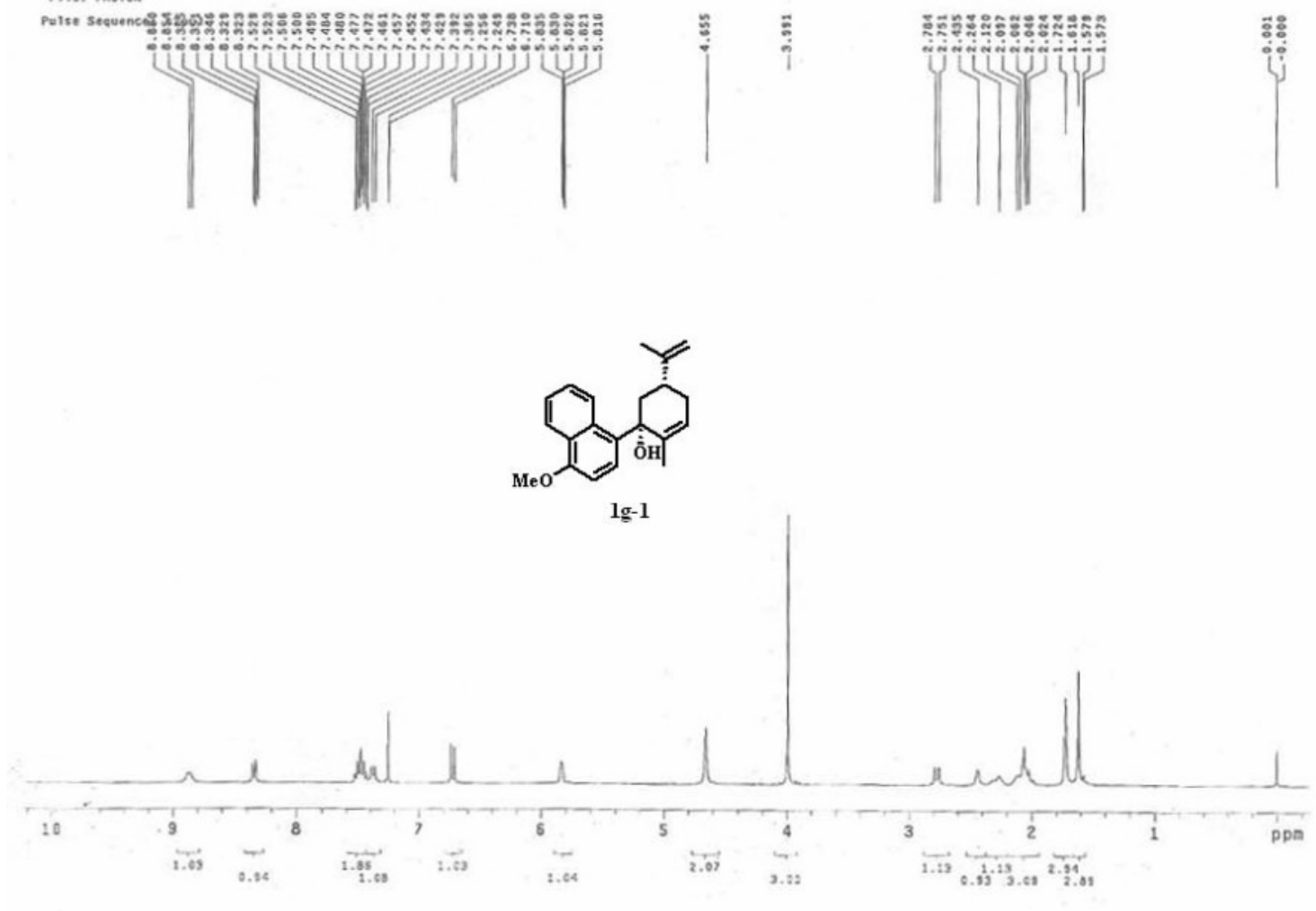

pomenaphy la 1coho

Pulse Sequence: s2pul

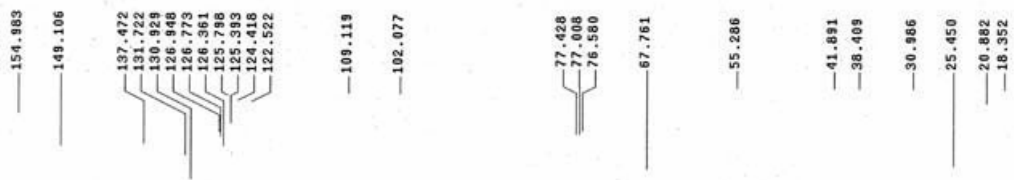

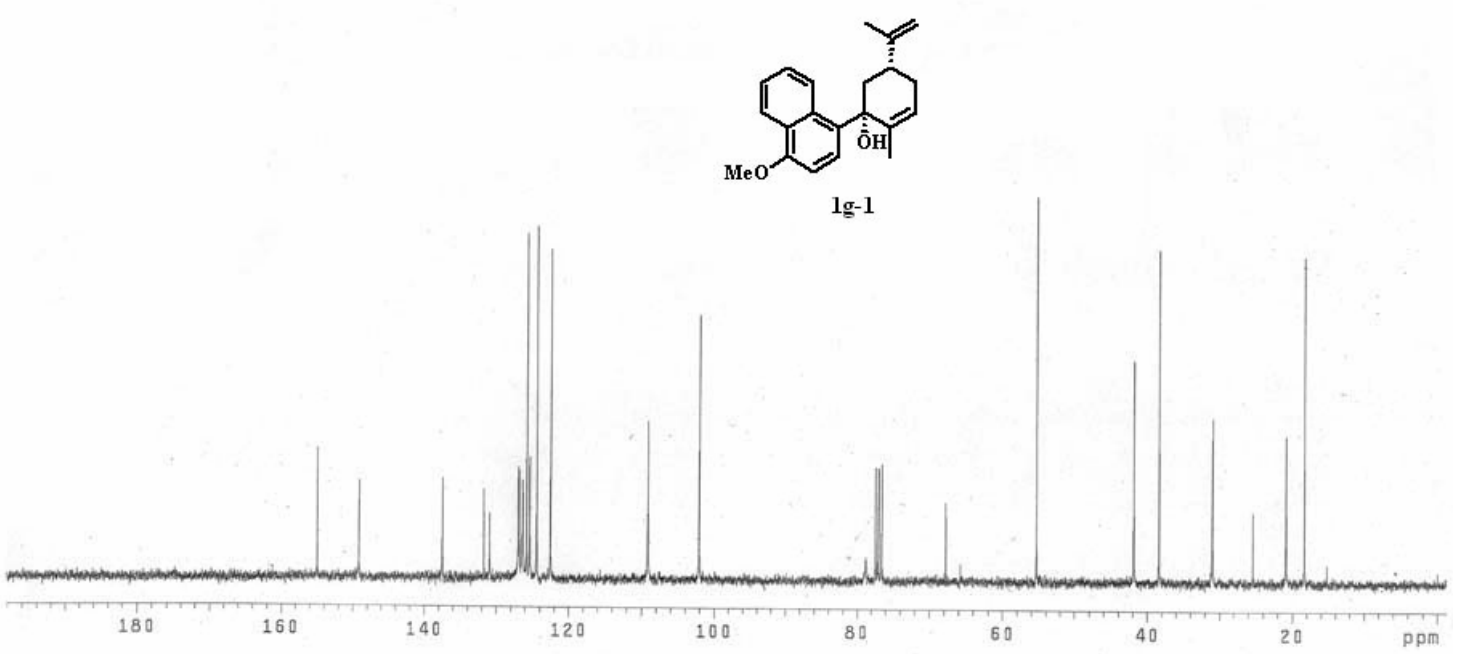




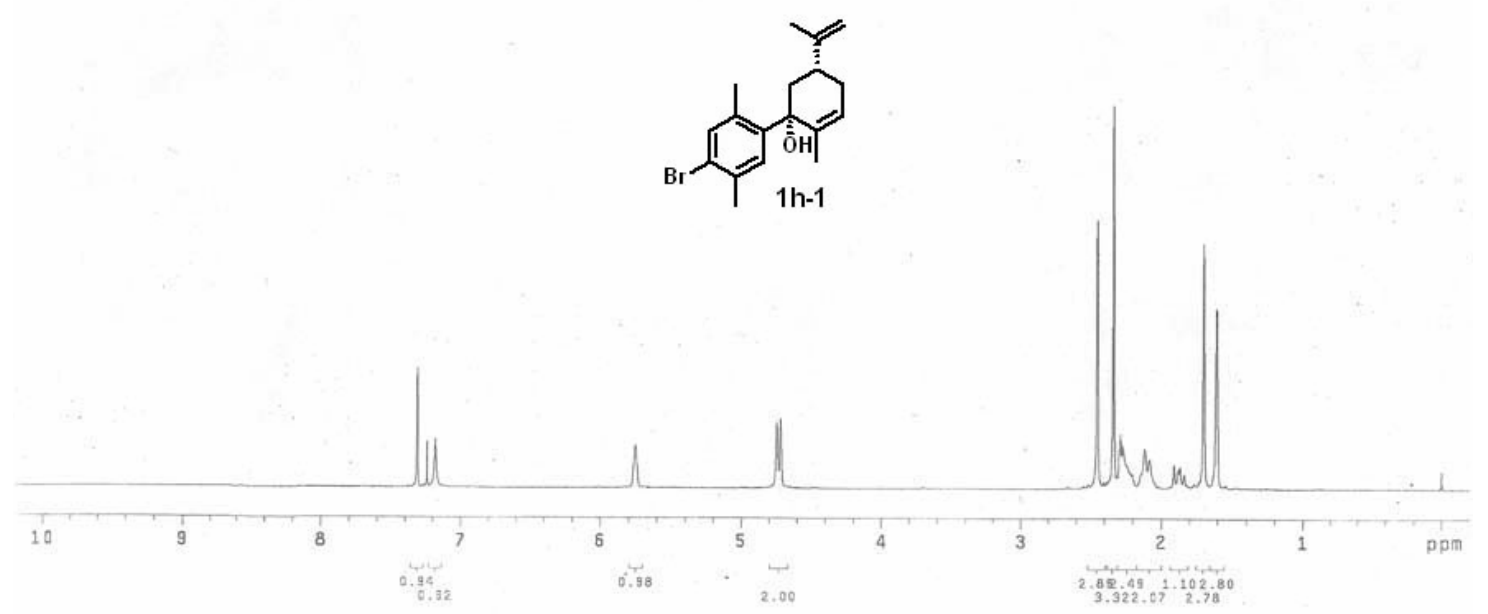

PuIse Sequence: 52puI
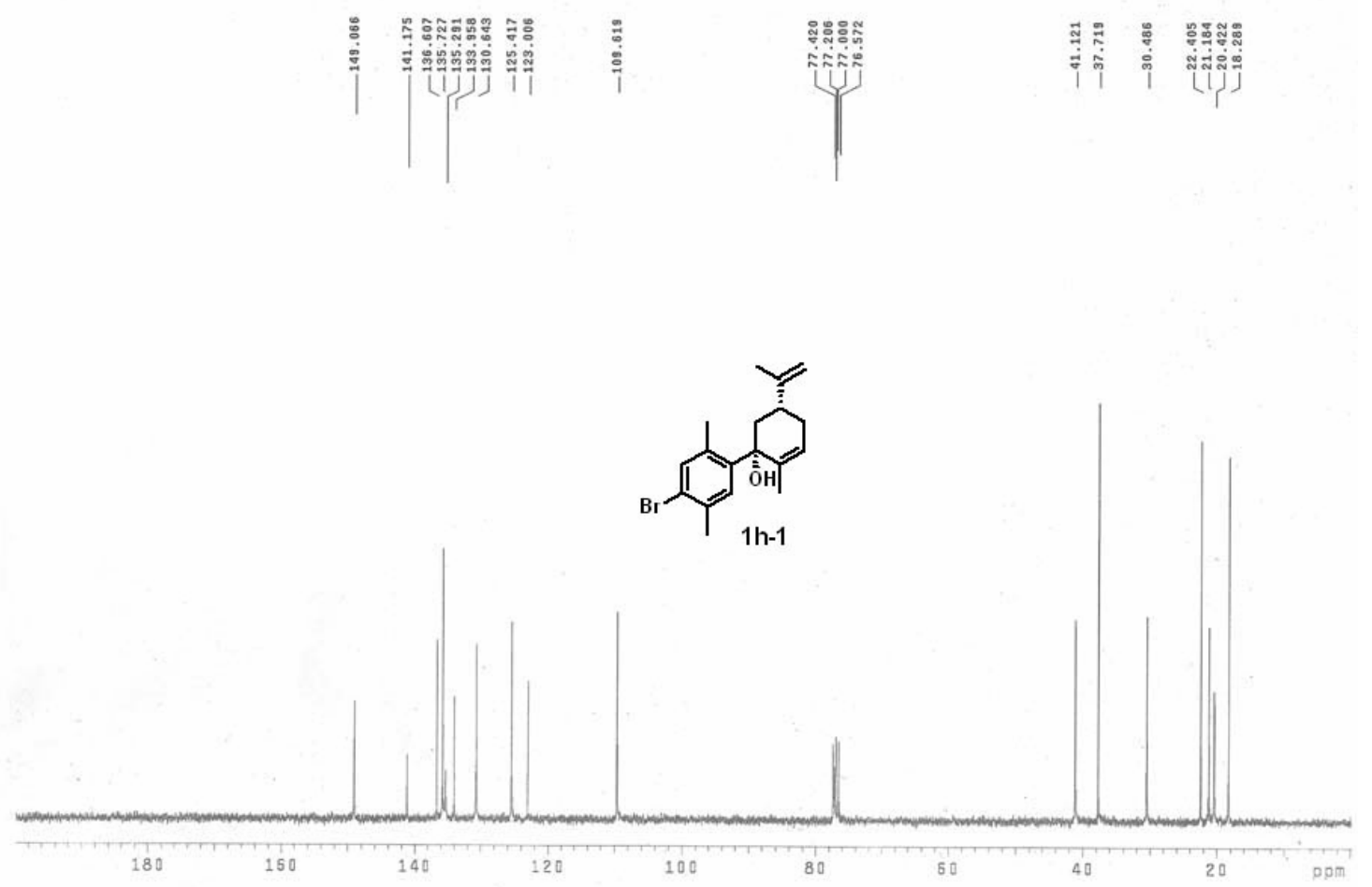
wethoxylbiary

Archive directoryn /export/mose/vnar 1/vmarsys/date

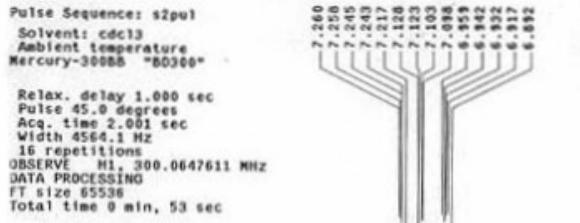
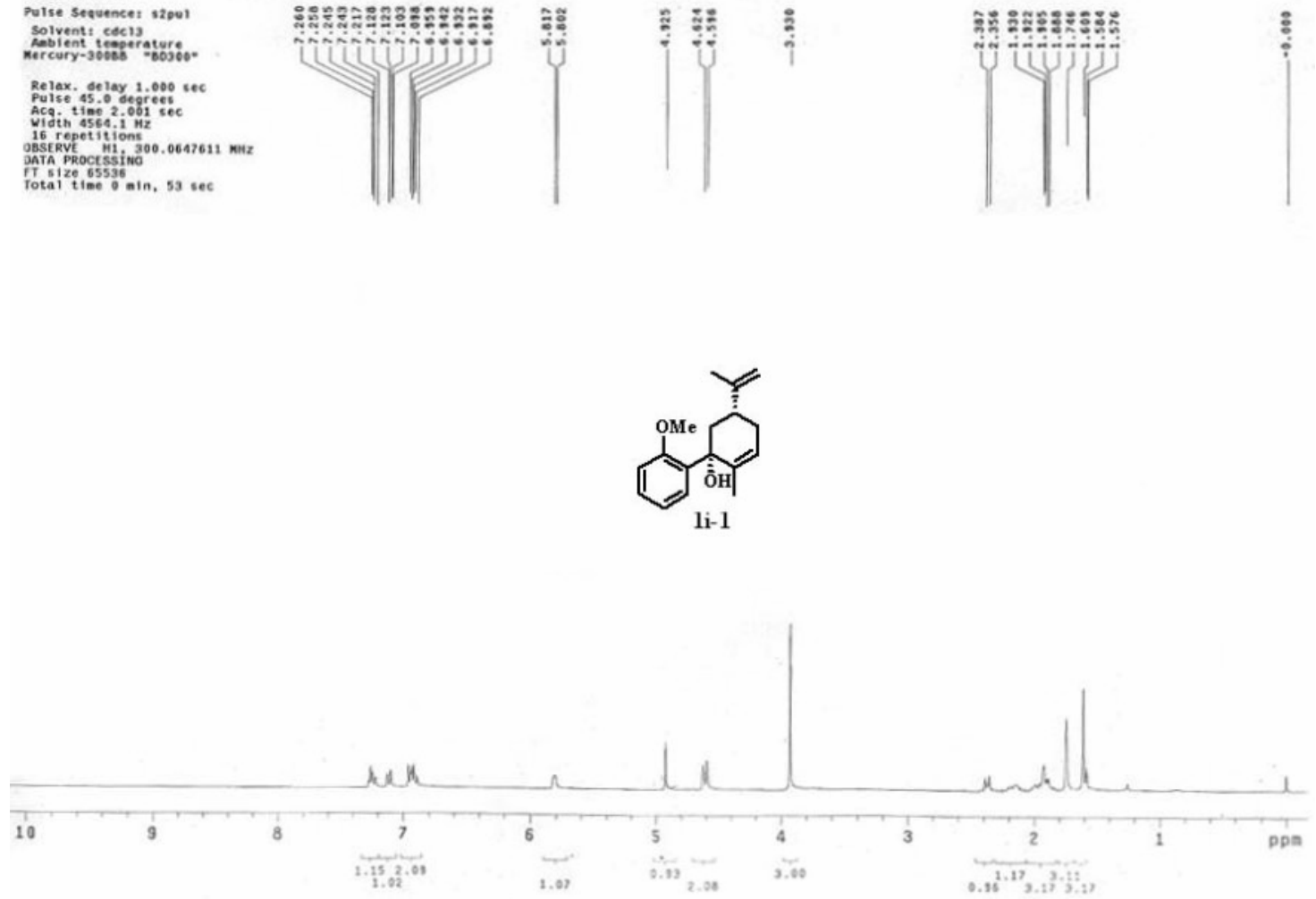

bromo-a lcohol-c13

Pulse Sequence: s2pul

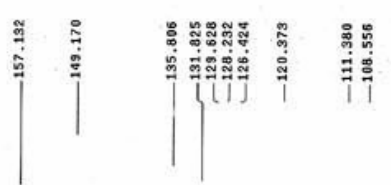

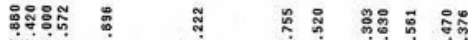

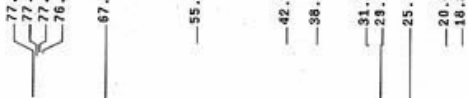
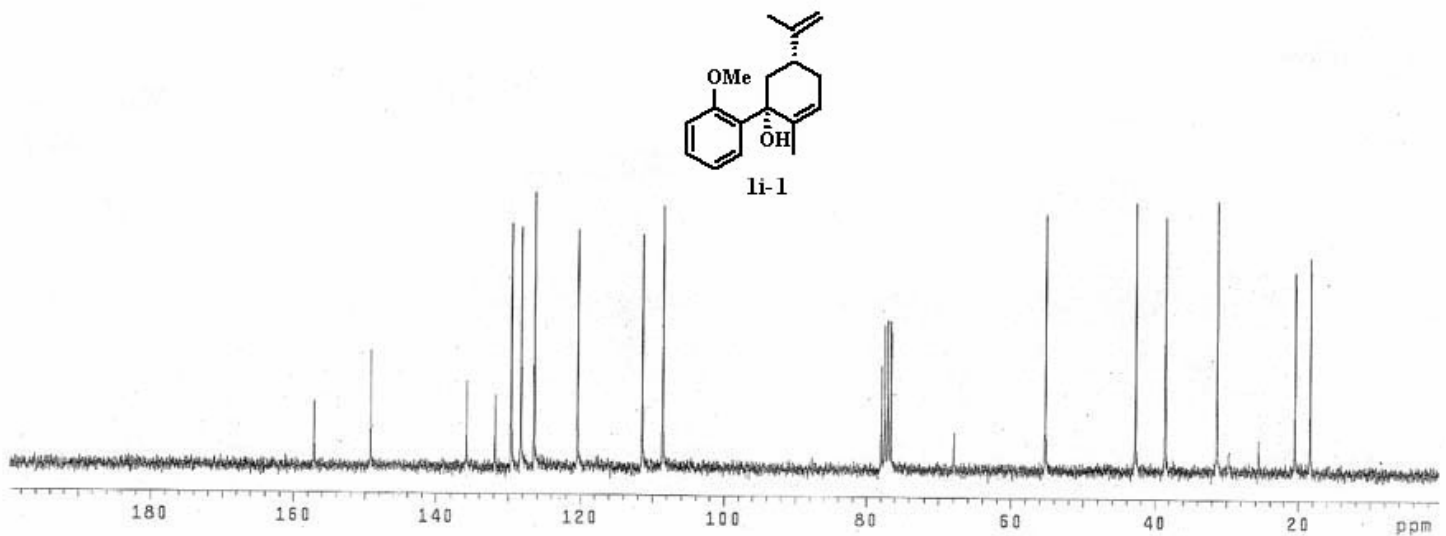
methketone

Archive directoryt /export/mowe/vnar 1/vnarsys/eata

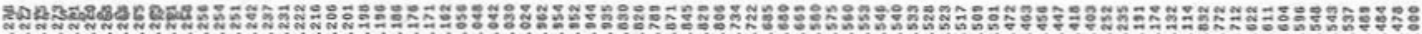

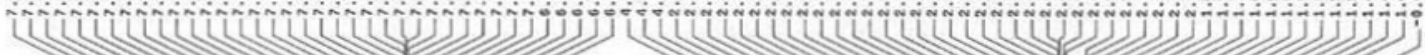

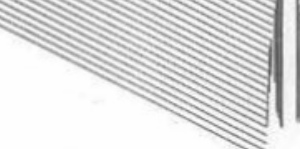
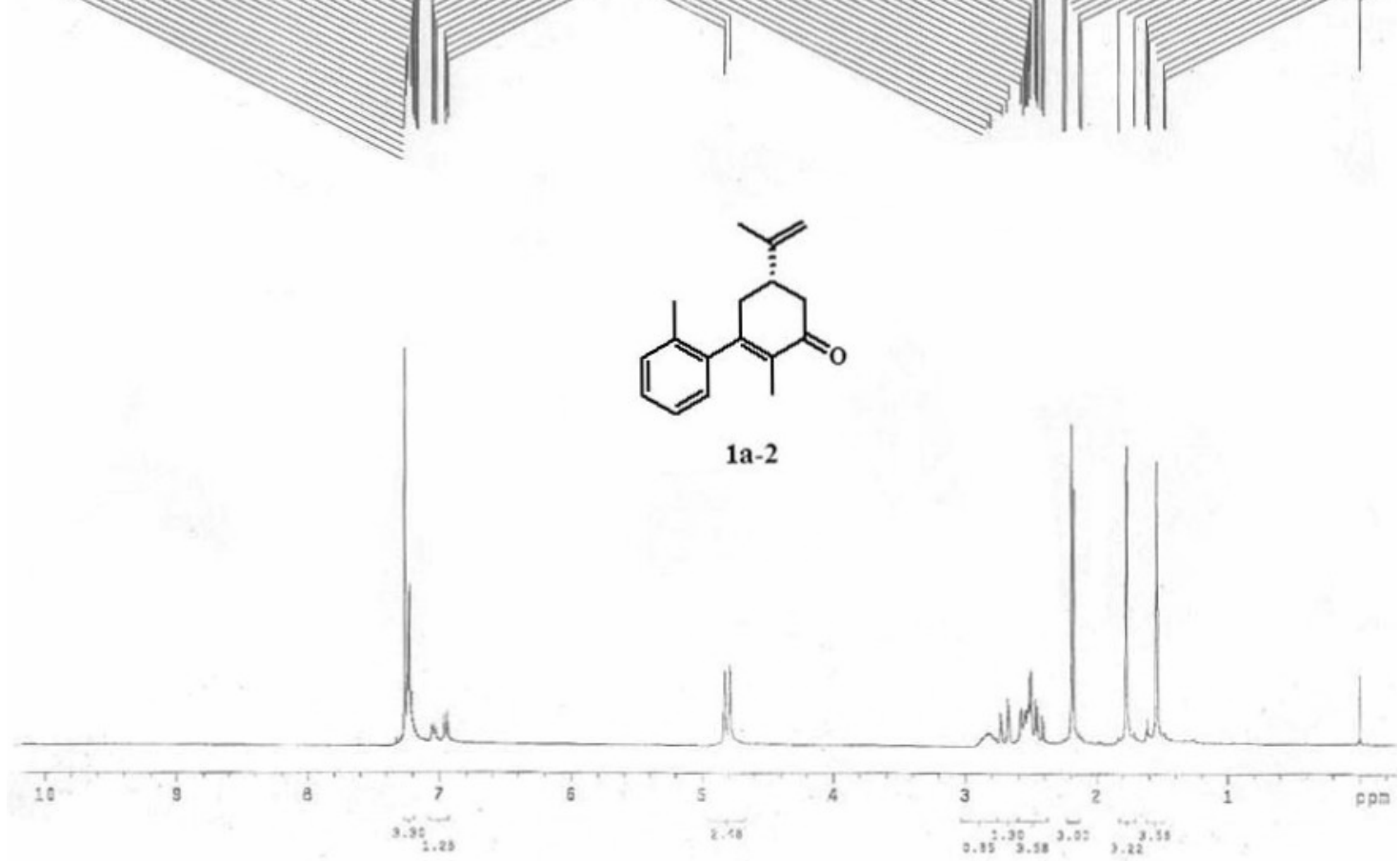

coketone

Pulse sequences szpui
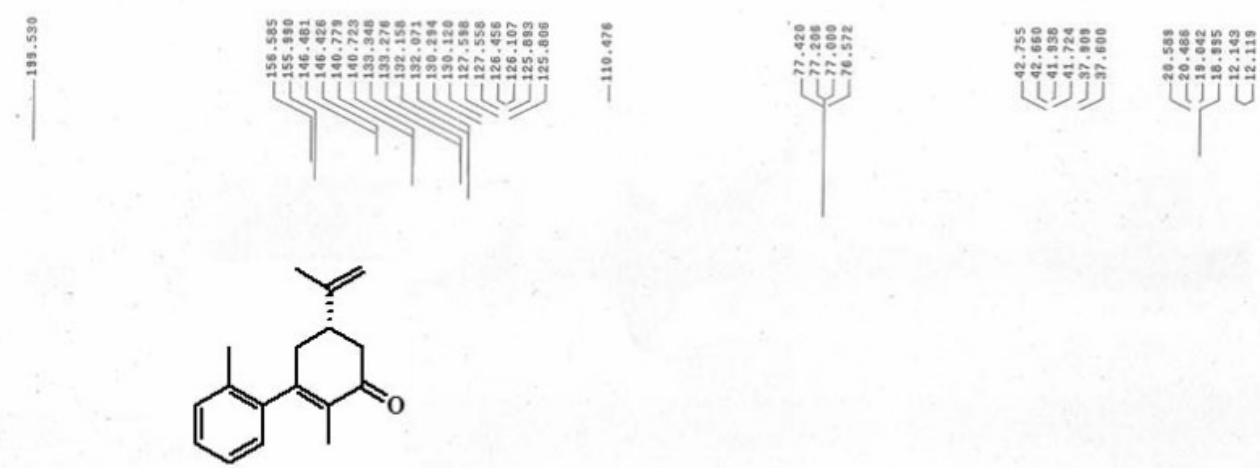

1a-2

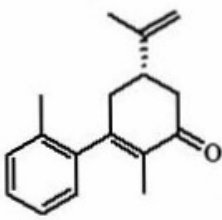

1a-2

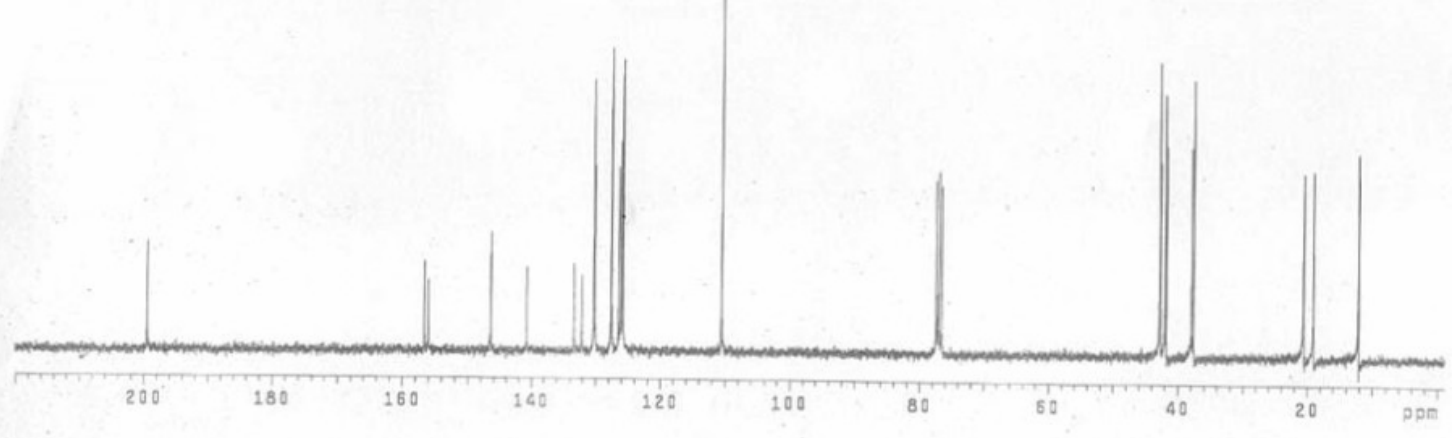


ethylketone

Archive directory: /export/home/vnar 1/vnmrsys/dato

Sample directory:
File: pRoton

Pulse Sequence: s2pுు

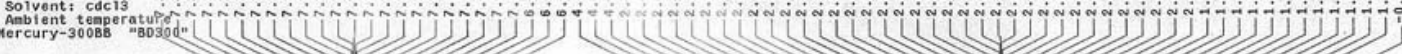

Relax. de lay $1.000 \mathrm{sec}$

Acq.

16 repetitions

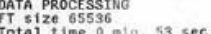

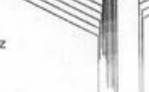

rotal time $0 \mathrm{win}, 53 \mathrm{sec}$
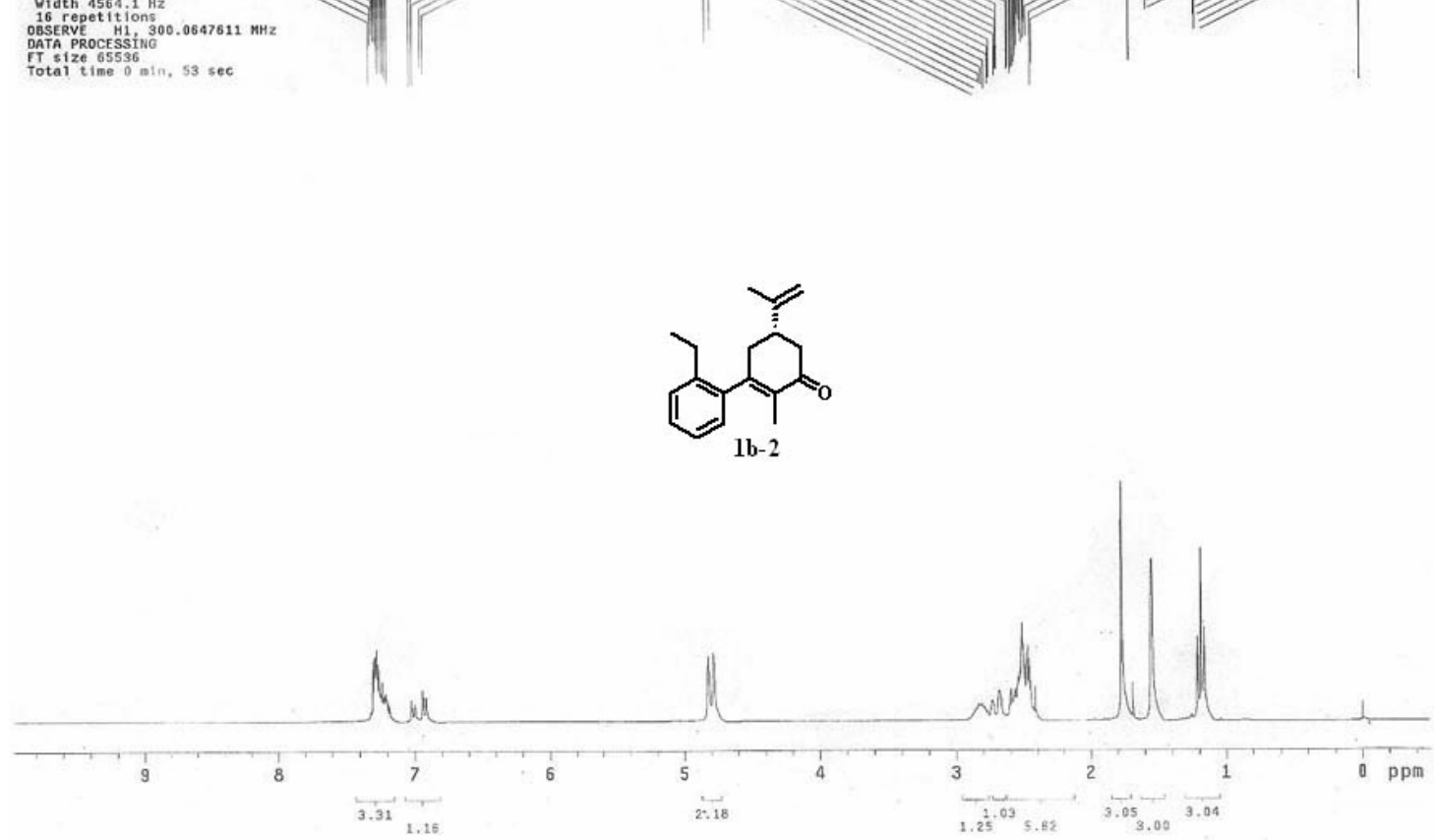

ethy1-ketone-c13

Pulse Sequence: s2pul

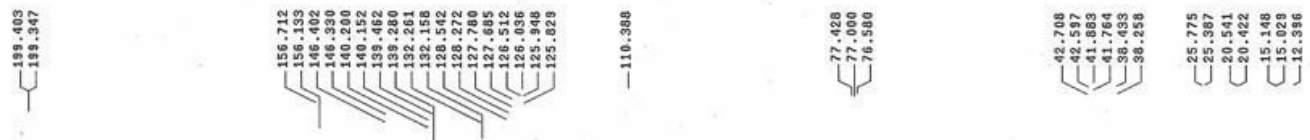

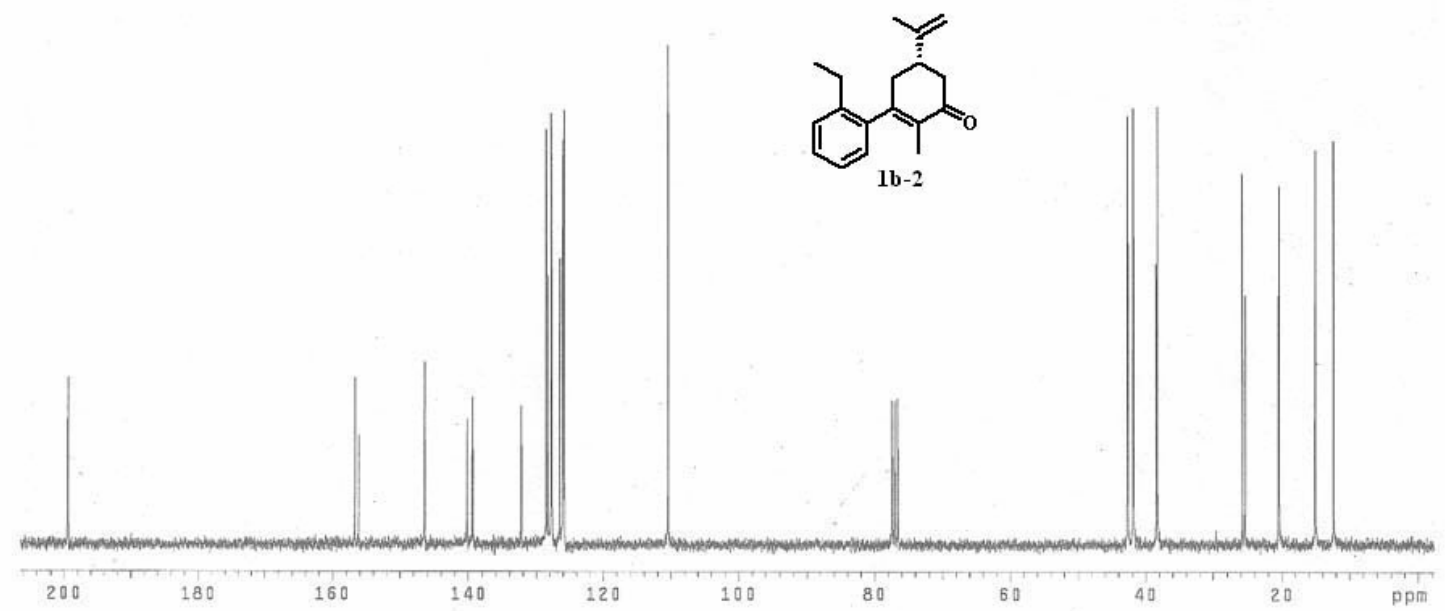


isopropylketone

Archive directory: /export/home/vnmr1/vnmarsys/data
Sample directory:
File: PRoToll

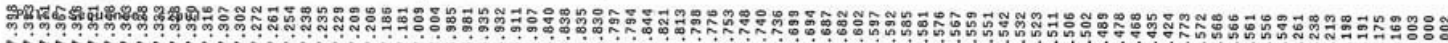

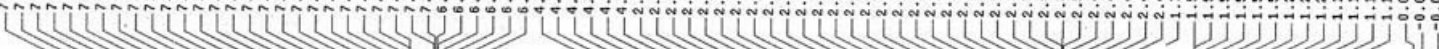

$\cdots \cdots \cdots \cdots$
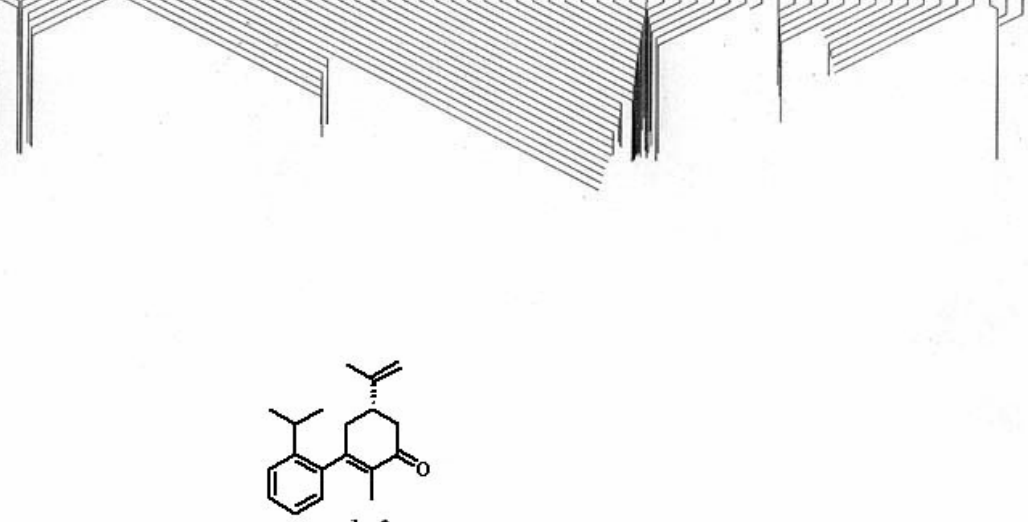

$1 c-2$

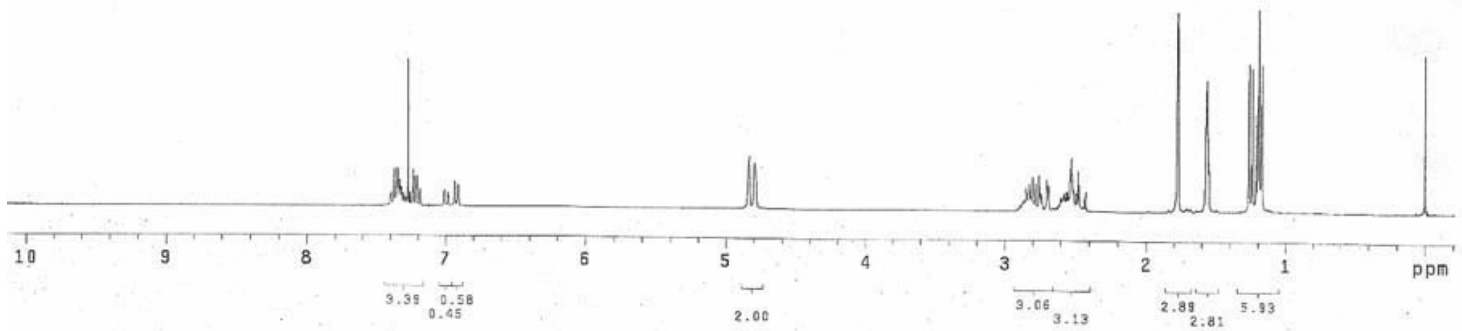

180propyiketone

nolse sequences stpul

บับ

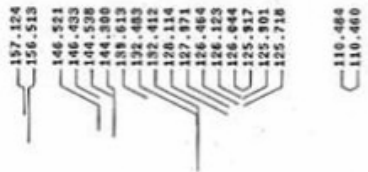

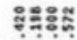

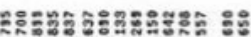

邹

กิิติ๊

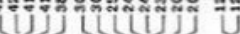

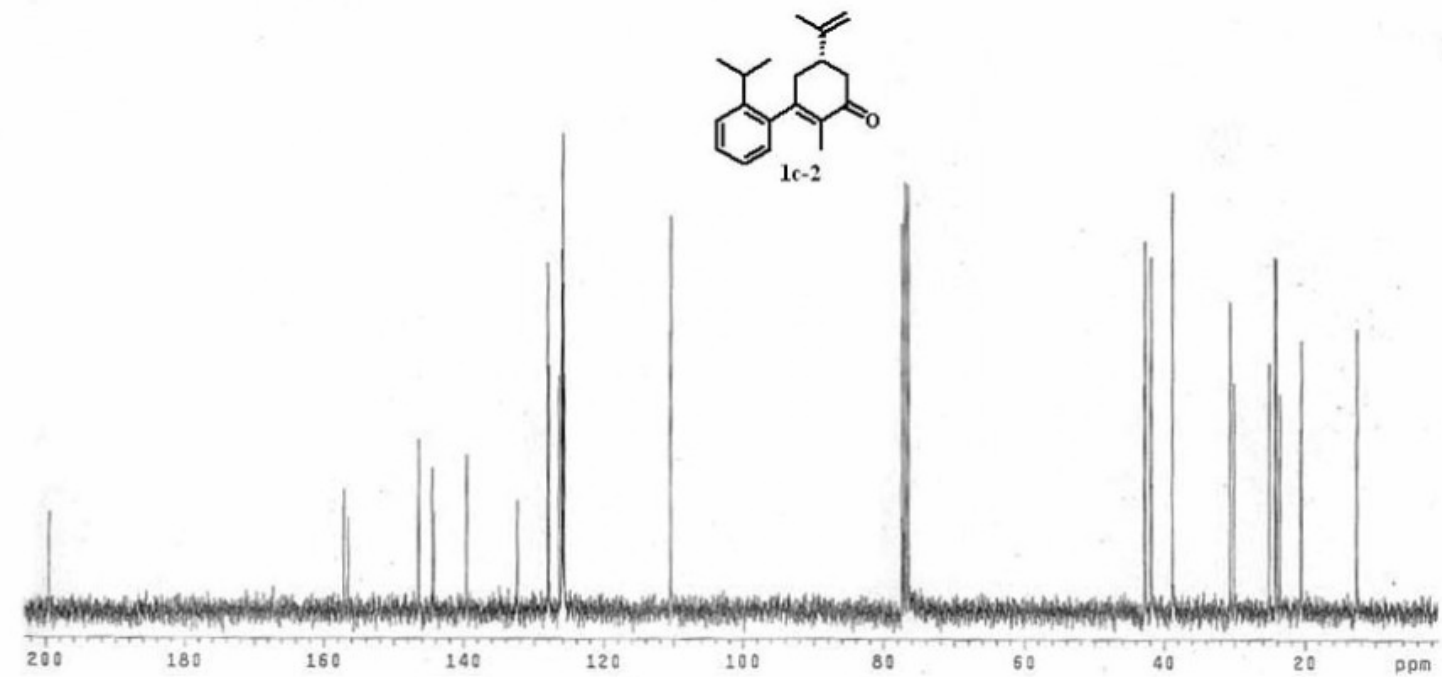


chloroateohot

Archive directory: /export/hone/vnar1/vnareys/date

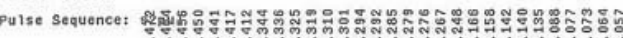

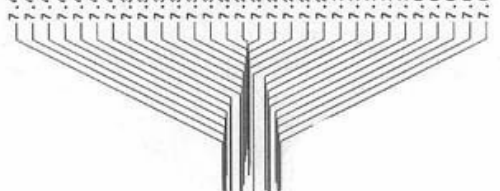

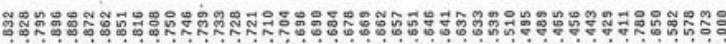
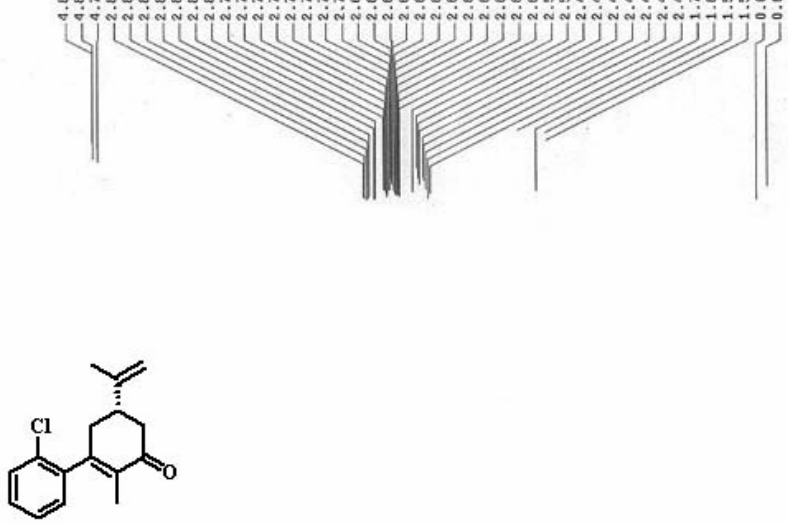

1d-2

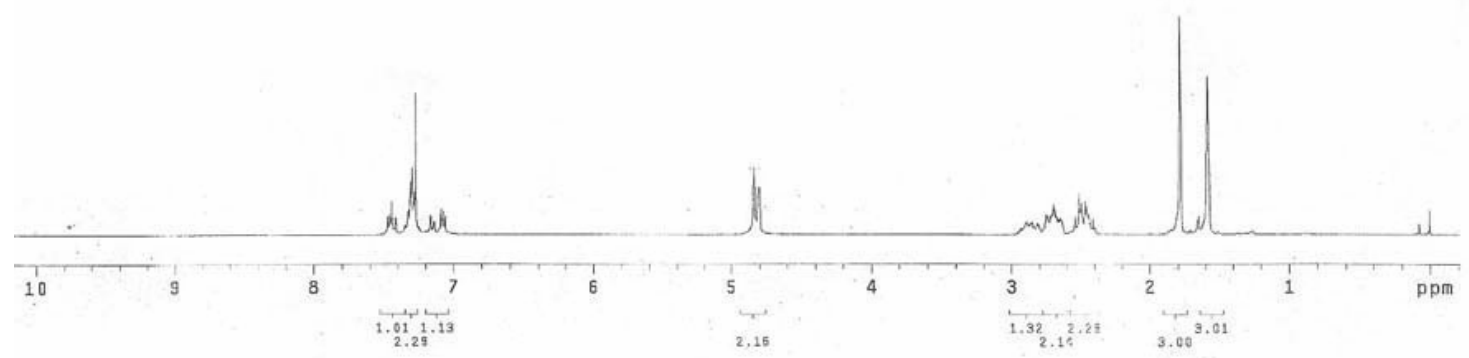

chloroketone-c13.

Pulse Sequence: s2pul
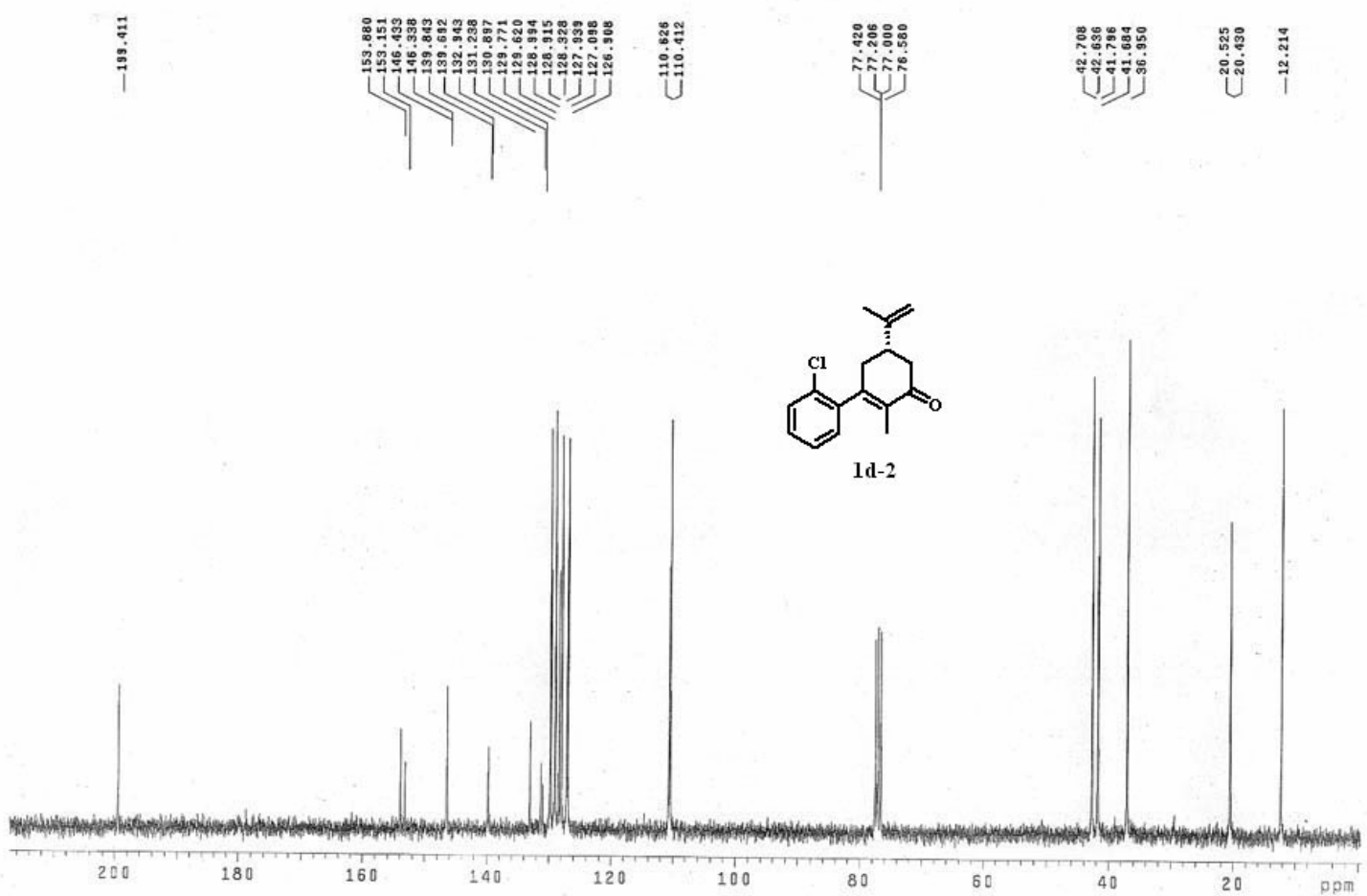
bromoketone

Archive directory: /export/home/vnmr1/vnmrsys/data
Sample directory:

Sample directory
Fille: PRoTON

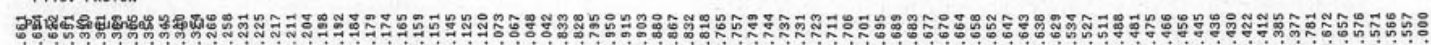

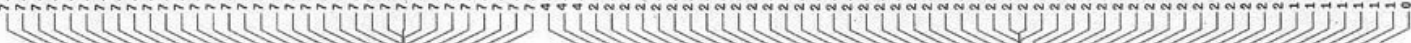
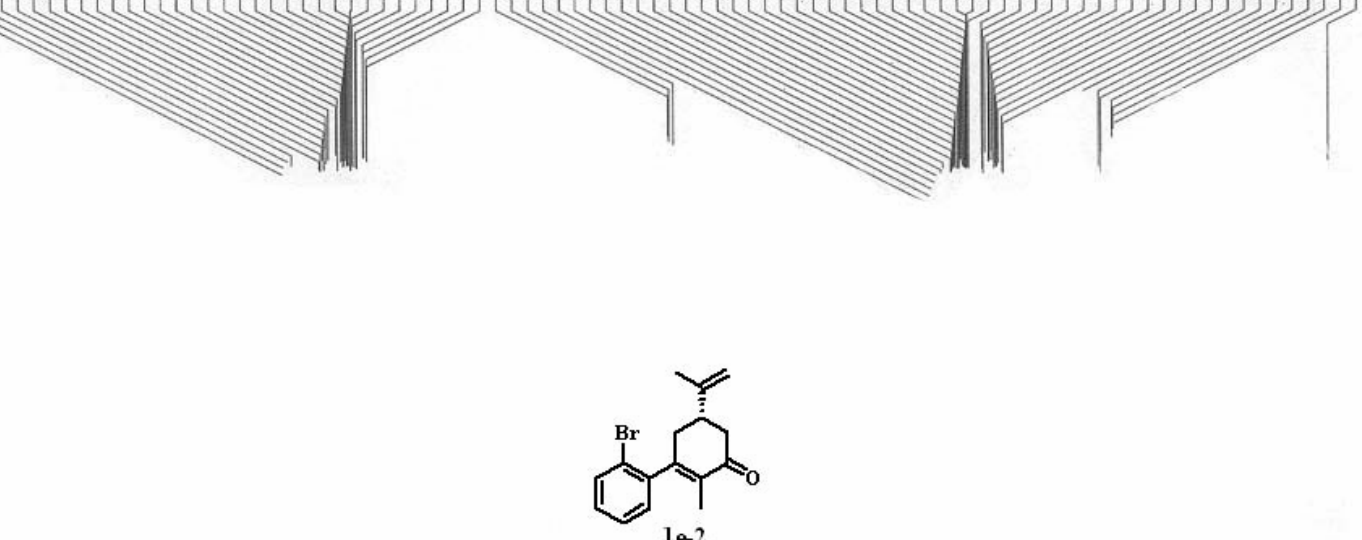

le-2

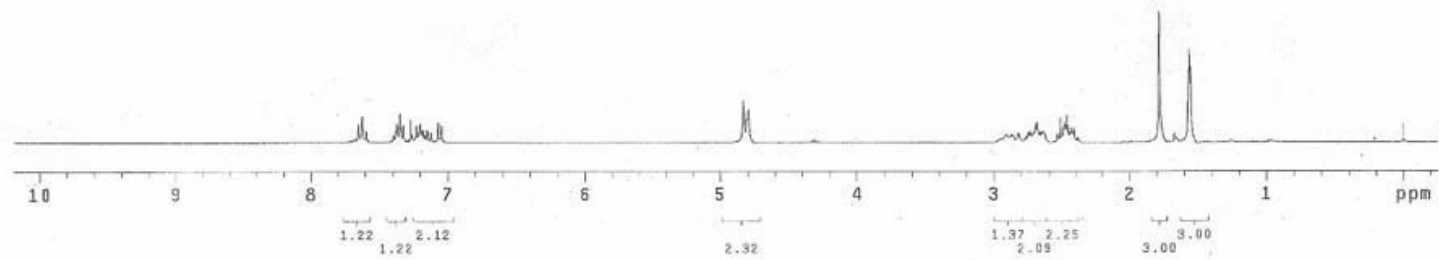

Pulse sequences sapul

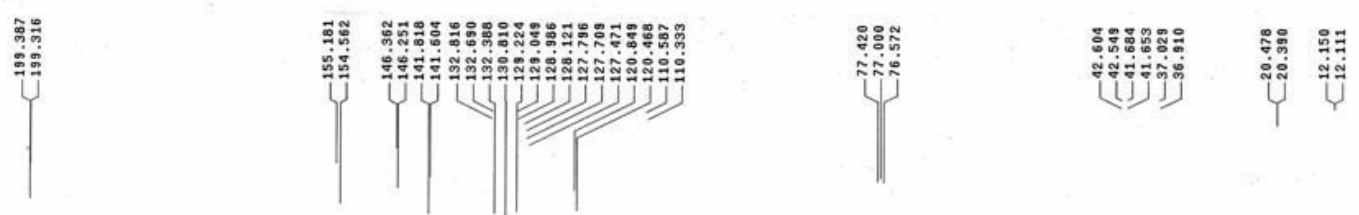

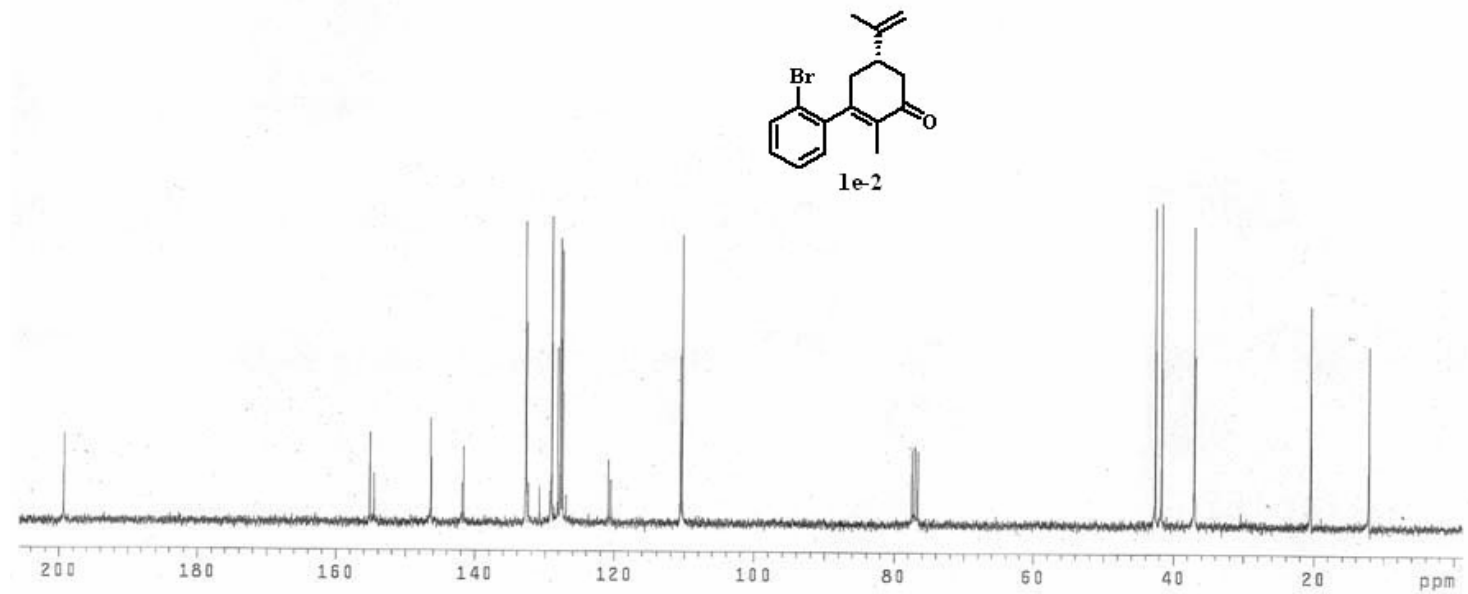


craketone

Archlve directory: /export/home/vnar 1/vnarsys/data
Sample directory:

Fie: pkotow

Pulse Sequence:

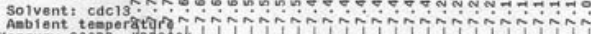

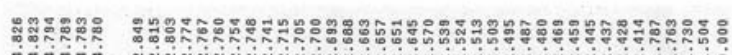

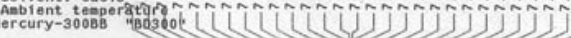

Relax. de lay 1.000 se

Aco ${ }^{2}$ time 2.010

OBSERVE Tritions 300.0647569 MHZ

OATA PROCESSING

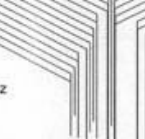

iijj ن்

Total t tme 0 min, $53 \mathrm{sec}$
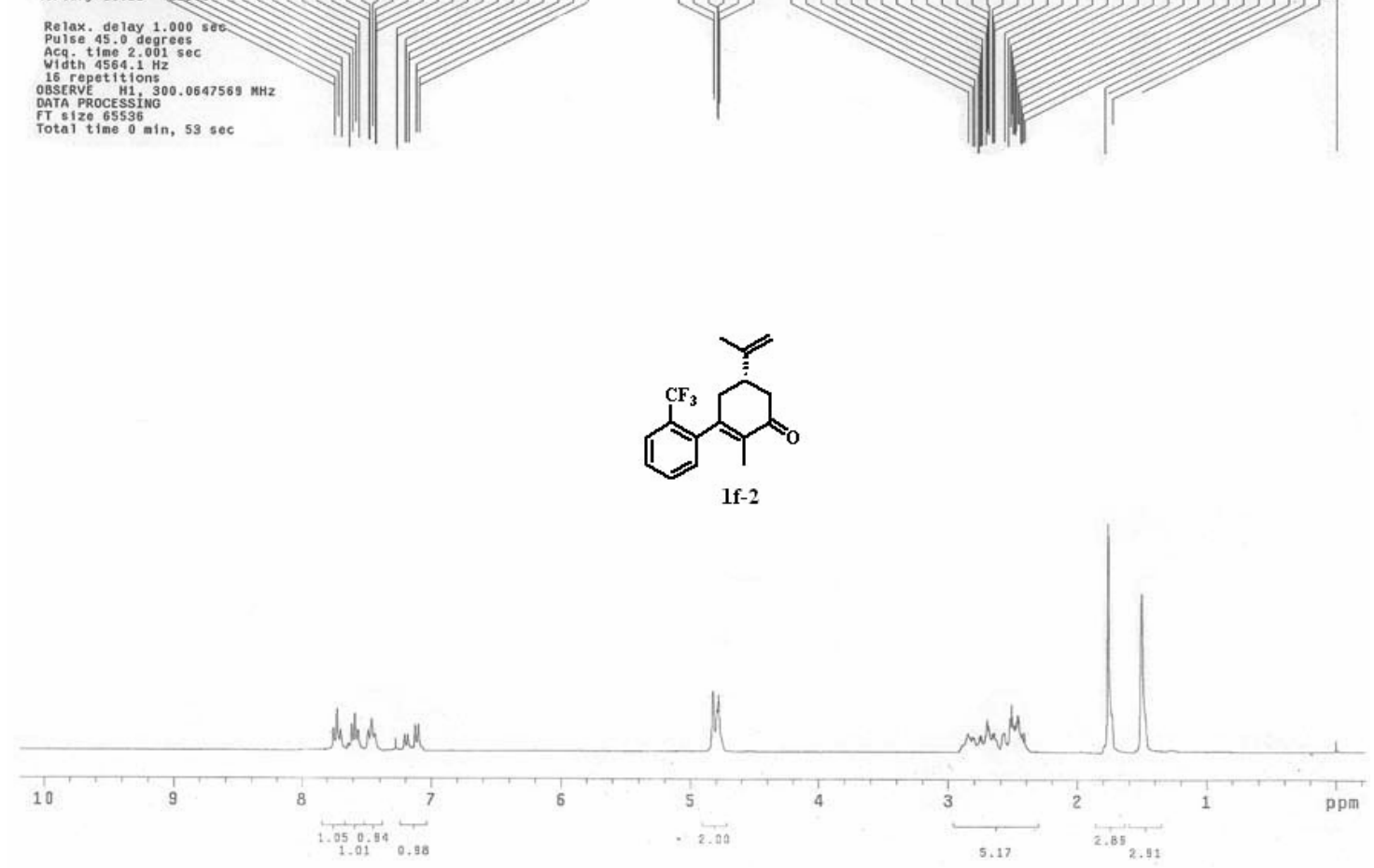

cf3-ketone-c13

Pulse Sequence: s2pur

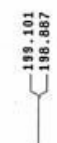

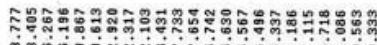

ต่

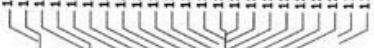

$1 \times \cdots$

|ิ่ง

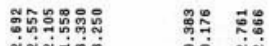

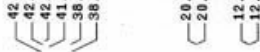

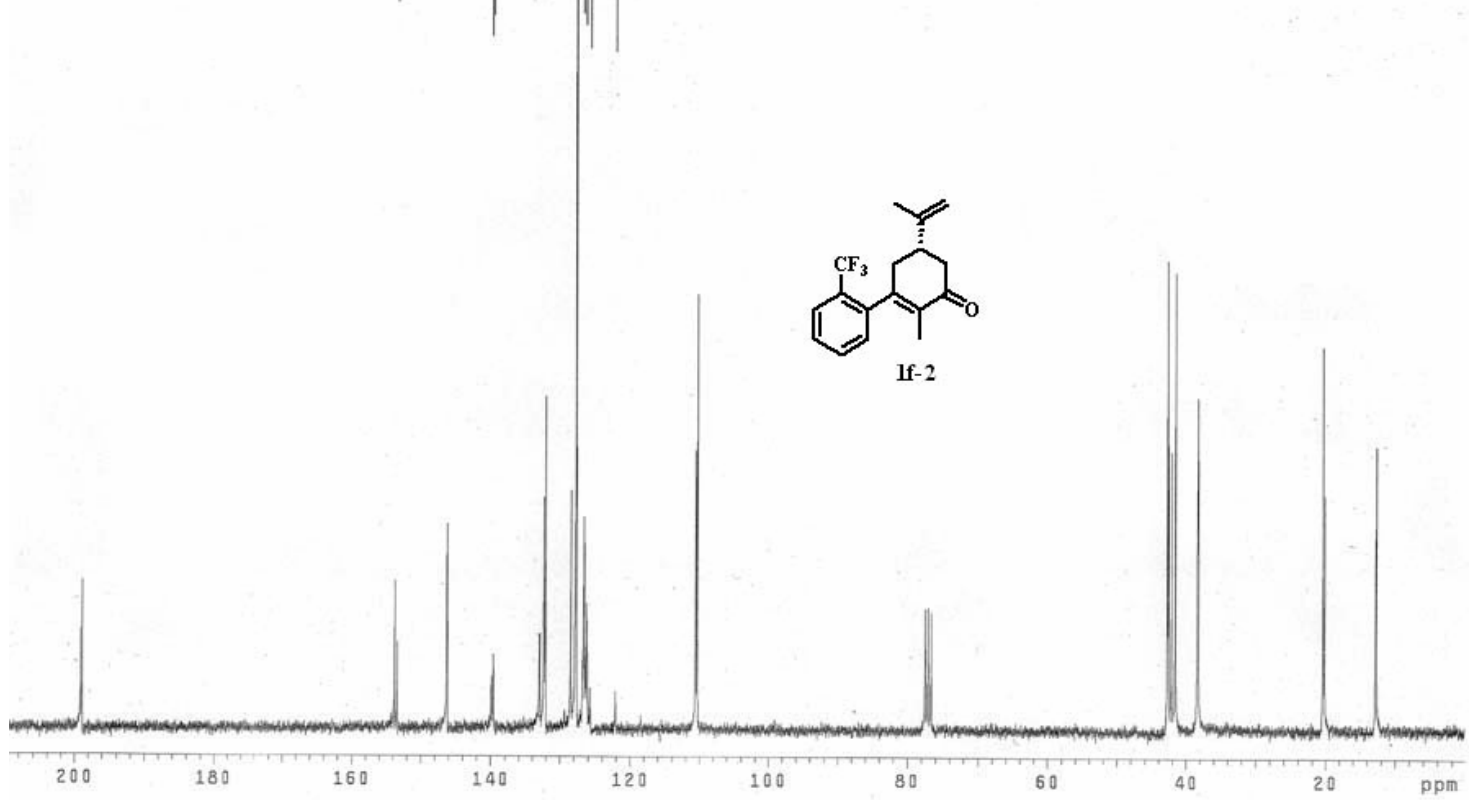


p-one-naphketone

Archive directory: /export/home/vnar1/vmarsys/dat
Sample directory:

File: PROTOW

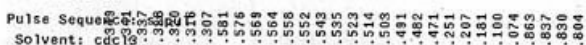

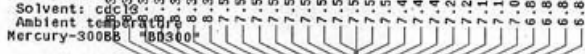

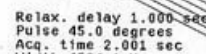

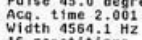

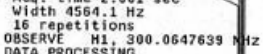

DATA PROCESSTM
FT S1ze 6536
Total time 0 min, $53 \mathrm{sec}$
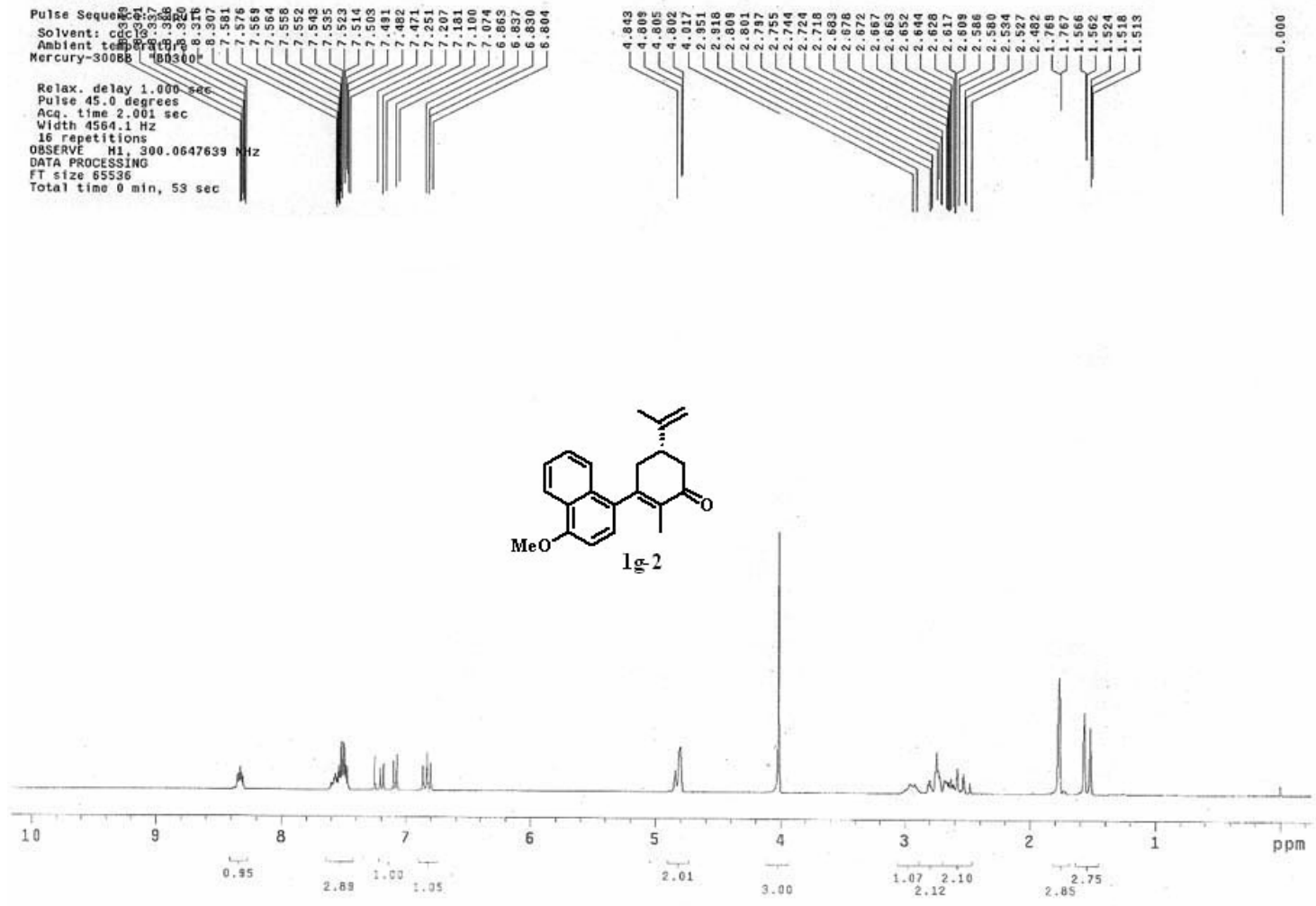

p-ome-nphketono-c13
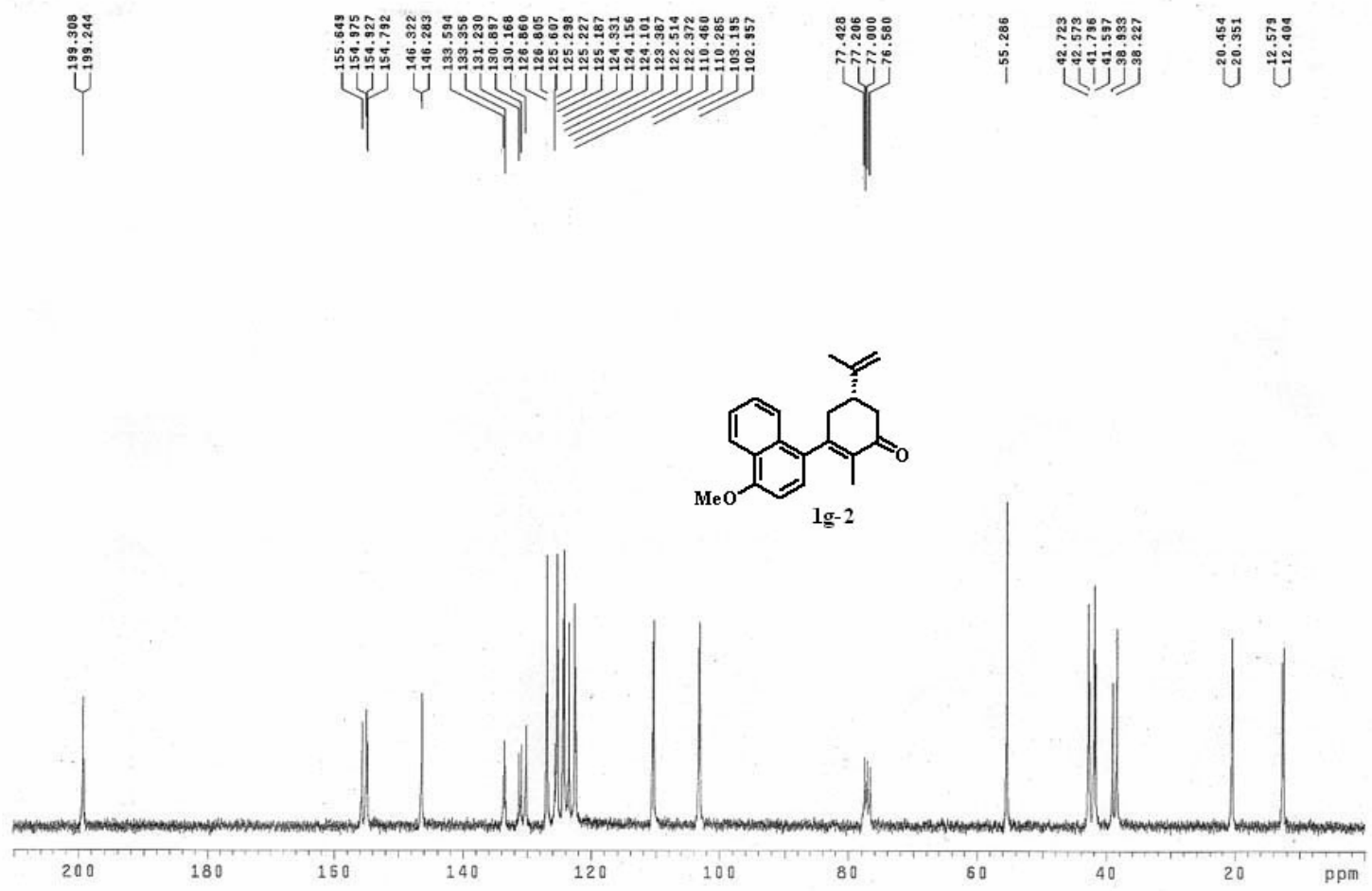

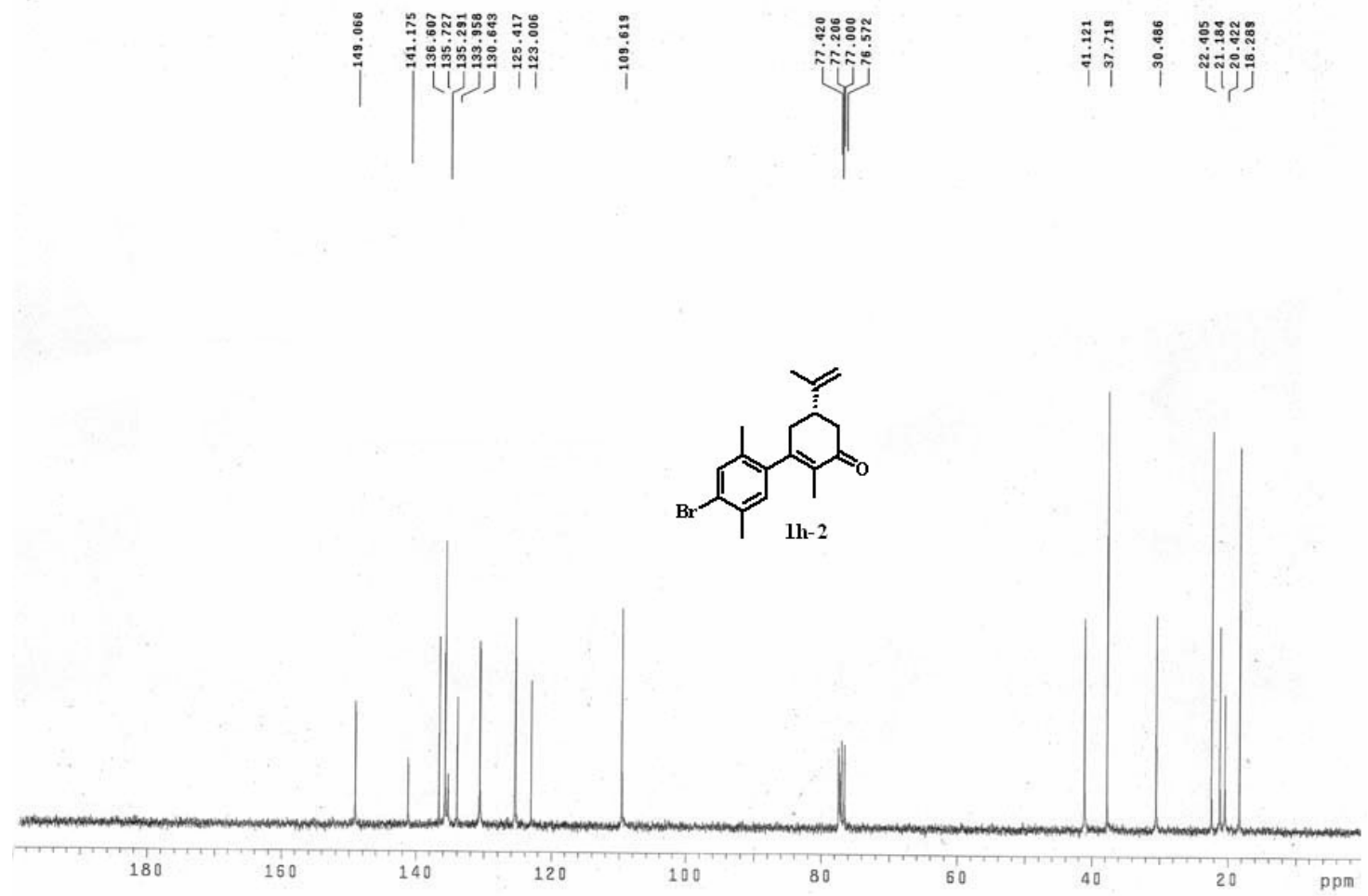

2,5-dimethy 1-4-brono-ketone

Archive directory: /export/home/vnar 1/vnmrsy5/data
Sample directory:

Pulse Sequence: s2pul

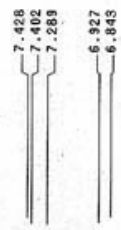

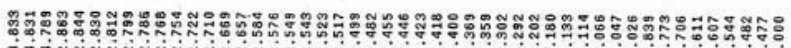

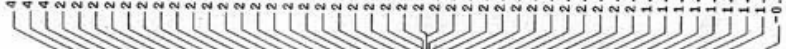
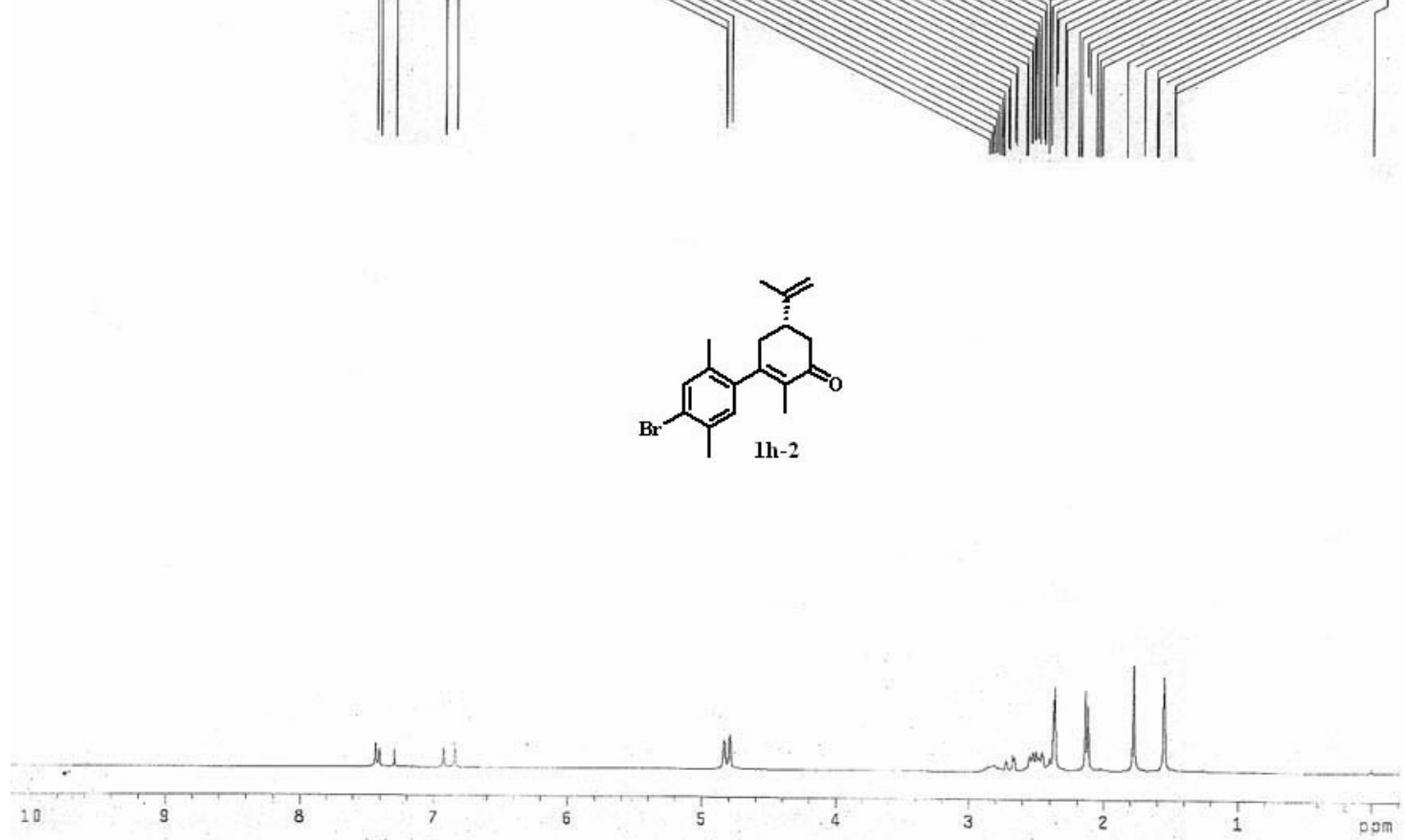


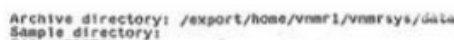
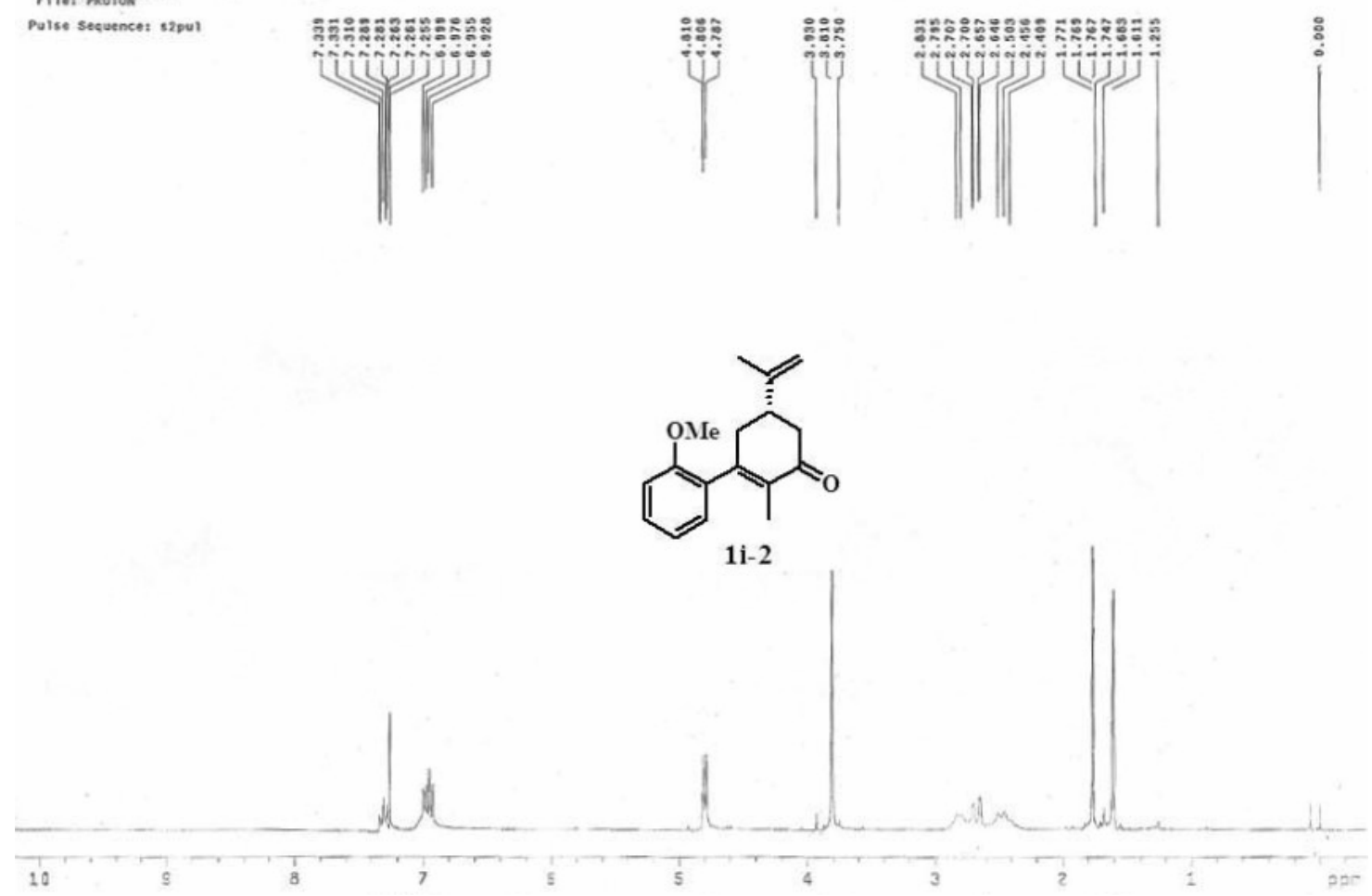

methoxy Iketone-c1s

pulse sequences szpul

$\stackrel{\vdots}{\vdots}$

|

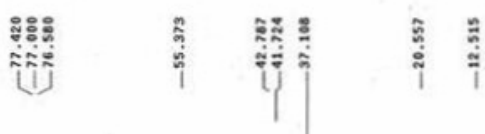

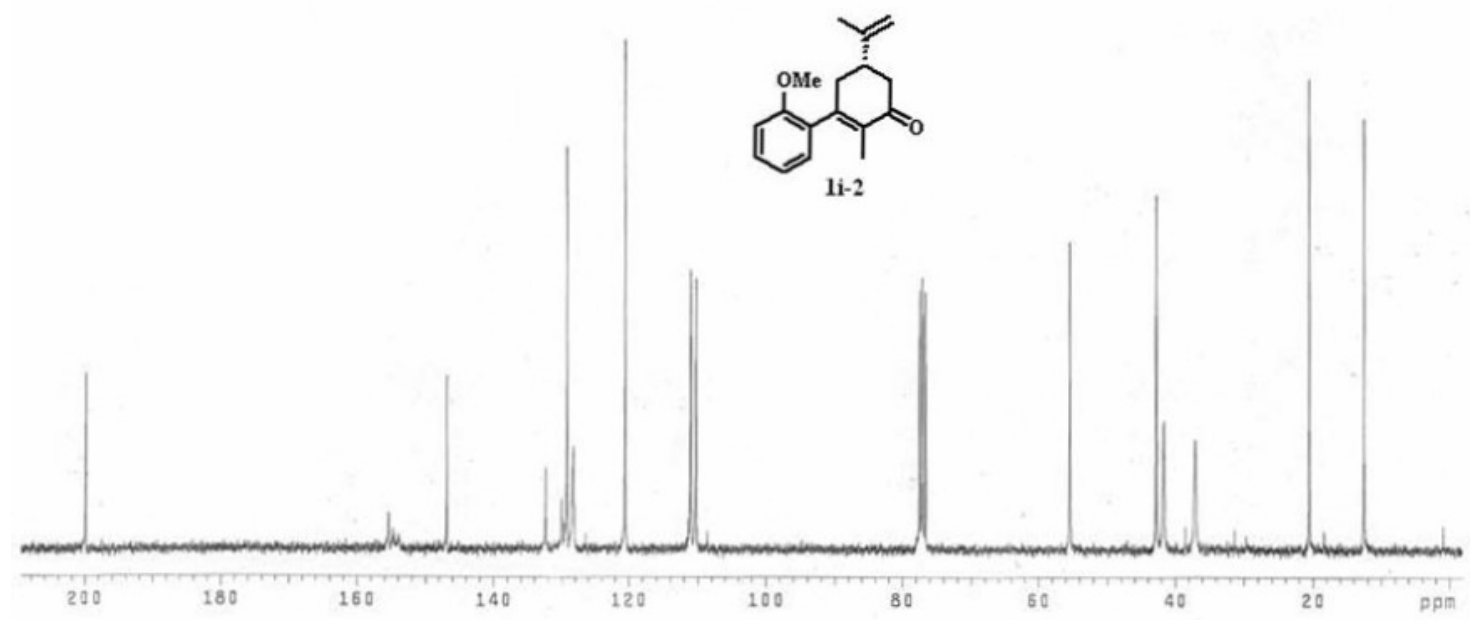


methylbiary1

Archive directory: /export/home/vnar1/vnarsys/data
Sample directory:

Pulse Sequence: s2pui

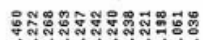

ฆัตัด

iniuinjujj

7 .

ขึ
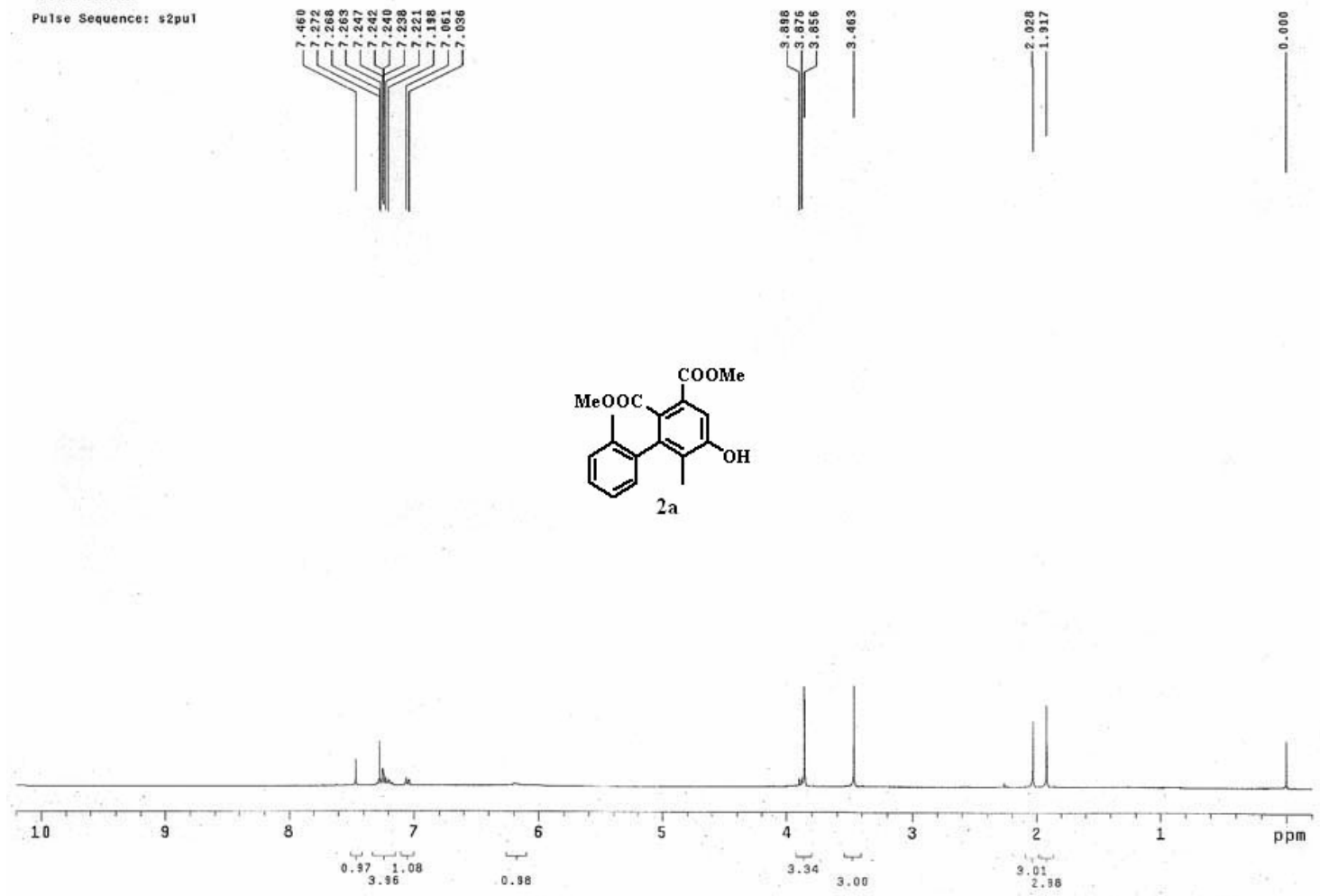

Pulse Sequence: s2pu

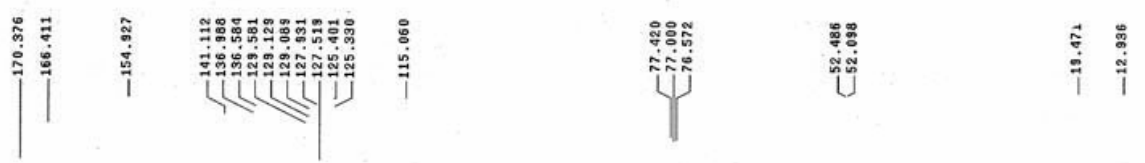
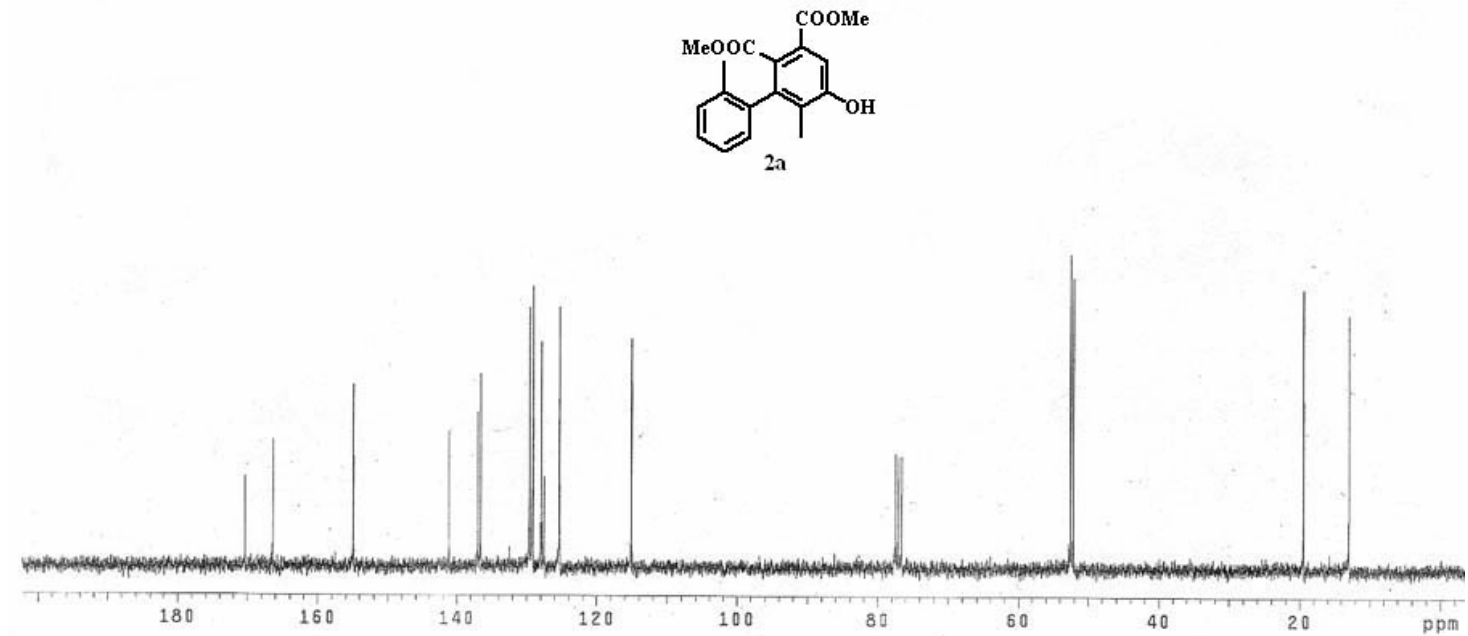


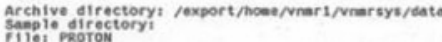
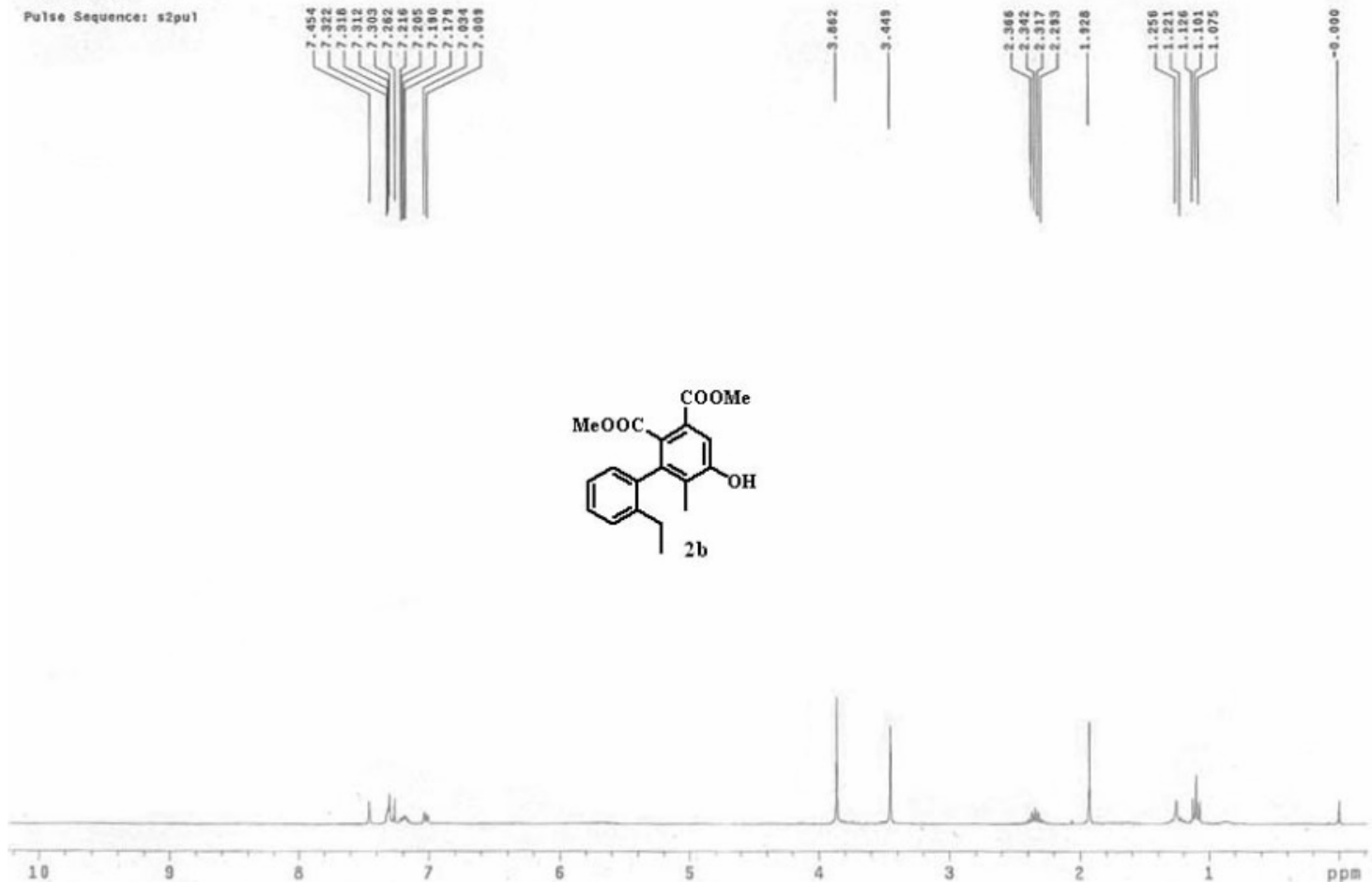

Pulse Sequence: s2pu

|
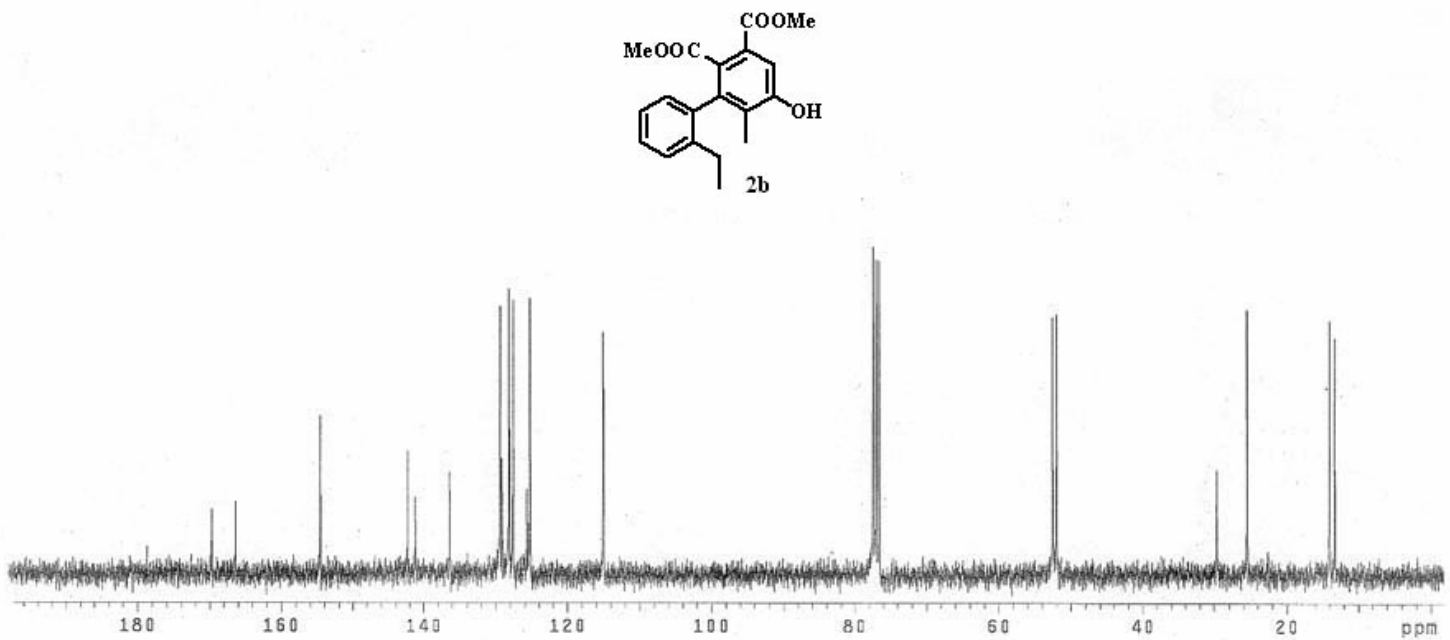
[sopropylbiary'

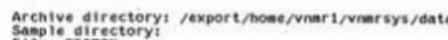

mei parow
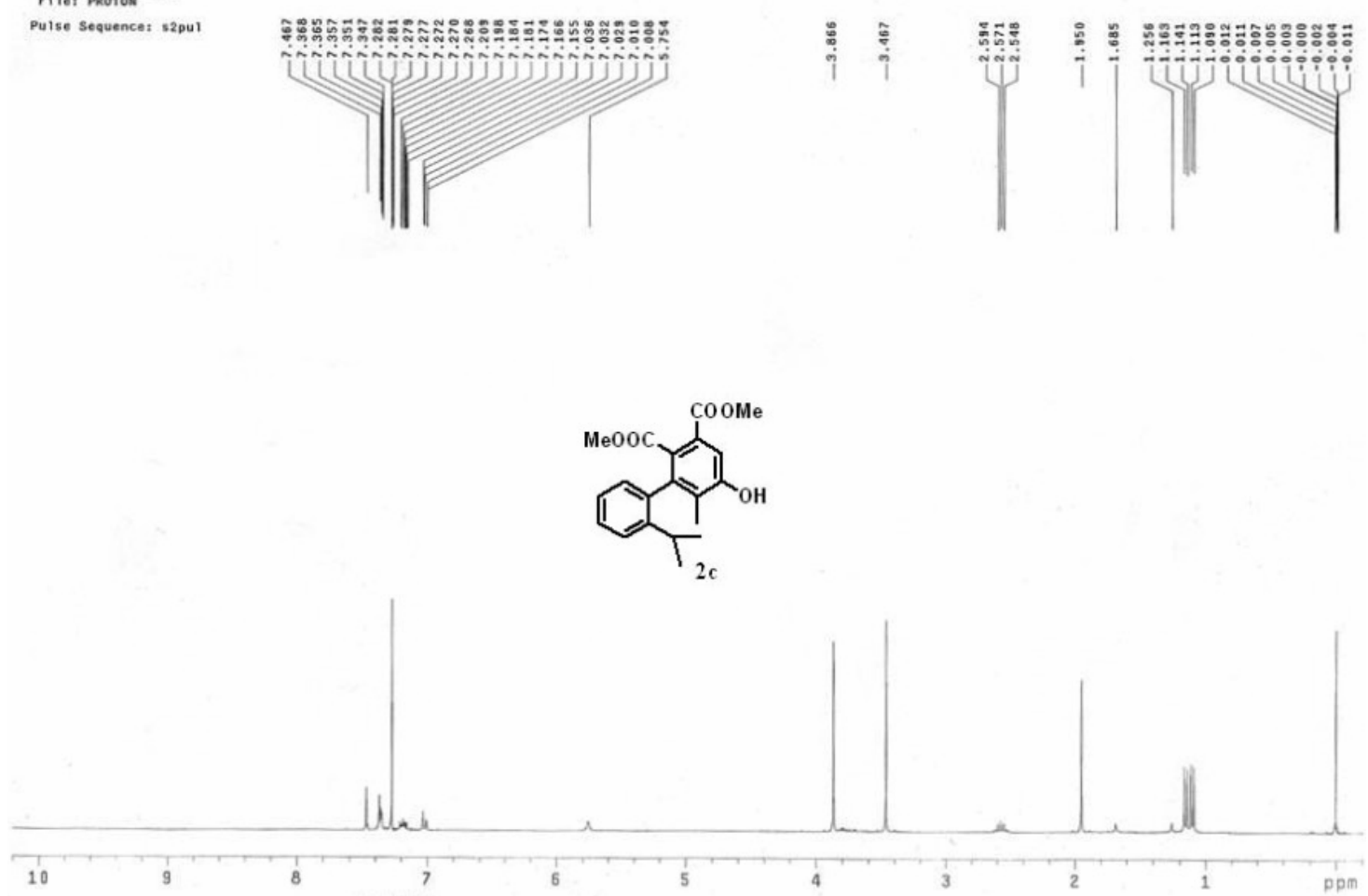

Pulse sequence: s2pul
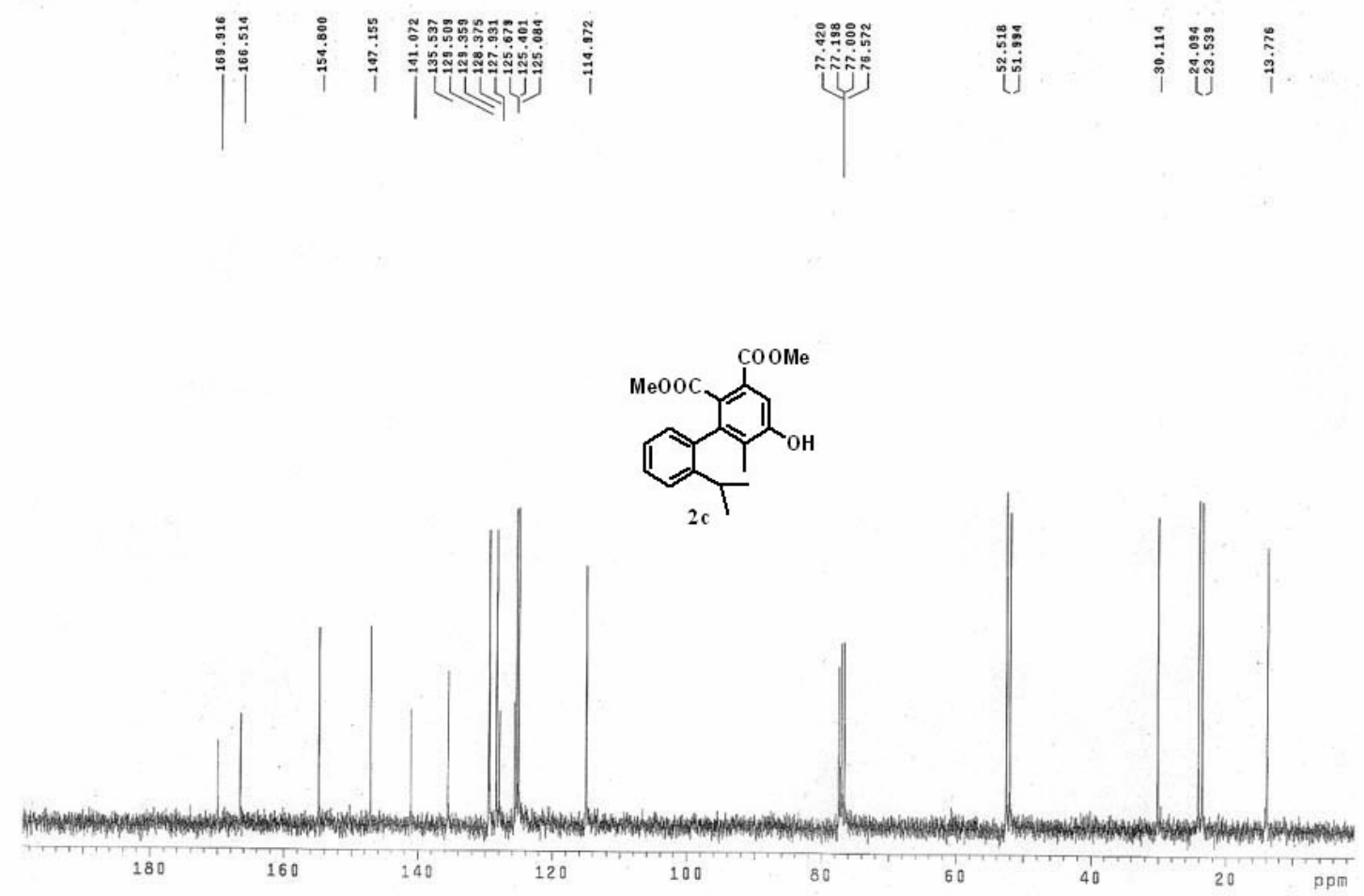

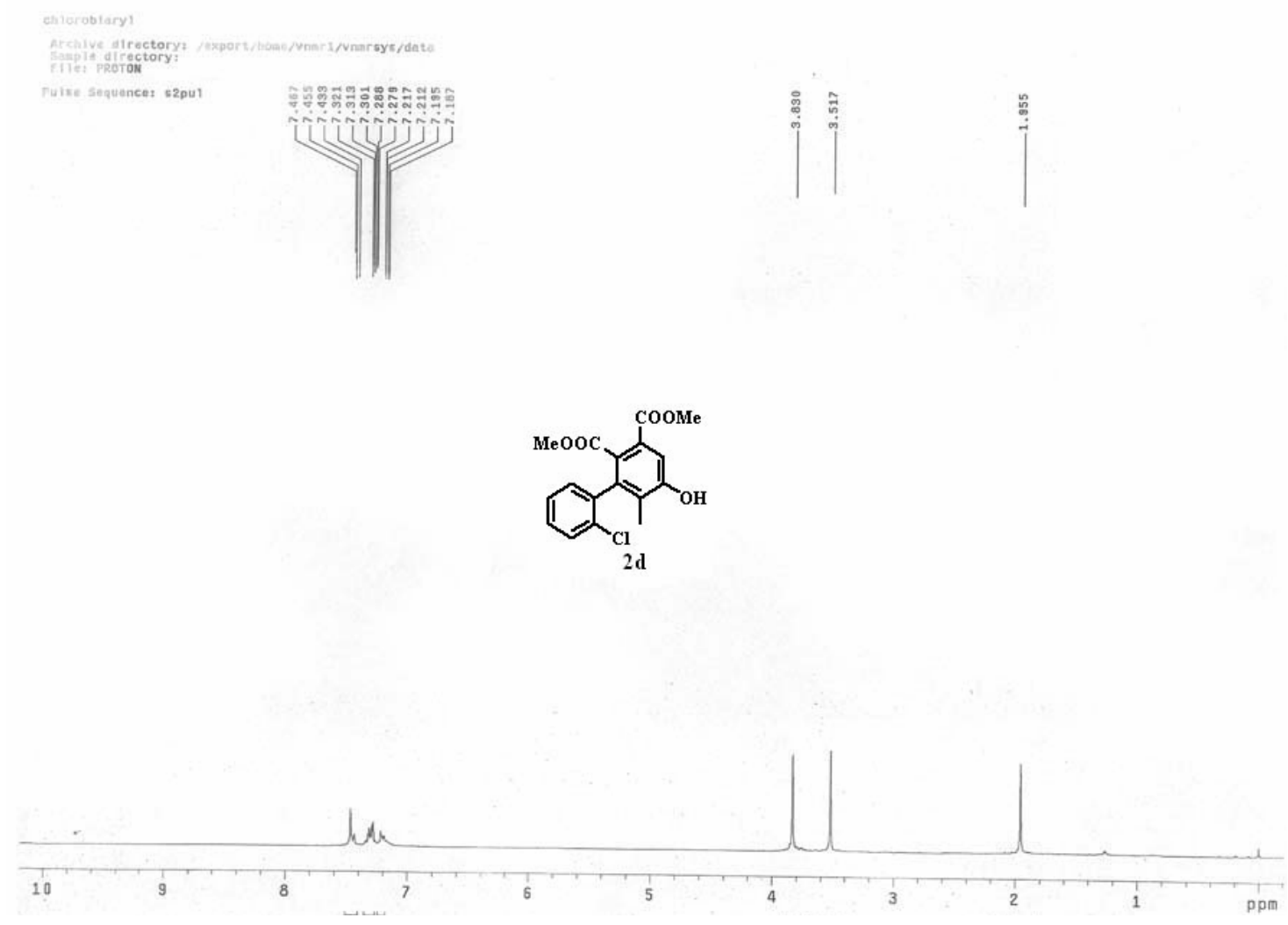

choloblary

Puise Sequence: s2put

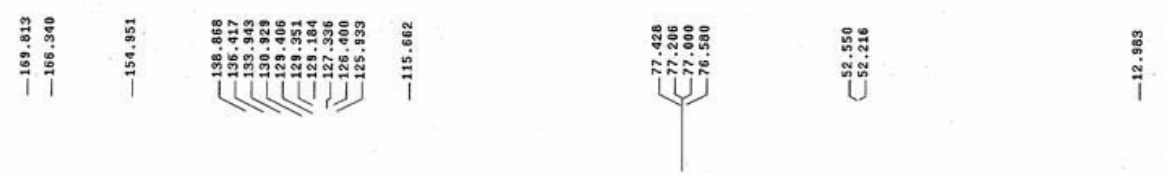

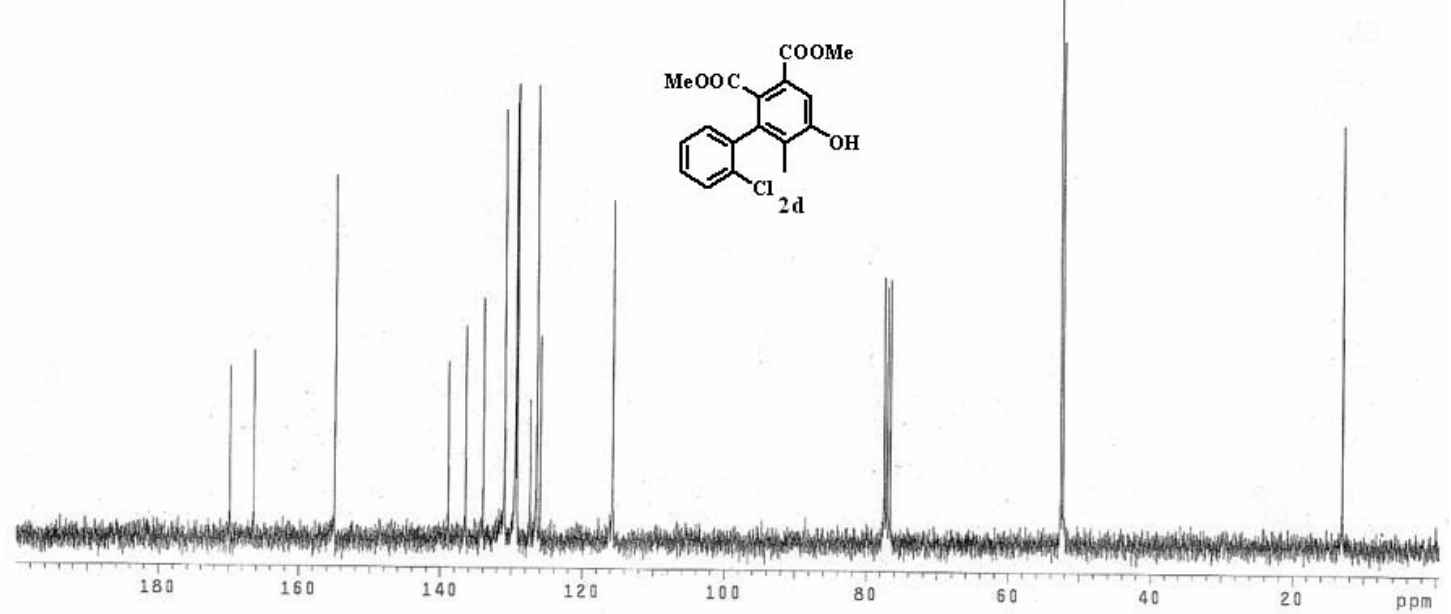


romoblary 1

Archive directory: /export/home/vnar 1/vnareys/date
Salp 10 directory:

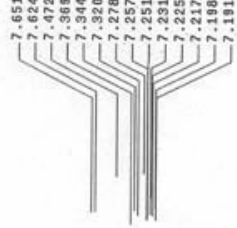

ฟै
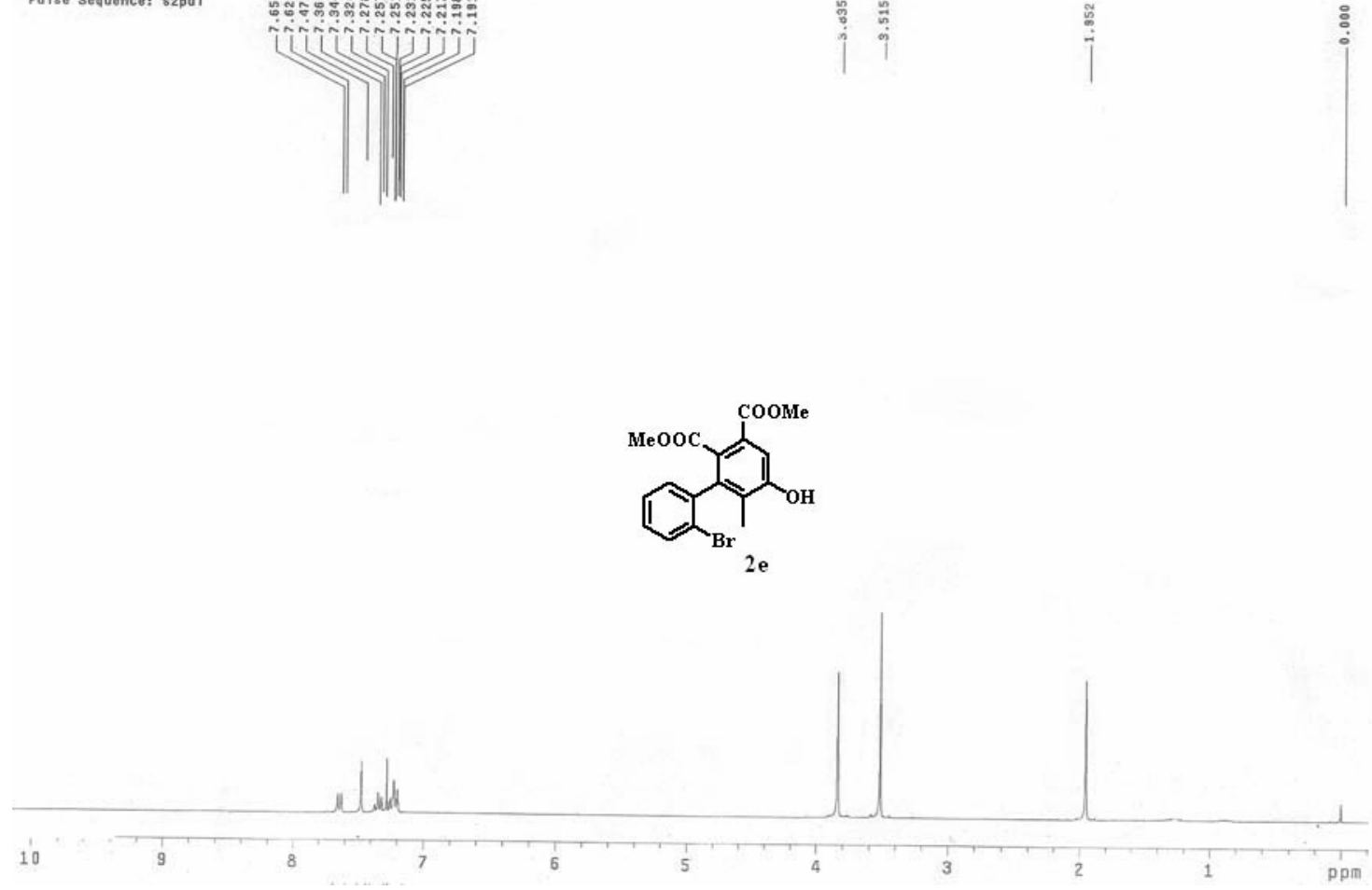

conory

Pulse sequencet s2pui
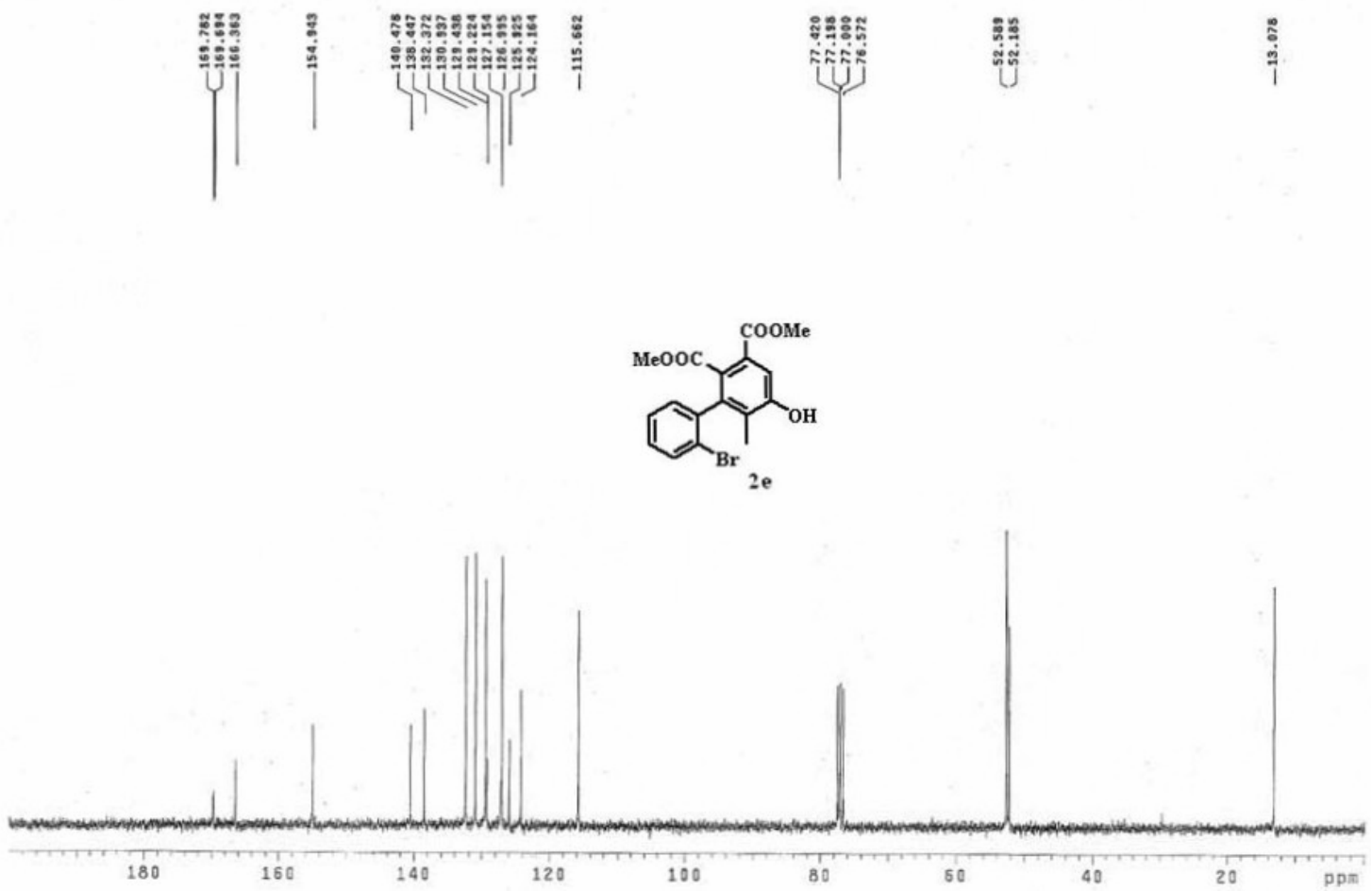
crsataken

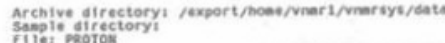

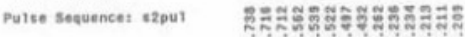

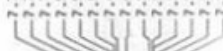
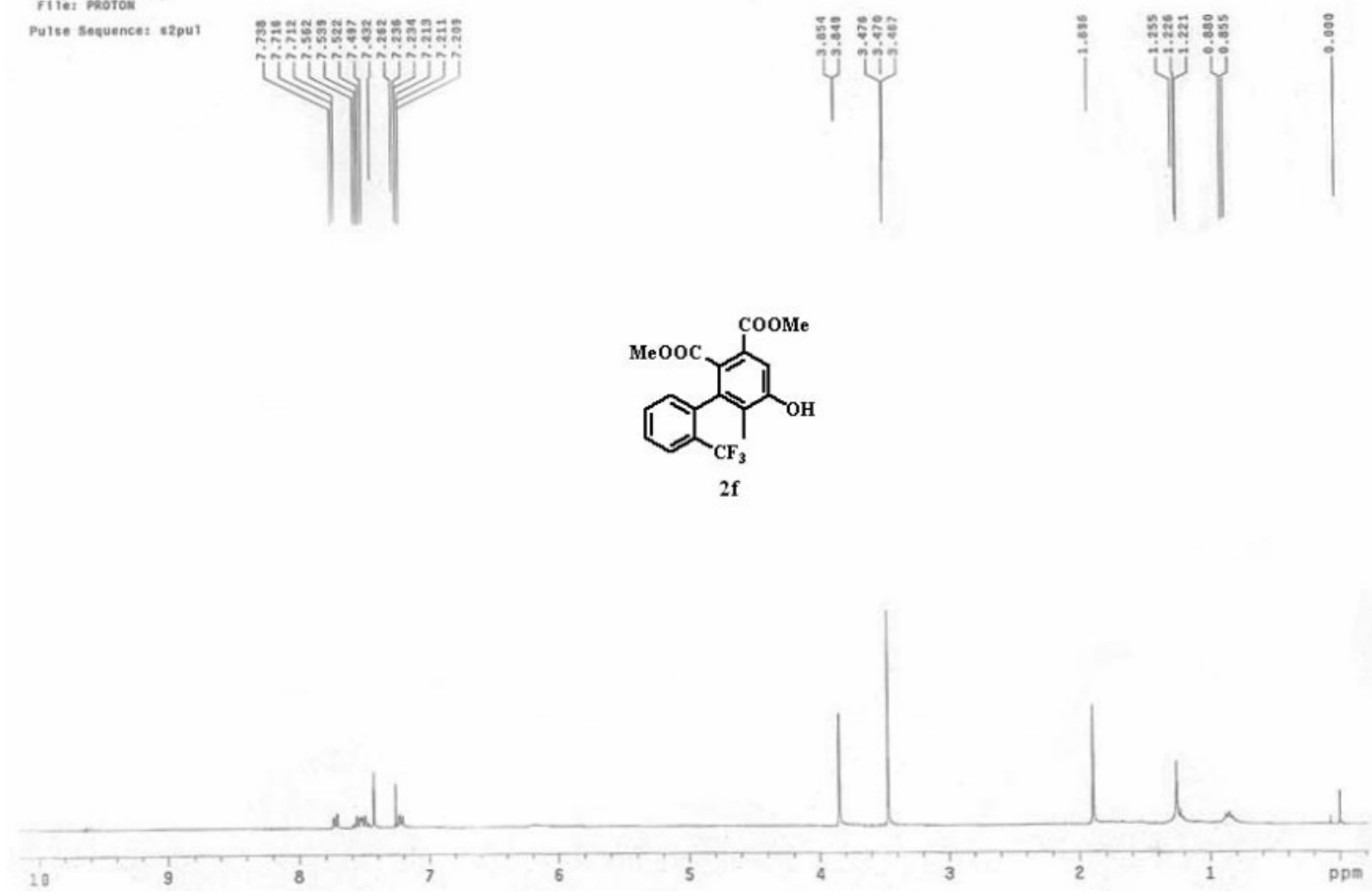

trifloblary)

Pulse Sequence: s2pu1

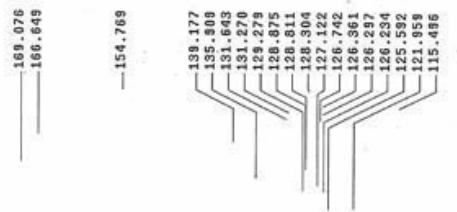

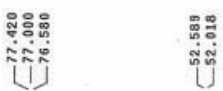
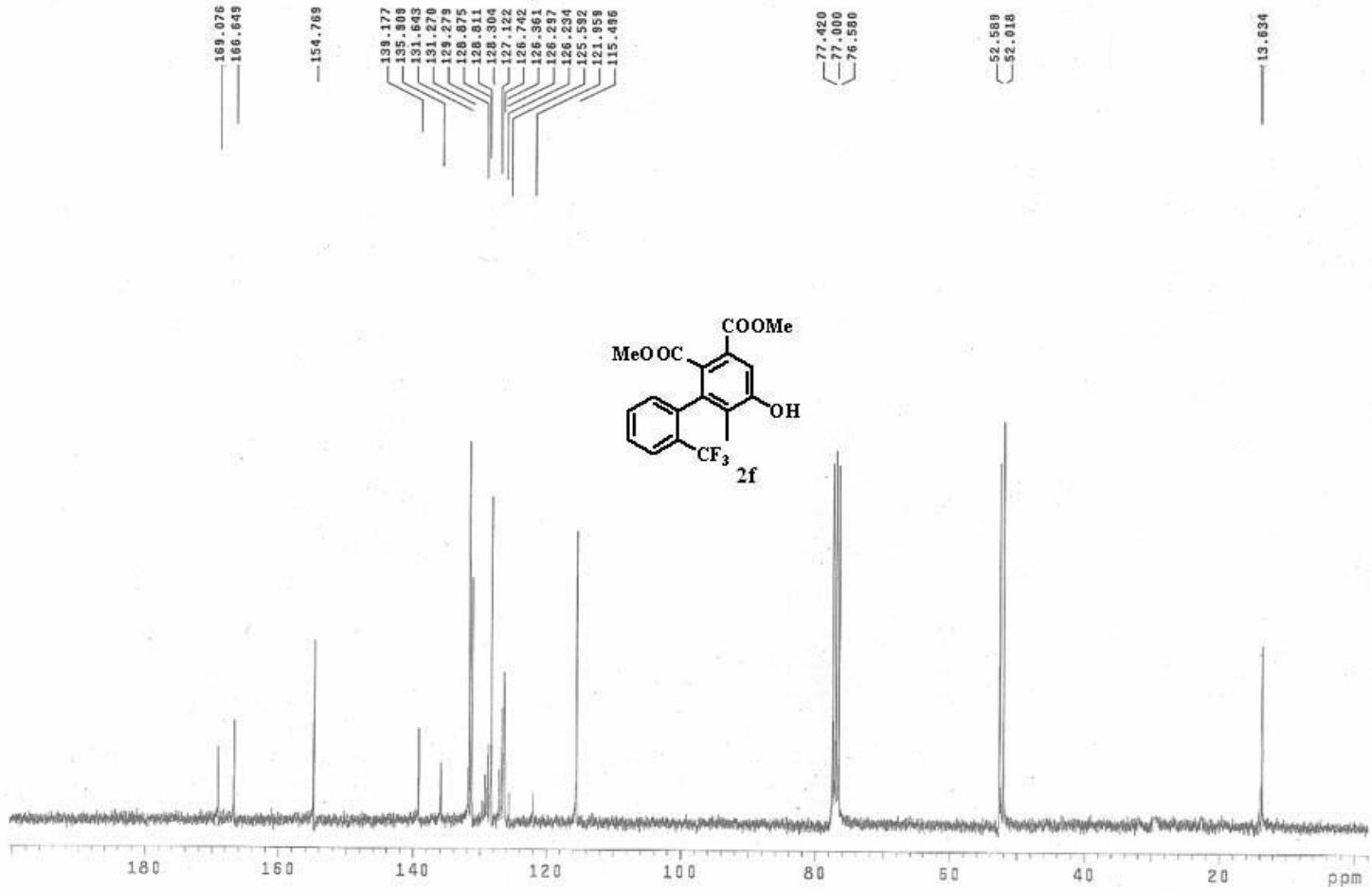
-une-napnotary!

Archlye Alrectorys /export/moso/vnar1/venrsys/date

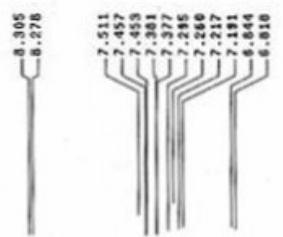

|
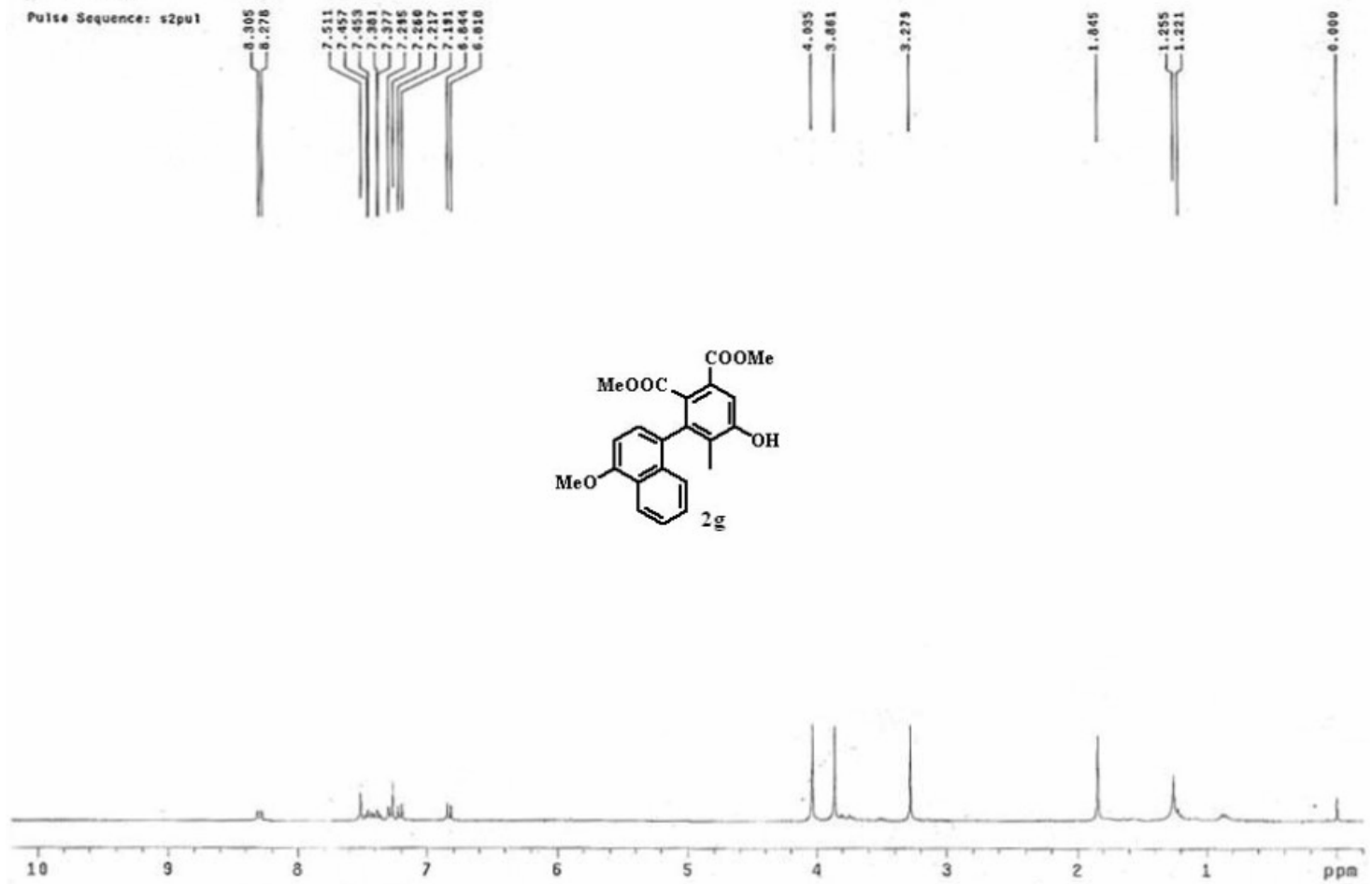

jomenaphbiary
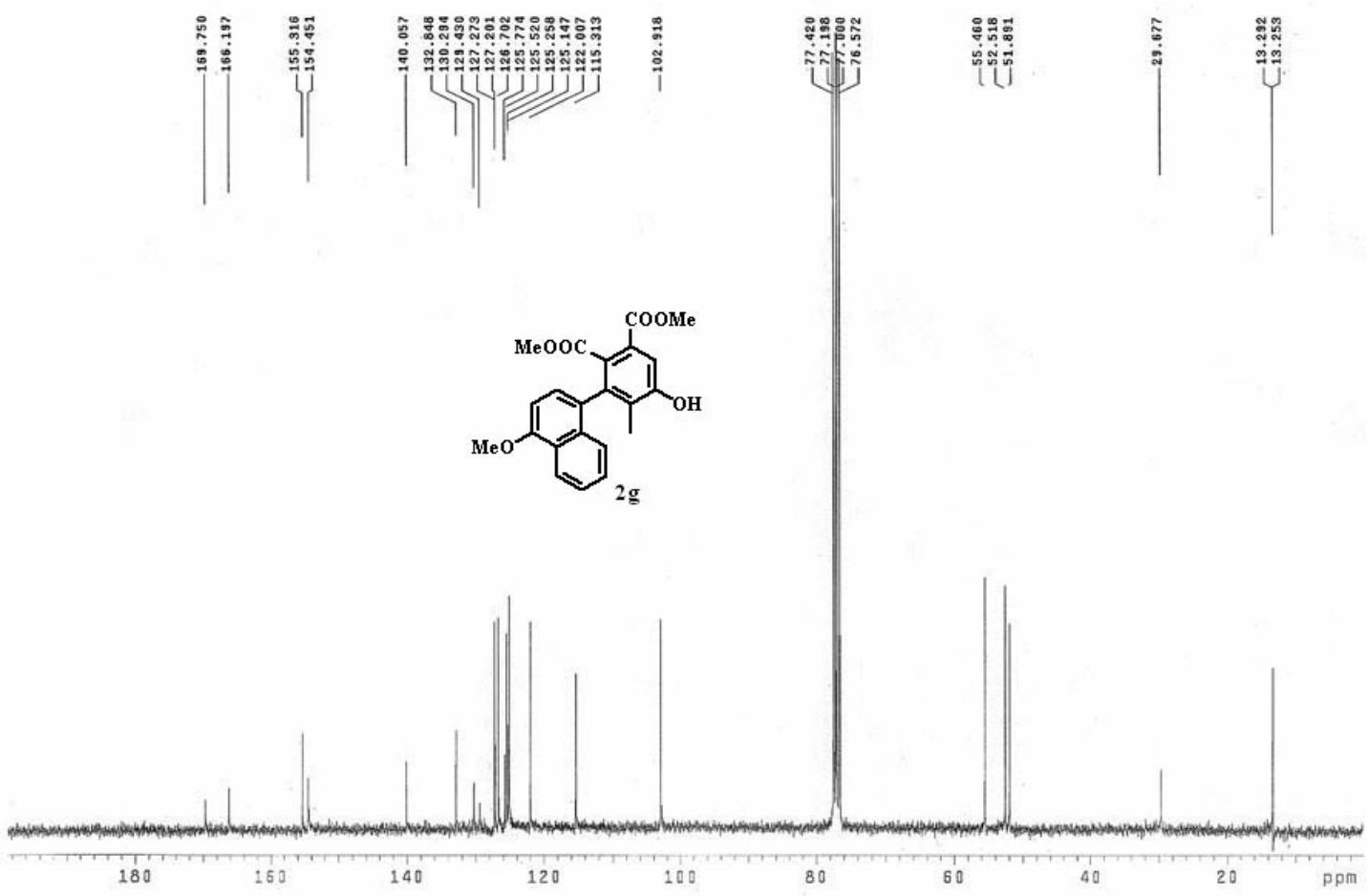
2,5-dime-4,brbiary

Archive directory: /export/home/vnar 1/vnarsys/dat
Sample directory:
fille: PRoToN

Pulse Sequence: s2pul
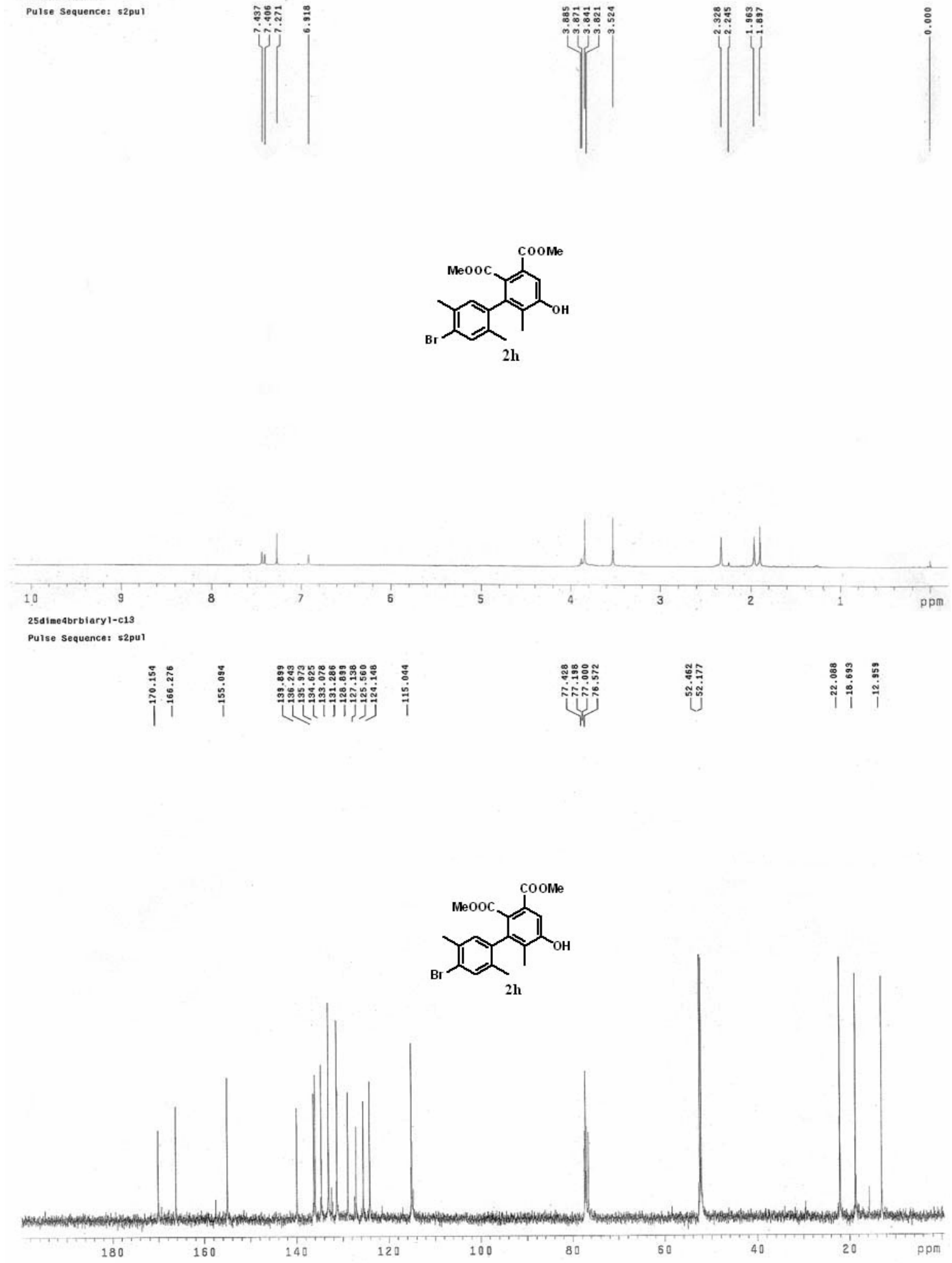
methoxy 1 biary

Archive directory: /export/hone/Vnar 1/vnmrsys/date

Pulse Sequence: 52 pu
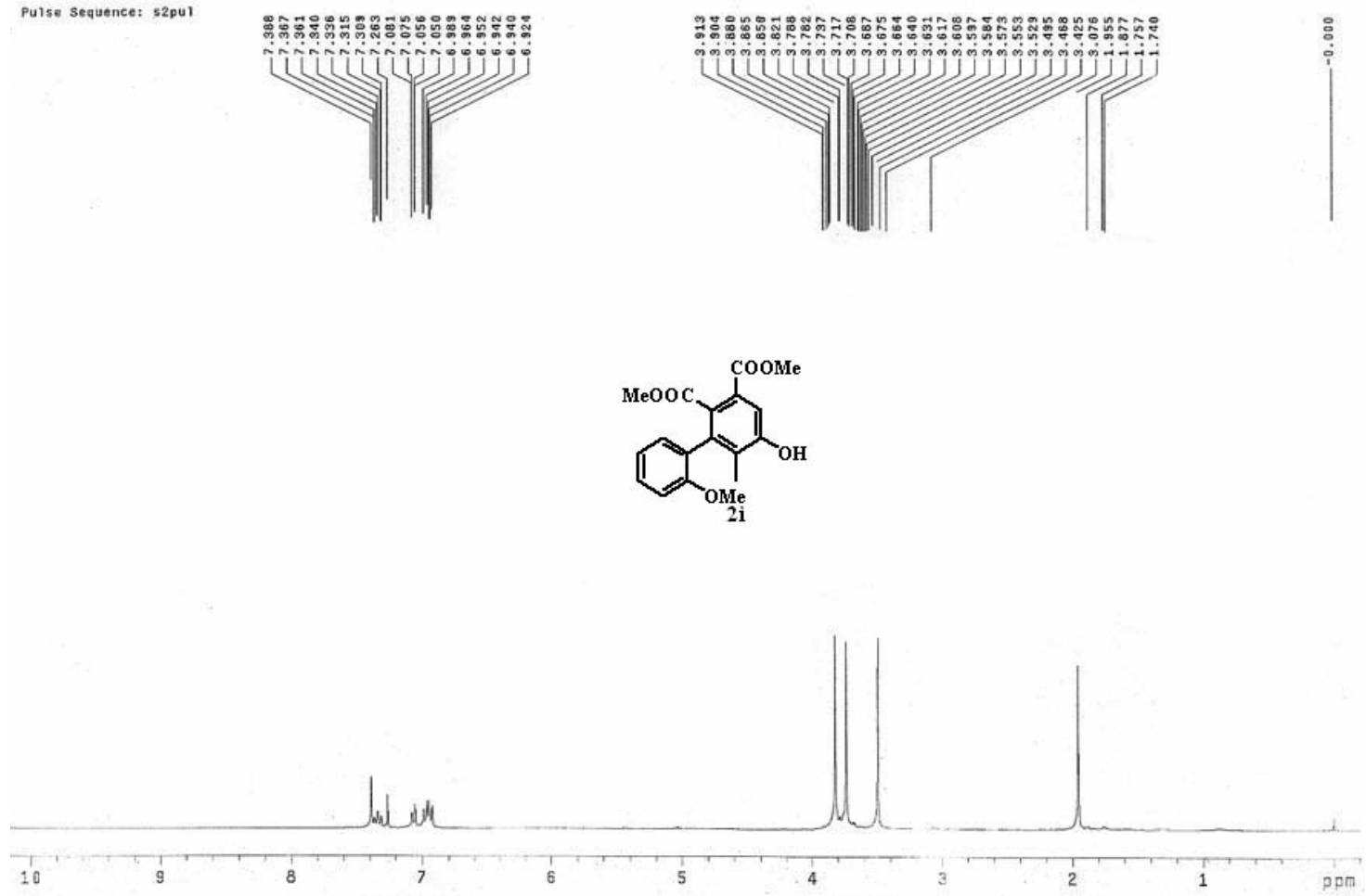

neobiaryi

pulse sequences szpul
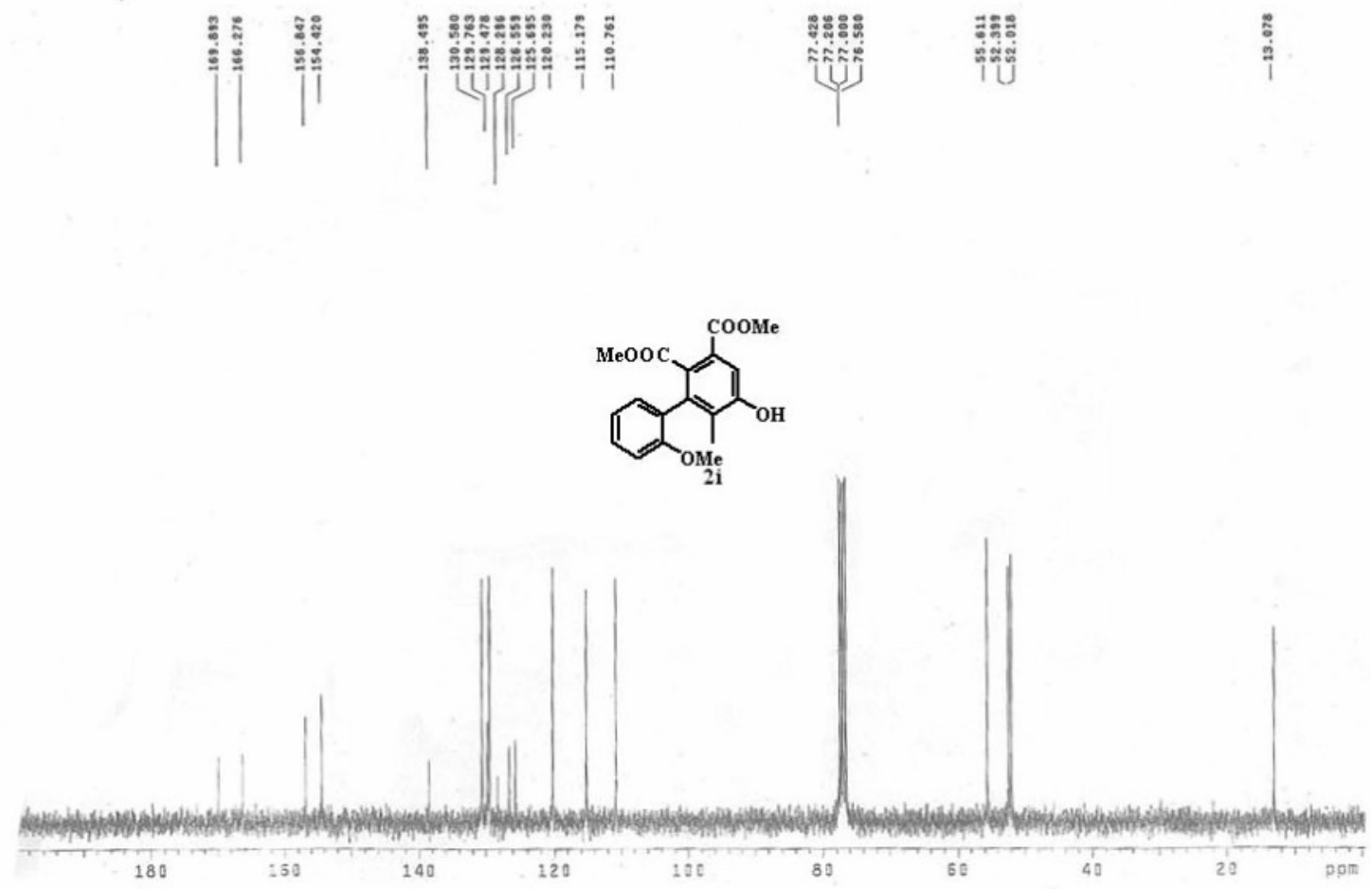

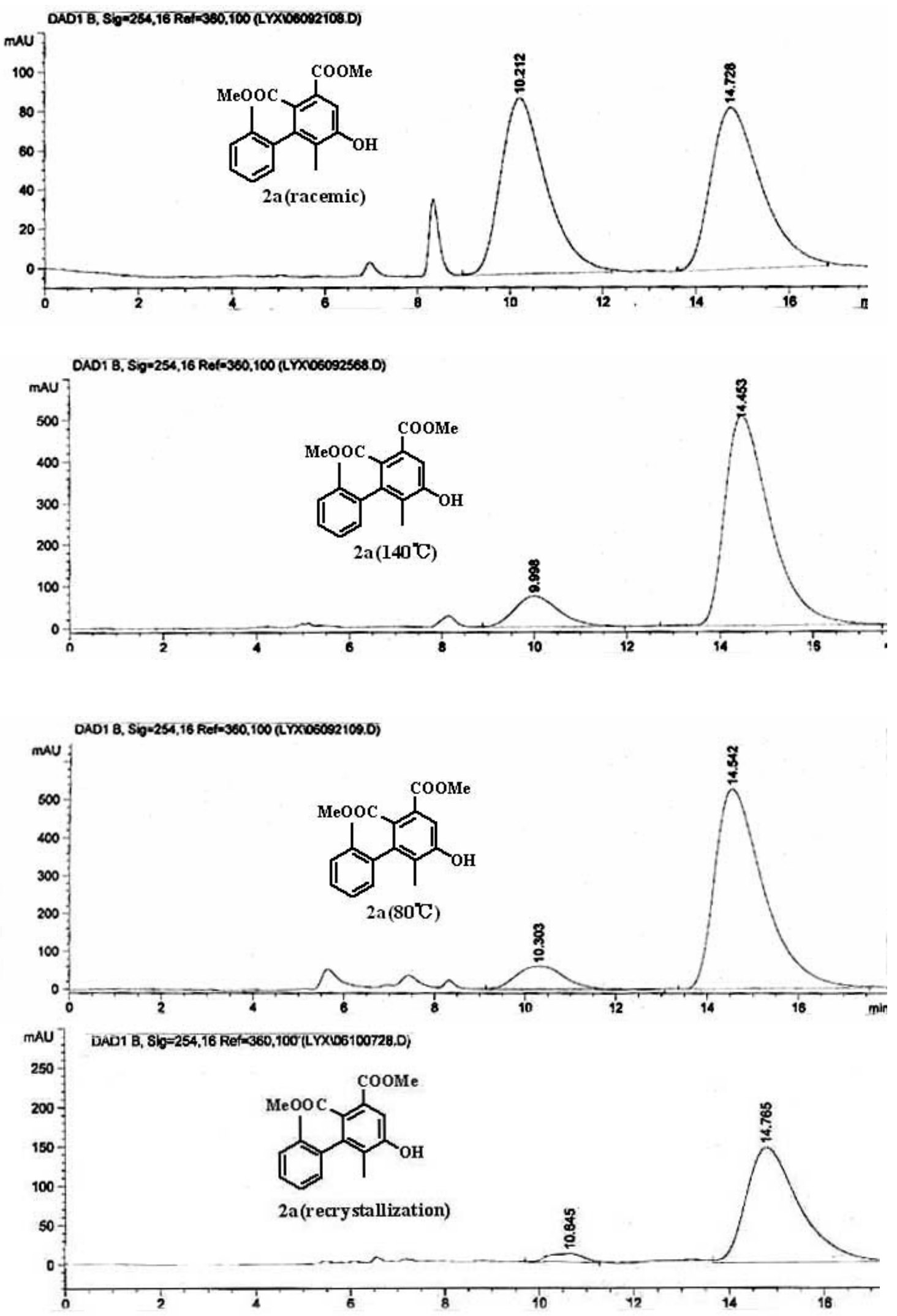

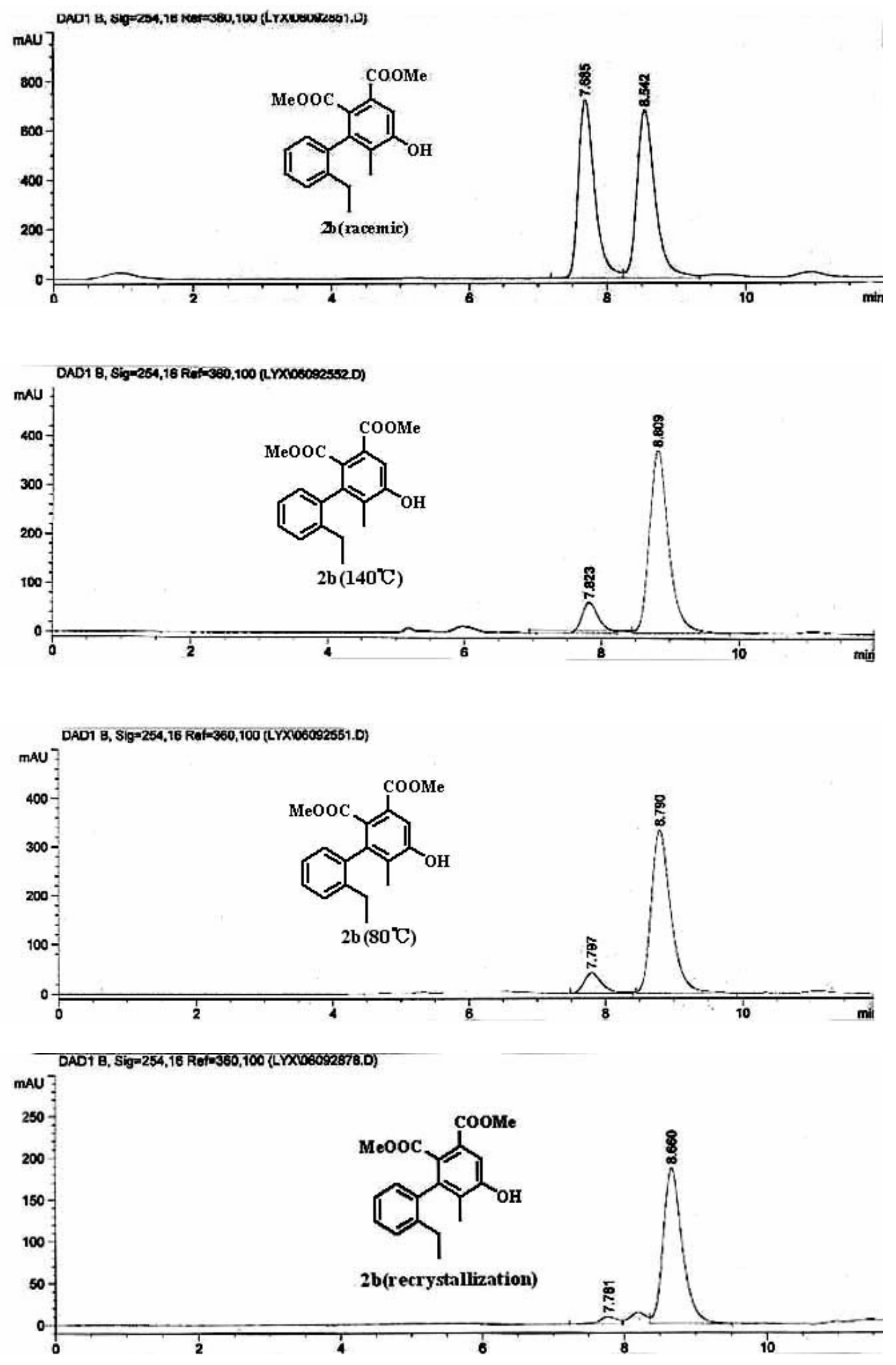

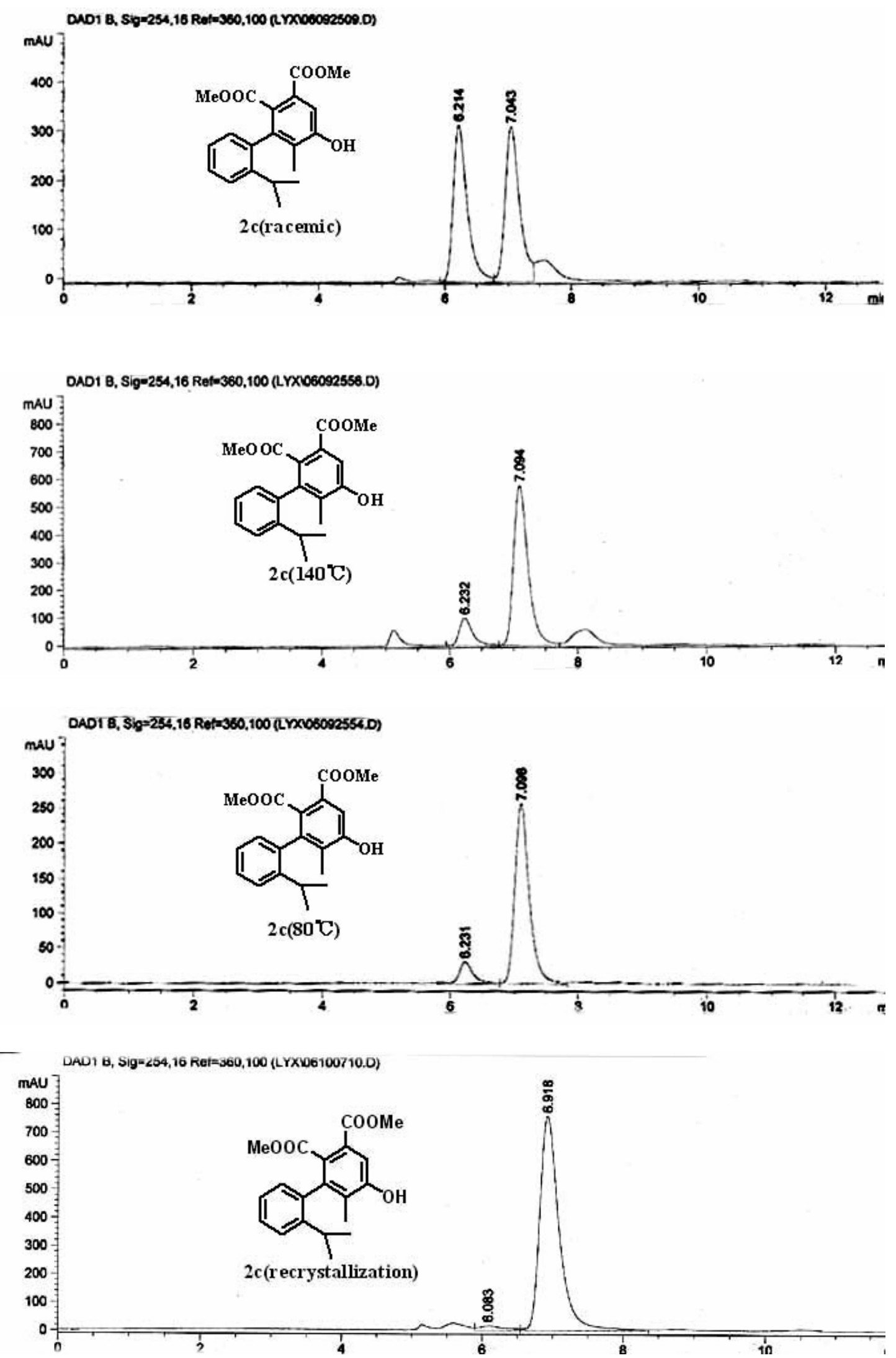

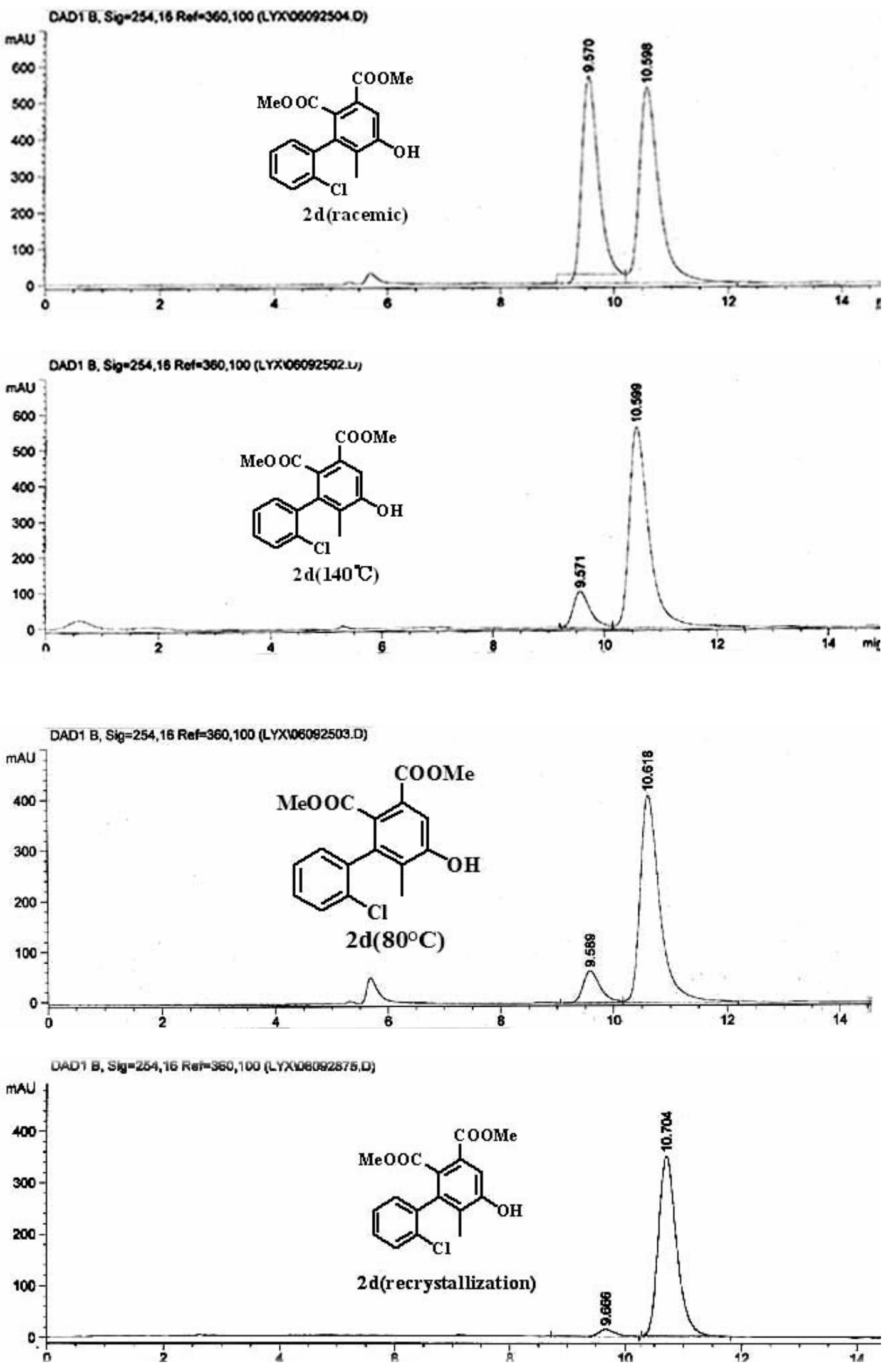

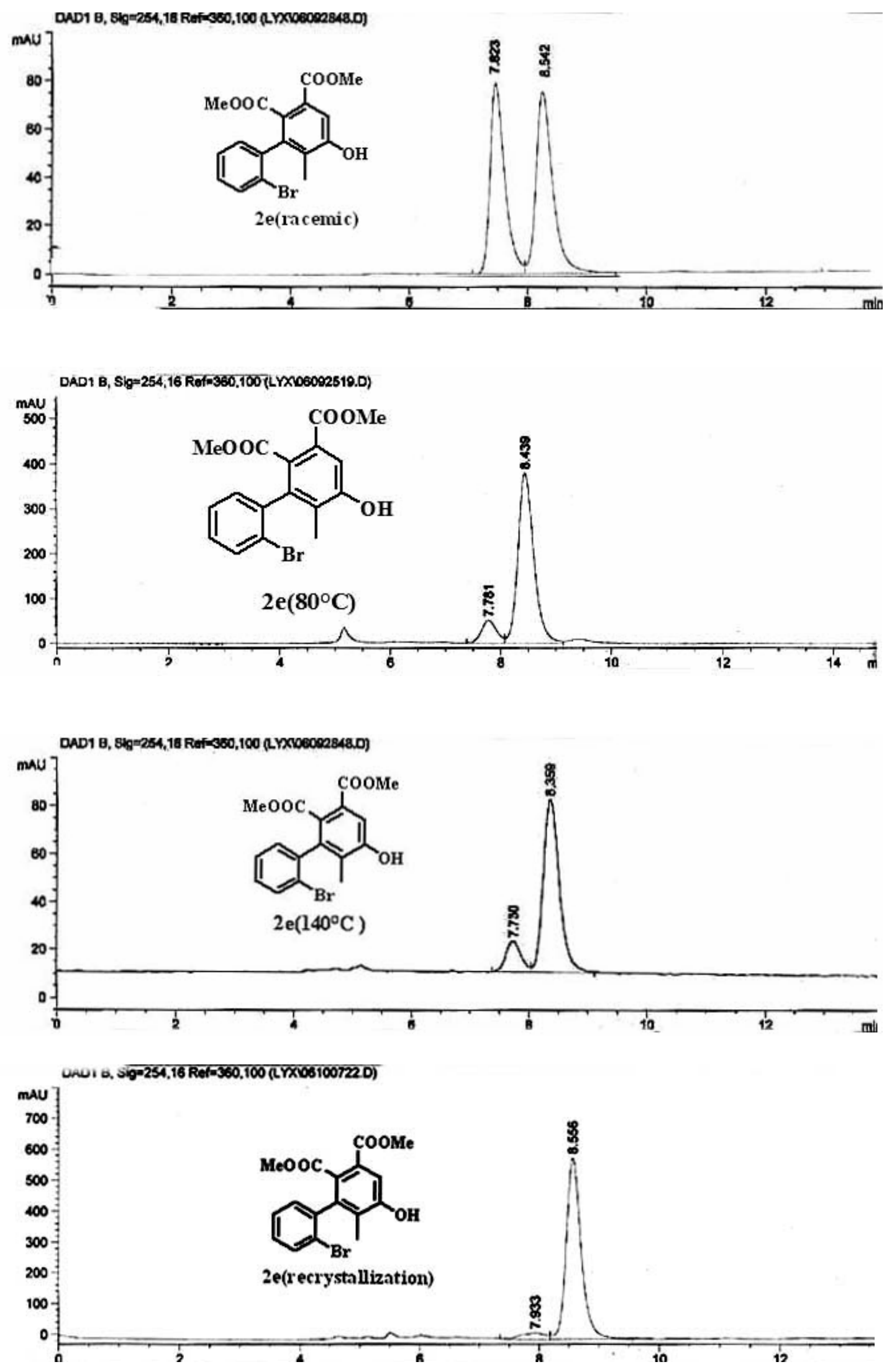

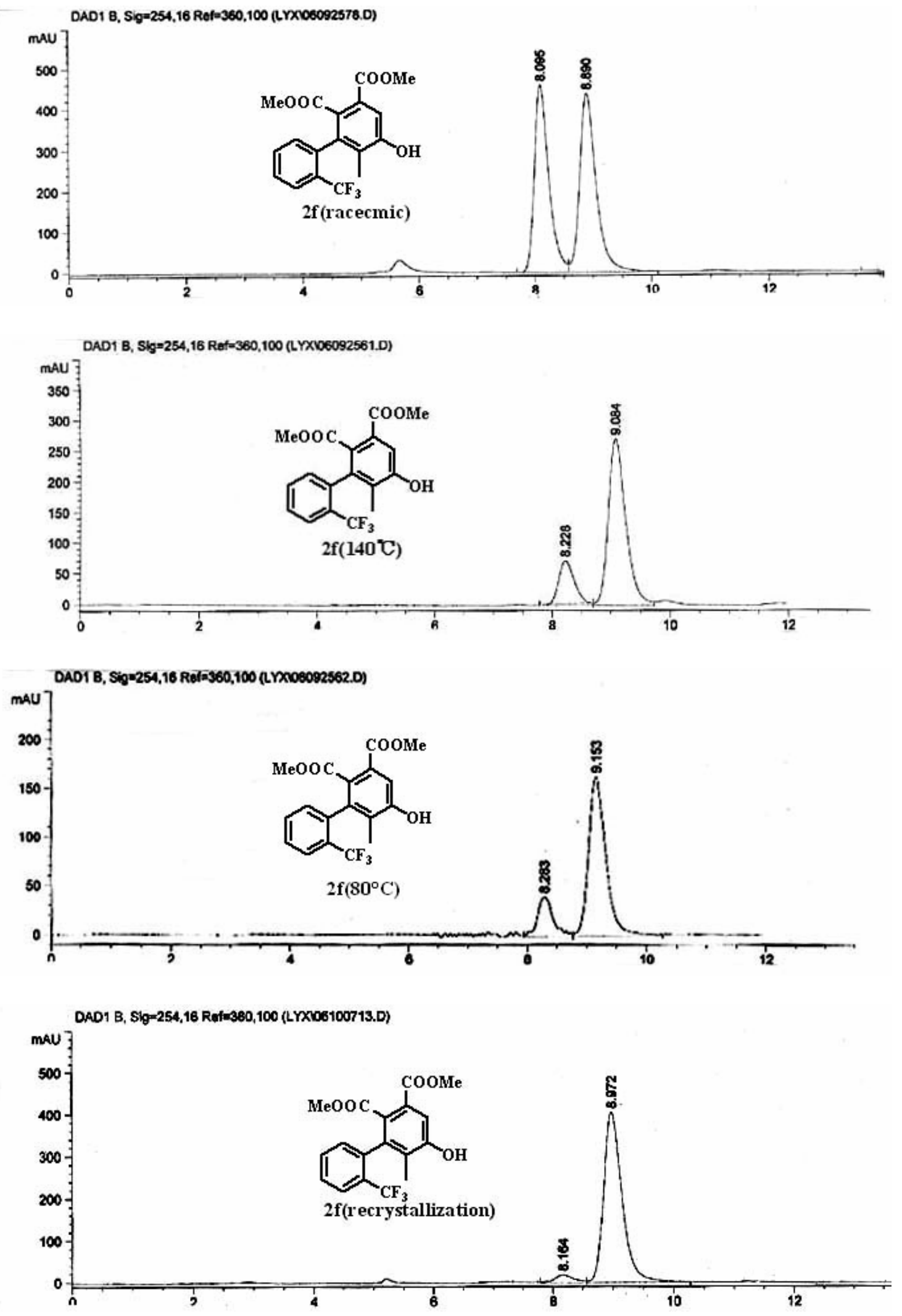

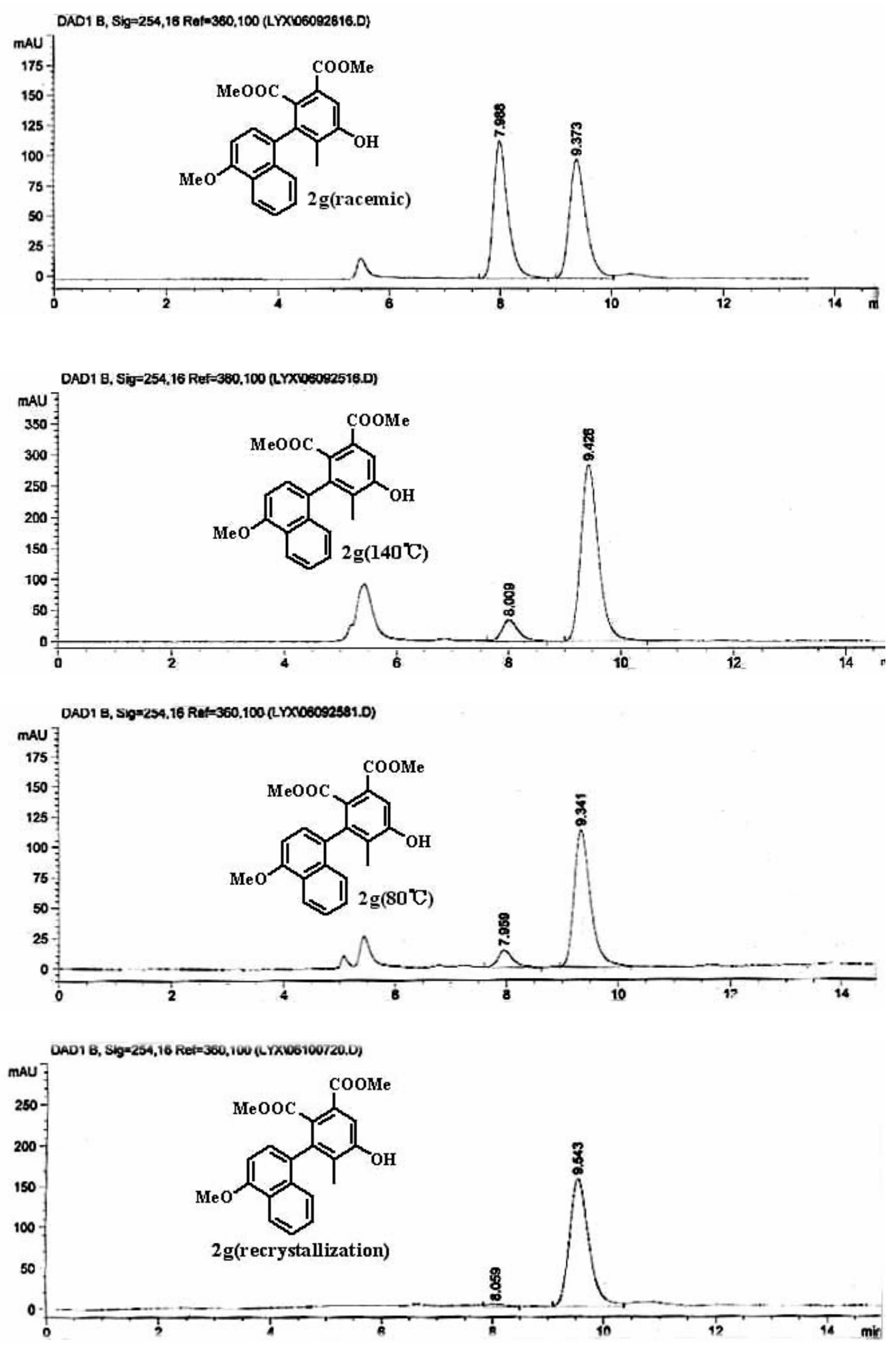

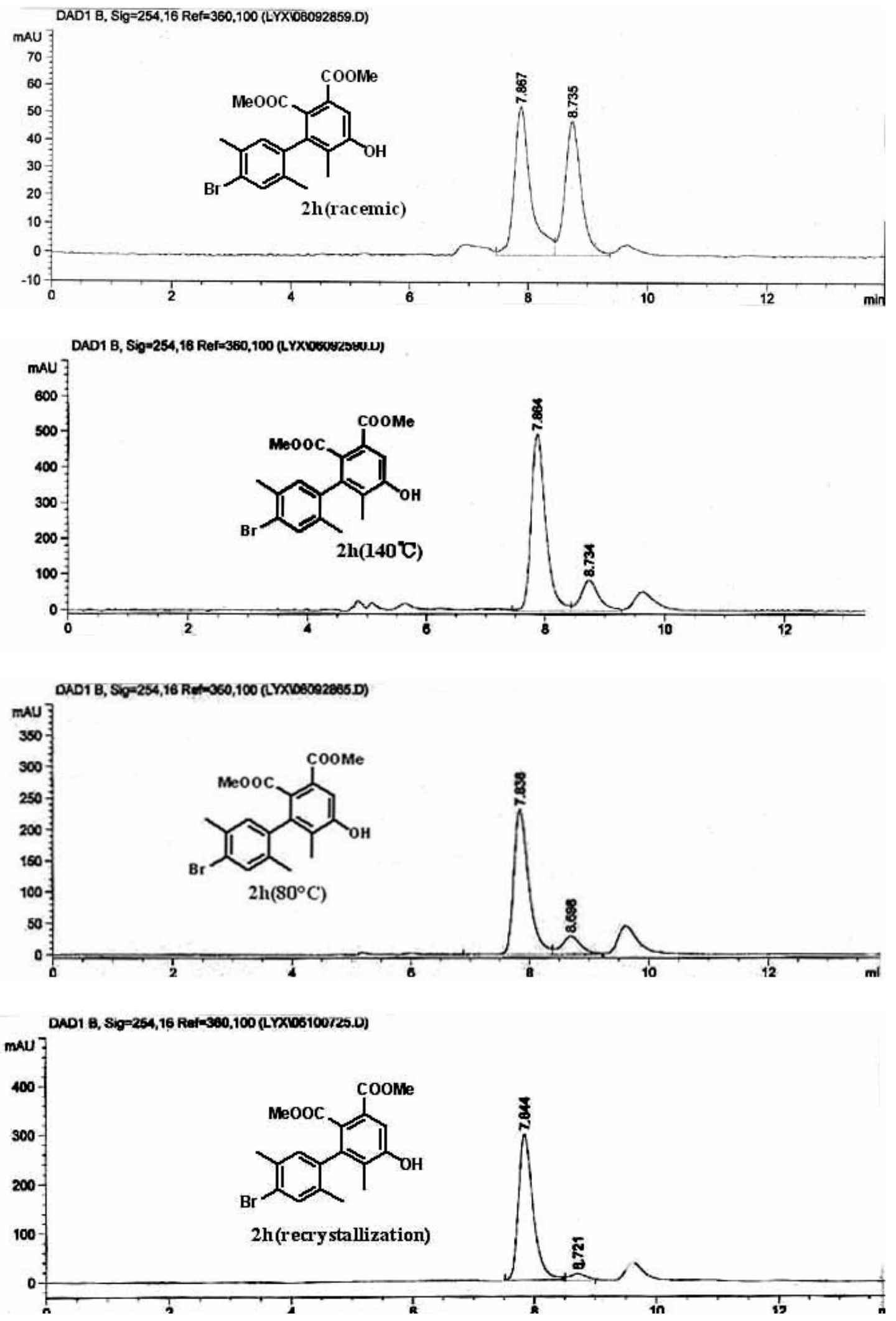

S36 

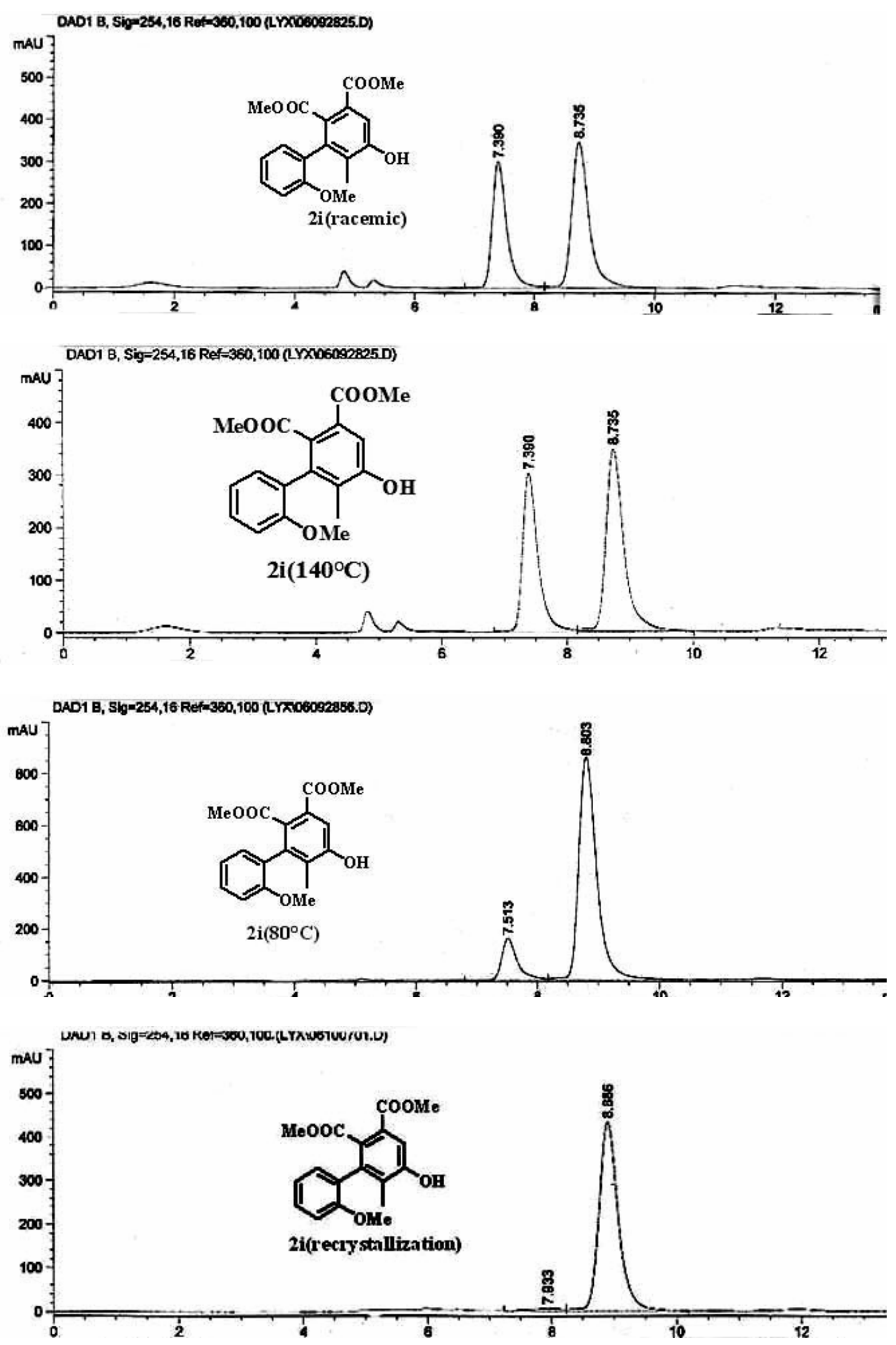